Adult-Child Relationships in Preschool:

Perceptions, Contributors to Change, and Associated Child Outcomes

\author{
A Dissertation \\ Presented to \\ The Faculty of the Curry School of Education \\ University of Virginia \\ In Partial Fulfillment \\ of the Requirements for the Degree \\ Doctor of Philosophy \\ by
}

Karyn Hartz, M.Ed.

August 2014 
(C) Copyright by

\section{Karyn Hartz}

All Rights Reserved

August 2014 


\begin{abstract}
This dissertation extended the literature base on adult-child relationships during early childhood and within the preschool context. Study 1 examined how children's negative emotionality moderated the links between both maternal and teacher sensitivity and children's kindergarten behavior problems. Study 1 results indicated that children's relationships with adults across multiple contexts of early childhood development interacted to predict children's internalizing and externalizing behavior. Adult sensitivity was differentially linked to outcomes for children high in early negative emotionality compared to children low in negative emotionality. Study 2 examined change in teachers' perceptions of the teacher-child relationship during one year of preschool. Results indicated that both a child's classroom engagement and a teacher's characteristics were associated with changes in the teacher's perception of his/her relationship with that child. Study 3 extended the limited research on preschool children's perceptions of the teacher-child relationship by examining the reliability and validity of children's relationship perceptions on two measures-a structured interview and a representational drawing. Study 3 findings indicated that in our sample of children as young as three years old with behavior problems, the measure structures were consistent with prior uses with slightly older children. Further, children's relationship perceptions were associated in expected directions with child characteristics, teacher's emotional support and children's classroom interactions. Taken together, these three studies contribute to our understanding of how and under what circumstances adultchild relationships are linked to children's outcomes, contributors to perceptions of teacherchild relationships, and how the teacher-child relationship can be measured.
\end{abstract}




\author{
Department of Human Services \\ Programs in Clinical and School Psychology \\ Curry School of Education \\ University of Virginia \\ Charlottesville, Virginia
}

\begin{abstract}
APPROVAL OF THE DISSERTATION
This dissertation, Adult-Child Relationships in Preschool: Perceptions, Contributors to Change, and Associated Child Outcomes, has been approved by the Graduate Faculty of the Curry School of Education in partial fulfillment of the requirements for the degree of Doctor of Philosophy.
\end{abstract}

Amanda Williford, Ph.D., Chair

Peter Sheras, Ph.D.

Jason Downer, Ph.D.

Sara Rimm-Kaufman, Ph.D.

Date 


\section{DEDICATION}

I dedicate this work to my parents, Bev and Greg Hartz, who instilled in me the value of education, hard work and persistence and whose love and support made this work possible.

I also dedicate this work to my husband, Jason Mandell, whose support and encouragement made this work possible, and to my siblings, Katy and Matt Hartz, for their encouragement throughout this process. 


\section{ACKNOWLEDGEMENTS}

First, I would like to thank my dissertation chair and advisor, Amanda Williford, for the training, guidance, and support she has provided over the past four years. I am incredibly grateful for her feedback on countless paper drafts, her generosity with her time, and the encouragement she has provided, which have made this work possible.

I would like to thank my program advisor, Peter Sheras, for his support, advice, and contributions to this work throughout my graduate school training.

I am grateful to my dissertation committee members, Jason Downer and Sara RimmKaufman for their interest in this work and their insightful contributions.

I am grateful for the training, support, and feedback on this work provided by the team at the Center for Advanced Study of Teaching and Learning. I am grateful for the many wonderful people I have had the opportunity to work with here and for the valuable training opportunities.

I would like to thank Helma Koomen for her contributions to this work and collaboration on the second study of this dissertation.

I would like to thank my graduate school cohort, Emily Nichols, Jenna Marshall, Neill Cox and Tory Phillips, for their friendship and support during the past four years. I am also grateful to my the my graduate school colleagues at the Center for Advanced Study of Teaching and Learning, Catherine Sanger, Lauren Carter, and Sadie Hasbrouck for their contributions to this work.

Finally, I am grateful for the generous support provided by the Virginia Education Science Training predoctoral fellowship funded by Institute for Education Sciences (IES) \#R305B090002 that provided funding and training to support this work. 
TABLE OF CONTENTS

Page

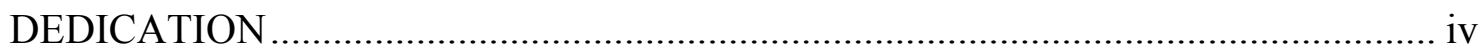

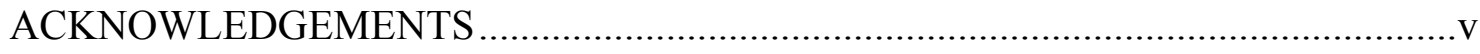

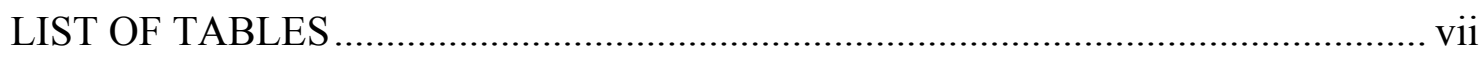

LIST OF FIGURES …...................................................................................... vii

\section{Conceptual Link}

Adult-Child Relationships in Preschool: Perceptions, Contributors to Change, and Associated Child Outcomes Conceptual Link

\section{Three Studies}

Study 1: Child Negative Emotionality and Caregiver Sensitivity Across Context: Links with Children's Kindergarten Behavior Problems.....................................13

Study 2: Changes in Teachers' Perceptions of Teacher-Child Relationships:

Children's Engagement and Teachers' Characteristics

Study 3: Children's Perceptions of the Teacher-Child Relationship: Associations with Teachers' Relationship Perceptions, Independent Observations, and Child

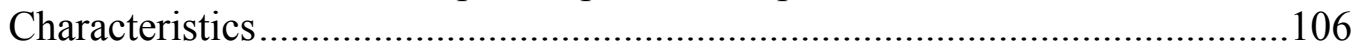

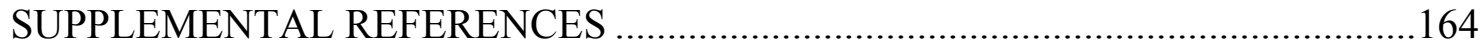

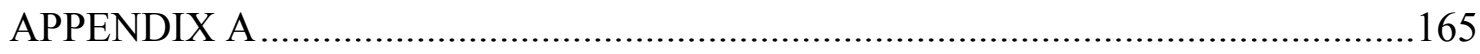




\section{LIST OF TABLES}

\section{Study 1}

Table 1. 2-year Assessment (Wave 2) Participant Characteristics

Table 2. Descriptive Statistics and Correlations for Predictors and Kindergarten Behavior Problems. .55

Table 3. Regression Analyses Predicting Kindergarten Behavior Problems......56

\section{Study 2}

Table 1. Teacher, Classroom, and Child Demographics

Table 2. Descriptive Statistics: Teacher-Child Relationship, Child Engagement, Teacher Psychological Characteristics 103

Table 3. Correlations among Teacher-Child Relationship, Child Engagement, and Teacher Psychological Characteristics 104

Table 4. Child Engagement and Teacher Psychological Characteristics predicting Teacher-Child Relationship Quality Stability.... 105

\section{Study 3}

Table 1. Descriptive Statistics: Child Demographics 159

Table 2. Descriptive Statistics: Teacher-Child Relationship Quality 160

Table 3. Descriptive Statistics: Teacher-Child Drawing Codes 161

Table 4. Correlations: Outcomes and Predictors 162

Table 5. Partial Correlations Controlling for Child Age and Verbal Ability....163 


\section{LIST OF FIGURES}

\section{Study 1}

Figure 1a. Moderating influence of preschool teacher sensitivity in the relation between maternal sensitivity and kindergarten internalizing behavior under conditions of high negative emotionality ....................................................57

Figure $1 \mathrm{~b}$. Moderating influence of preschool teacher sensitivity in the relation between maternal sensitivity and kindergarten internalizing behavior under

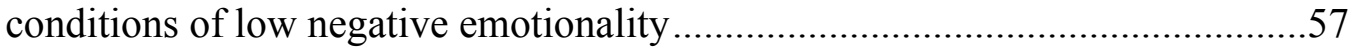

Figure 2. Moderating influence of preschool teacher sensitivity in the relation between maternal sensitivity and kindergarten externalizing behavior...............58 


\section{Adult-Child Relationships in Preschool: Perceptions, Contributors to Change, and Associated Child Outcomes \\ Conceptual Link}

\section{Introduction}

Children's early relationships with adults across multiple contexts of development are key contributors to the development of social, emotional, and behavioral competencies that facilitate children's positive adjustment to school and academic success (Birch \& Ladd, 1997, 1998; Hamre \& Pianta, 2001; Hughes, Cavell \& Jackson, 1999; Maldonado-Carreño, \& Votruba-Drzal, 2011; NICHD ECCRN, 1998, 2003; Pianta, Nimetz \& Bennett, 1997; Pianta \& Stuhlman, 2004; Pianta, Steinberg, Rollins, 1995; Roorda, Koomen, Spilt, \& Oort, 2011). Many children enter school without the social and behavioral competencies needed to succeed in school (Rimm-Kaufman, Pianta, Cox, 2000), which puts them at risk for a host of negative outcomes including lower academic achievement, grade retention, and special education placement (Arnold, 1997; Hinsaw, 1992; Raver \& Knitzer, 2002; Tremblay et al., 2004). Both mother-child and teacher-child relationships support children's development of these competencies and may protect children who have these risk factors from later negative outcomes (Baker, 2006; Hamre \& Pianta, 2001; Pluess \& Belsky, 2010; Early et al., 2002).

Examining the nuances of how adult-child relationships relate to children's outcomes and change over time may clarify the processes through which adult-child relationships are longitudinally linked to children's academic, social, and behavioral 
competencies. Although both mother-child and teacher-child relationships are consistently associated with children's outcomes independently, less is known about how children's experiences with mothers and teachers in combination contribute to their development during early childhood (e.g., Pluess \& Belsky, 2009). Additionally, both adults' and children's individual characteristics and past experiences contribute to their perceptions of these dyadic relationships (Birch \& Ladd, 1998; Ewing \& Taylor, 2009; Hamre et al., 2008; Kesner, 2000; Spilt, Koomen, Thijs, van der Leij, 2012; Yoon, 2002). Although much is known about the factors that contribute to the individual differences, perceptions, and changes in the mother-child relationship, less is known about these mechanisms and characteristics in the teacher-child relationship (Verschueren $\&$ Koomen, 2012). Additional insight may be gained by examining factors that are related to teachers' and children's classroom interactions. Further, the majority of research regarding the teacher-child relationship has examined teachers' perceptions of the relationship (e.g., Hamre \& Pianta, 2001). Relatively little research has examined children's relationship perceptions, especially during the preschool years (for an exception see: Mantzicopoulos \& Neuharth-Pritchett, 2003). Having valid, reliable measures of preschool children's perceptions of the teacher-child relationship could allow for a deeper understanding of the teacher-child relationship and its relation to children's outcomes. Because increasing evidence indicates the developmental significance of teacher-child relationships for children, it is important to increase our knowledge about the mechanisms by which this relationship develops and ways in which it may be enhanced to support children's competencies (Sabol \& Pianta, 2012; Verschueren \& Koomen, 2012). 


\section{Adult-Child Relationships}

Children's relationships with key adults are central contributors to their development (Bowlby, 1988; Pianta, 1999). Extensive work has focused on the importance of the mother-child relationship, and with good reason-- it has been established as a critical factor for many aspects of children's development including their behavior problems, emotion regulation abilities, self-concept, and social skills (NICHD ECCRN, 1998, 2003; Pianta et al., 1997; Smith et al., 2000). Mother-child relationships are particularly important in the early childhood years as they are the first relationships most children experience, one of few close relationships during the first few years of life, and one of the strongest predictors of children's outcomes (Bowlby, 1988; NICHD ECCRN, 1998, 2003). Nonetheless, children experience multiple relationships with adults, particularly as they are exposed to influential developmental contexts outside of the home (Bronfenbrenner, 2005).

However, questions remain about how children's relationships with adults across multiple contexts (i.e., home and school) are related to their social-emotional development. In particular, little work has examined the interaction between teacher-child and mother-child relationships for children's outcomes during the preschool years, when children often begin to experience both of these relationships (e.g., Mitchell-Copeland, Denham, \& DeMulder, 1997; Pluess \& Belskly, 2010). The value of examining both relationships is underscored by developmental theory regarding the importance of early relationships, multiple developmental contexts, and by empirical work indicating how these relationships differentially relate to children's development (Bronfenbrenner, 2005; Bowlby, 1988; Early et al., 2002; Rimm-Kaufmann et al., 2002). Although mother-child 
relationships continue to be a primary influence, children's relationships with their teachers are also important predictors of development, particularly within the school context (Sabol \& Pianta, 2012). Understanding how both of these relationships relate to children's outcomes provides a more comprehensive picture of how adult-child relationships are linked to children's outcomes, which can increase the precision of intervention efforts targeting these developmental processes.

\section{Importance of Teacher-Child Relationship in Preschool}

As one of the primary relationships children have with adults outside the home, teacher-child relationships are important contributors to children's development, particularly during preschool. Children who experience a warm, open, supportive relationship with their teacher in the early school years tend to be more engaged in school and have higher academic achievement concurrently and longitudinally (Palermo, Hanish, Martin, Fabes, \& Reiser, 2007; Pianta, Nimetz \& Bennett, 1997; Pianta \& Stuhlman, 2004; Roorda, Koomen, Spilt \& Oort, 2011). Conversely, children’s early conflictual relationships with teachers are particularly related to poor outcomes, including persistent and escalating behavior problems, lower school engagement, and less academic success (Palermo et al., 2007; Pianta \& Stuhlman, 2004; Roorda et al., 2011; Zhang \& Sun, 2011). The early school years, preschool in particular, are a sensitive period for addressing children's risk factors, such as poor teacher-child relationships, because children's trajectories become less malleable during elementary school (Pianta, 1999). Preschool is an important time for developing the social and behavioral school readiness skills that contribute to school success, yet many children enter school at risk for poor 
social, academic and behavioral adjustment because they are lacking these skills (RimmKaufman et al., 2000).

Children who are at risk for poor school-related outcomes (e.g., those who display early behavior problems or experience low quality mother-child relationships) tend to form less positive, more conflictual relationships with their teachers (Hamre \& Pianta, 2001; Howes \& Hamilton, 1992; O’Connor \& McCartney, 2007). However, the teacherchild relationship can have a protective influence for these children (Baker, 2006; Silver, Measelle, Armstrong, Essex, 2005). For instance, for children who have a less positive relationship with their mother, the teacher-child relationship can be compensatory (Mitchell-Copeland et al, 1997; Buyse et al., 2011). Additionally, a quality teacher-child relationship can buffer children against developing or escalating behavior problems for children who are at risk due to negative temperament attributes (i.e., negative emotionality) (Pluess \& Belsky, 2009, 2010; Griggs et al., 2008; Bradley \& Corwyn, 2008) or because of their early behavior problems (Baker, 2006; Baker, Grant, Morlock, 2008; Hughes et al., 1999; Hamre \& Pianta, 2001; Silver et al., 2005). Thus, a close, sensitive and supportive teacher-child relationship is most important for the children who are the least likely to experience them. This association between children's risk and teacher-child relationships highlights the bidirectional links between children and teachers contributing to relationship quality and children's outcomes.

\section{Perceptions of the Teacher-Child Relationships}

The majority of the work examining the association between teacher-child relationships and children's outcomes (e.g., behavior problems) has employed teacher reports of both the relationship and children's behavior (e.g., Hamre \& Pianta, 2001; 
Birch \& Ladd, 1997). However, these reports are teachers' perceptions of this relationship, and the child, the other half of the dyad, has their own internal representation of the relationship that may be similar or different from the perception the teacher holds. Much of the work establishing the importance of children's perceptions of their relationship with their teacher has been conducted with elementary school children (e.g., Hughes, 2011; Rey et al., 2007). Among elementary school children, children's perceptions are important predictors above and beyond teachers' relationship perceptions of children's school adjustment including, children's perceptions of academic their competence, school belonging, interest involvement, and behavior in the classroom (Hughes, 2011; Spilt et al., 2010; Rey et al., 2007). Preliminary work indicates that young children, including those in preschool, may be able to reliably report on their perceptions of the teacher-child relationship (Mantzicopoulos \& Neuharth-Pritchett, 2003). It is critical to examine preschool children's perceptions because at this young age, children are likely to be establishing their first teacher-child relationship and these early perceptions set the stage for future teacher-child relationships (Pianta, 1999).

In order to extend the limited previous literature and further examine whether preschool children can accurately report on their own perceptions of the teacher-child relationship it will be important to understand how children's perceptions are linked with other measures of the teacher child relationship, including teacher-reported relationship quality and observed teacher-child interactions, as well as other factors associated with teacher-child relationship quality such as children's characteristics and the classroom context. Children's characteristics, including age, gender, race, and behavioral style, have been consistently linked teachers' perceptions of relationship quality (Birch \& Ladd, 
1998; Ewing \& Taylor, 2009) and more recently have been linked to elementary school children's own perceptions of the teacher-child relationship (Spilt et al., 2010; Harrison et al., 2007; Murray et al., 2008). In addition, the classroom context in which children develop relationships with their teachers is likely to be related to their perceptions of these relationships. Specifically, children's perceptions of the teacher-child relationship are likely to be linked with the warmth, sensitivity and responsiveness to children's feelings, ideas, and needs, that teachers' provide in the classroom, as adult sensitivity is considered a "proximal determinant" of adult-child relationship quality (Verschueren \& Koomen, 2012). Children's perceptions of the teacher-child relationship would be expected to be associated with how children's interact in the classroom, as children's feelings and beliefs about relationships are likely to contribute to their behavior (Bowlby, 1988; Pianta, 1999). Finally, although children and teachers' perceptions of the teacherchild relationship may not be perfectly aligned, we would expect them to be modestly associated as they aim to measure the same construct and have been associated in prior research (Harrison et al., 2007; Mantzicopoulos \& Neuharth-Pritchett, 2003). Associations between children's perceptions of the teacher-child relationship and these previously established measures this relationship and other factors linked with relationship quality would provide evidence that young children can report on their own perceptions of the teacher-child relationship. Young children's relationship perceptions could then be measured in future research to better understand the teacher-child relationship and it longitudinal relation to children's developmental outcomes.

One reason that it is important to examine both teachers' and children's perceptions of the teacher-child relationship is that an individual's relationship 
perceptions may be related not just to their interactions with the other person, but also to personal characteristics. For example, children's characteristics, both demographic (e.g., age, gender) and behavioral (e.g., behavioral style, temperament and language abilities), are consistently associated with teachers' perceptions of relationship quality (Birch \& Ladd, 1998; Ewing \& Taylor, 2009; Rudasill, Rimm-Kaufman, Justice \& Pence, 2006). Although less emphasis has been placed on how teachers' characteristics relate to their perceptions of teacher-child relationships, teachers' classroom functioning (self-efficacy and stress), personal characteristics (symptoms of depression and attachment history) and demographic characteristics (gender and ethnicity) are associated with their perceptions (Hamre, Pianta, Downer \& Mashburn, 2008; Kesner, 2000; Spilt et al., 2012; Thijs \& Koomen, 2009; Yoon, 2002). Teachers reporting lower self-efficacy, more depression, and greater stress report higher conflict in the teacher-child relationship, whereas teachers with more positive perceptions of their attachment history report more closeness in their relationships with children (Hamre et al., 2008; Kesner, 2000; Spilt et al., 2012; Yoon, 2002). These teacher and child factors, beyond demographics, may contribute to their classroom interactions and in turn be proximally related to perceptions of the relationship. Furthermore, the contribution of teacher and child attributes to perceptions of the teacher-child relationship highlights the complexity of these relationships and the importance of studying them from multiple angles in order to obtain a comprehensive picture of how they contribute to children's development.

Multiple previous investigations have found that teachers' reports of teacher-child relationship quality are moderately stable across the early elementary school years, but that there is significant individual variability. O'Connor \& McCartney (2007) found that 
from preschool through elementary school only $25 \%$ of children were moderately stable in teachers' perceptions of the relationship, and the remaining $75 \%$ had changes in relationship quality. Although this work has demonstrated changes in children's relationship quality across school years in their relationships with different teachers, less work has examined how teachers' perceptions of their relationship with a particular student changes over the course of a school year (e.g., Zhang \& Sun, 2011). As the field of research on teacher-child relationships is relatively new, less work in this area has focused on mechanisms of change in teachers' and children's perceptions of one particular teacher-child relationship (Verschueren \& Koomen, 2012).

Early adult-child relationships have been firmly established as key predictors of preschoolers' developmental outcomes, yet much remains to be learned about how and why these relationships can be strongly linked to children's developmental outcomes. Insight into these underlying mechanisms may be gained by further exploring nuances in the association between adult-child relationships and children's outcomes and in the contributors to relationship changes. Examining how teacher and child attributes related to classroom interactions relate to their relationship perceptions, rather than more distal demographic characteristics, offers increasingly specific information about what factors are most closely related to relationship quality. Similarly, testing how child and adult factors interact to predict relationship quality and child outcomes provides a window into the complexity of development in relationships and preschoolers' academic, social, and behavioral competencies. Ultimately, a better understanding of how these relationships develop, change, and relate to children's outcomes may contribute to increasingly effective interventions to support teacher-child relationships, including identifying 
children and teachers may benefit from intervention and ways to tailor intervention efforts to different types of children and teachers.

\section{Three Study Approach}

This line of research in this dissertation extended the literature base on adult-child relationships, particularly in the preschool years and within the context of schools. The following studies addressed gaps in the literature regarding how children's characteristics moderate links between adult-sensitivity across multiple early childhood developmental contexts and children's behavior when they enter kindergarten, contributors to change in teachers' perceptions of the teacher-child relationship across one year of preschool, and methods to comprehensively assess preschool children's perceptions of the teacher-child relationship. Study 1 aimed to bridge work that has focused independently on motherchild and teacher-child relationships by examining how both mother-child and teacherchild relationships interacted with children's characteristics to predict children's kindergarten behavior problems. Given the importance of the teacher-child relationship for children's outcomes, Study 2 took a closer look at contributors to change in teachers' perceptions of this relationship. Finally, Study 3 extended the very limited research on preschool children's perceptions of the teacher-child relationship by examining the reliability and validity of children's relationship perceptions through two measures- a self-report measure and a representational measure.

Study 1 examined the association between maternal and teacher sensitivity, a "proximal determinant" of the quality of adult-child relationship quality (Verschueren \& Koomen, 2012), and kindergarten behavior problems. The moderating influence of children's negative emotionality in this association was also tested. Results indicated that 
children's relationships with adults across the multiple contexts of early childhood development (i.e., home and preschool) interacted to predict both children's internalizing and externalizing behavior when they enter kindergarten. Results also indicated that children's characteristics are an important consideration when examining how adult-child relationships are related to children's outcomes. Adult sensitivity was differentially linked to kindergarten internalizing behavior problems for child high in early negative emotionality compared to children low in negative emotionality.

Given the importance of the teacher-child relationship based on Study 1 findings and previous empirical work, Study 2 took a closer look at contributors to change in the teacher-child relationship across one year of preschool. This study examined how children's engagement in the preschool classroom as well as teacher's well-being and classroom-related beliefs predicted changes in teachers' perceptions of the teacher-child relationship. Study 2 also tested whether the association between child engagement and changes in teachers' perceptions differed based on teachers' well-being and classroomrelated beliefs. Results indicated that children's positive engagement with tasks in the classroom predicted increases in teachers' perceptions of closeness and that children's negative engagement in the classroom predicted increases in teachers' perceptions of conflict. Children's positive engagement with their teachers and their peers was not related to changes in the teachers' perceptions of the relationship. Teachers' work-related stress predicted increases in their perceptions of conflict and teachers' anxiety was associated with decreases in their perceptions of closeness. However, teachers' selfefficacy, work-related stress, child-centered beliefs, and trait levels of anger and anxiety 
did not moderate the relation between children's engagement and changes in teachers' perceptions of the teacher-child relationship.

Most of the research on the teacher-child relationship has focused on the teachers' perceptions of this relationship; however, in Study 3 I was interested in understanding children's perceptions of this important relationship. Study 3 was among the first to comprehensively assess preschool children's perceptions of their relationship with their teachers. Specifically, Study 3 extended limited previous work by examining the reliability and validity of preschool children's perceptions of the teacher-child relationship using two different measures (i.e., a self report and a representational drawing) in a sample of children who display early disruptive behavior in the classroom and are at-risk for forming poor quality relationships with their teachers. Study 3 findings indicated that children as young as three-years-old can reliability report on their own relationship perceptions as evidenced by the replication of the measure structures previously established with slightly older children. Findings also supported the validity of children's report in the associations of children's relationship perceptions on two different measures, and associations with child characteristics, independent observations of teachers' emotional support, and independent observations of children's classroom interactions. 
RUNNING HEAD: Sensitivity and Behavior Problems

Child Negative Emotionality and Caregiver Sensitivity Across Context: Links with Children's Kindergarten Behavior Problems

Karyn Hartz and Amanda Williford

University of Virginia

(provisionally accepted pending final revisions, Infant and Child Development) 


\begin{abstract}
Behavioral adjustment is critical for children's school readiness. This study used data from a nationally representative sample of children from the Early Childhood Longitudinal Study - Birth Cohort. We examined the effects of interactions between children's negative emotionality, maternal sensitivity and preschool teacher sensitivity on children's kindergarten internalizing and externalizing behaviors. Parent-report of children's negative emotionality and observations of maternal sensitivity were obtained at age two; teacher sensitivity was observed in preschool; and teacher-report of children's behavior problems was obtained in kindergarten. Negative emotionality moderated links between maternal sensitivity, teacher sensitivity, and children's internalizing behaviors. For children high in negativity, maternal sensitivity was positively associated with internalizing behavior in the context of low teacher sensitivity, whereas for children low in negativity, maternal sensitivity was negatively associated with internalizing behavior. For children high or low in negativity, internalizing behavior was comparable when teacher sensitivity was high regardless of maternal sensitivity. Maternal and teacher sensitivity interacted to predict externalizing behavior regardless of child negativity. Children who experienced high teacher sensitivity displayed comparable externalizing behavior regardless of maternal sensitivity. When children experienced low teacher sensitivity, maternal sensitivity was negatively associated with externalizing behavior. Interactions between child characteristics and caregiving across developmental contexts are discussed.
\end{abstract}


Child Negative Emotionality and Caregiver Sensitivity Across Context: Links with Children's Kindergarten Behavior Problems

Young children who display high levels of classroom behavior problems do not enter school with the skills needed to learn, and their opportunities for later school success may be limited (Bub, McCartney, \& Willett, 2007; Raver \& Knitzer, 2002). Children with early behavior problems are at risk for forming negative relationships with peers and teachers, lower academic achievement, grade retention, school dropout, and delinquency (Raver \& Knitzer, 2002). Teachers indicate that working independently, following classroom rules, and getting along with peers are critical skills for children in kindergarten - even more important than pre-academic skills. However, up to one third of teachers report that half or more of their class entered kindergarten lacking these behavioral competencies (Rimm-Kaufman, Pianta, \& Cox, 2000).

Both children's personal characteristics (e.g., temperament) and the environment in which they develop (e.g., maternal and teacher sensitivity) independently (National Institute of Child Health and Human Development Early Child Care Research Network, 2003; Pianta, LaParo, Payne, Cox, \& Bradley, 2002; Rothbart \& Bates, 2006) and in combination (Mitchell-Copeland, Denham, \& DeMulder, 1997) contribute to children's behavior problems. Children's proximal interactions with their parents and teachers during early childhood contribute uniquely to children's school readiness (NICHD ECCRN, 2003). However, the potential impacts of mother-child and teacher-child interactions on children's school readiness are most often examined in separate studies (e.g., Burchinal, Peisner-Feinberg, Bryant, \& Clifford, 2000; Smith, Landry, \& Swank, 2000) and when they are measured in the same study (e.g. National Institute of Child 
Health and Human Development Study of Early Child Care and Youth Development; NICHD SECC) they are often analyzed and reported in separate papers (e.g., NICHD ECCRN, 2002, 2004). In addition, children are impacted differentially by interactions with their mothers and teachers based on individual child characteristics, including negative emotionality (Pluess \& Belsky, 2009, 2010). The present study aimed to further understand the processes prior to school entry that may protect children from displaying behavior problems in kindergarten. Specifically, the present study examined how the interactions between children's individual characteristics (negative emotionality) and their caregiving experience across multiple developmental contexts (maternal and teacher sensitivity) are linked to children's kindergarten behavior problems.

\section{Developmental theory linking child temperament, caregiver sensitivity, and child behavior}

The bioecological model of human development (Bronfenbrenner \& Morris, 2006) theorizes the importance of both child characteristics and caregiver characteristics in determining children's ongoing, increasingly complex interactions with caregivers, known as the proximal processes of child development. Based on individual characteristics (e.g., temperament), children are affected differently by their environment (e.g., caregiver responsiveness and sensitivity) and these child characteristics may elicit different environments (e.g., caregiver response to child's behavior). The caregiving interactions that children experience across multiple ecological contexts (e.g., home and school) as well as the interactions between these contexts are key contributors to children's development (Bronfenbrenner \& Morris, 2006).

One process through which child temperament and caregiver sensitivity may 
interact to shape children's behavior is through differential susceptibility. The differential susceptibility hypothesis (Belsky, Bakermans-Kranenburg, \& van IJzendoorn, 2007) theorizes that children characterized by high negative emotionality, reactivity, or "difficult" temperaments, are more susceptible to environmental input than children with "easy" temperament, or low negative emotionality, and therefore will have the most positive outcomes in an optimal environment and the most negative outcomes in a disadvantageous environment. Thus, when children high in negative emotionality have highly sensitive caregivers, they would be expected to have few behavior problems; conversely, when they experience less sensitive caregiving, they would be expected to have more behavior problems (Belsky et al., 2007).

\section{Kindergarten Behavior Problems}

Children's behavior problems when they enter formal schooling are commonly described on a spectrum that includes at one end externalizing behaviors, including hyperactivity, impulsivity, and oppositionality, and on the other end, internalizing behaviors, including anxiety, withdrawal, and depression (Bub et al, 2007; NICHD ECCRN, 2003). Early externalizing problems have long been associated with academic underachievement (Bulotsky-Shearer \& Fantuzzo, 2011; Hinshaw, 1992). On the other end of the behavior problems spectrum, early internalizing problems are also associated with lower academic skills and achievement (Dobbs, Doctoroff, Fisher, \& Arnold, 2006; Rapport, Denney, Chung, \& Hustace, 2001).

During early childhood, externalizing and internalizing behavior problems may co-occur, are moderately stable over time, and may be similarly predictive of negative outcomes (Bub et al., 2007; Fanti \& Henrich, 2010). Despite overlap between 
internalizing and externalizing behavior, children's overcontrol has been indicated as an underpinning for internalizing behavior, whereas children's undercontrol has been indicated in externalizing behavior (Campbell, 2002). Additionally, unique pathways have been hypothesized to underlie the association between these different types of behavior problems and children's later academic achievement (Hinshaw, 2002; Rapport et al., 2001). Hyperactive and disruptive children spend more time off-task, defy rules and have less control over their learning engagement (Barkley, 2006; Fantuzzo, Bulotsky-Shearer, Fusco, \& McWayne, 2005). Children who exhibit internalizing behaviors may withdraw and show fewer adaptive learning behaviors (Dominguez, Vitiello, Maier, \& Greenfield, 2010). Relatively less research has been conducted regarding early internalizing behavior and its contributors. The present study will examine both internalizing and externalizing behavior, extending the literature on internalizing behavior in early childhood.

\section{Maternal and teacher sensitivity may protect children from developing behavior problems}

Maternal sensitivity consistently and strongly predicts positive social development for children, including fewer internalizing and externalizing behavior problems (NICHD ECCRN, 1998, 2003). Children whose mothers demonstrate sensitive interactions, characterized by warmth, consistency, and responsiveness to their children's cues, demonstrate fewer internalizing and externalizing behavior problems in preschool and the early school years as reported by mothers and teachers (NICHD ECCRN, 1998, 2003; Pianta, Nimetz, \& Bennett, 1997; Smith et al., 2000). Through sensitive interactions mothers help regulate children's behavior, and gradually children learn the 
skills to do this on their own (Campbell, 2000; Sroufe, 1996; Early et al., 2002). Children who do not experience sensitive maternal interactions may display behavior problems because they have fewer early opportunities to learn behavioral regulation skills. Despite the overall positive influence of maternal sensitivity for children's behavior problems, these parenting behaviors are increasingly recognized to interact with child temperament in predicting children's behavior problems (Kiff, Lengua, \& Zalewski, 2011).

As children increasingly spend time in out-of-home early childhood settings, it is important to understand the influences of their interactions with teachers in these contexts. Similar to how a sensitive mother interacts with her child, a sensitive teacher's interactions with the children in her classroom are defined by "behavior that is consistent, positive, and warm toward children and appropriately responsive to children's cues" (Rimm-Kaufman et al., 2002, p. 454). Children who experience a classroom characterized by high quality childcare, including child-centered, positive interactions with their kindergarten teachers, are rated by their teachers as more competent and also demonstrate fewer behavior problems (Burchinal et al., 2000; Pianta et al., 2002). Similarly, children who experience a classroom with high emotional support, including teacher sensitivity, tend to have fewer mother-reported internalizing and overall behavior problems in elementary school (Bub, 2009; NICHD ECCRN, 2003). Despite these associations between teacher sensitivity and fewer behavior problems, other studies find no association with high quality preschool and children's behavior problems (NICHD 2002; Deater-Deckard, Pinkerton, \& Scarr, 1996). One reason for these discrepant findings may be that the influence of these interactions is not the same for all children (Pluess \& Belsky, 2009, 2010). 
In addition to their independent influences, the combination of parent and teacher behaviors a child experiences influences children's development (Bronfenbrenner \& Morris, 2006; Buyse, Verschueren, \& Doumen, 2011). Teacher sensitivity may be particularly important for behavior problems for children who experience low maternal sensitivity. When a child is insecurely attached to his/her mother, a positive relationship with his/her preschool teacher can partially compensate as these children tend to have higher social competence and less aggressive behavior than insecurely attached children who have a negative teacher relationship (Buyse et al., 2011; Mitchell-Copeland et al., 1997). Taken together, maternal and teacher sensitivity contribute to children's behavior problems independently as well as in their unique combination.

\section{Negative emotionality may moderate links between sensitivity and child behavior problems}

In addition to environmental influences on children's behavior problems, children's temperament has been repeatedly linked to later development (Rothbart \& Bates, 2006; Sanson et al., 2011). One aspect of temperament, negative emotionality, consists of young children's frequent and intense displays of negative emotion (i.e., fear, sadness, anger), their difficulty being soothed, and their tendency to become easily distressed (Rothbart \& Bates, 2006; Sanson, Hemphill, \& Smart, 2004). Negative emotionality and related temperament characteristics are considered constitutionally based traits with biological underpinnings that underlie stability across childhood (Rothbart \& Bates, 2006; Sanson et al., 2004). Negative emotionality is at least moderately stable across early childhood with stability as high as .8 being reported (Pedlow, Sanson, Prior, \& Oberklaid, 1993; Sanson et al., 2004). Early high negative 
emotionality, typically measured through parent and/or teacher report of the intensity of children's expression of negative emotions (e.g., anger, frustration, sadness), has been linked to greater externalizing behavior problems and internalizing problems in school and in general (Eisenberg et al., 2009; Nelson, Martin, Hodge, Havill, \& Kamphus, 1999; Sanson et al., 2004).

The significance of examining children's early negative emotionality as a predictor of their later behavior problems is underscored by recent theoretical and empirical research indicating that children high in negative emotionality may be particularly at-risk for behavioral difficulties because they are more susceptible to environmental influences than children low in negative emotionality. Consistent with the differential susceptibility hypothesis (Belsky et al., 2007) and the biological sensitivity to context hypothesis (Boyce \& Ellis, 2005), research indicates that compared to children with easy temperaments, children with difficult temperaments are more susceptible to caregiving quality at home and at school. Children with difficult temperaments, as measured by their mother's report of their approach, activity, intensity, mood, and adaptability, display more externalizing behavior when they have less sensitive mothers; conversely, these children demonstrate fewer externalizing behaviors when their mothers are more sensitive (Bradley \& Corwyn, 2008). Further, children high in early negativity demonstrate fewer behavior problems in preschool when they experience high quality childcare; the reverse is true when they experience low quality childcare (Pluess \& Belsky, 2009). Early caregiving experiences have long lasting links to the behavior problems of children high in negative emotionality as high quality childcare predicts fewer behavior problems for these children into sixth grade (Pluess \& Belsky, 2010). 
Differential caregiving influences based on children's susceptibility have primarily been examined in independent studies (e.g., Straight, Gallagher, \& Kelly, 2008). However, the interaction of maternal and teacher caregiving that a child high in negativity experiences is likely to be particularly important because of his/her high environmental sensitivity. It remains unclear how the interaction of adult-child relationships at home and school may be moderated by child temperament. Children high in negative emotionality, who are more susceptible to caregiving, may be so affected by early parenting that a subsequent teacher-child relationship may not substantially alter their developmental trajectory. However, it may be that these children remain highly susceptible to environmental input, a hypothesis supported by literature demonstrating children's differential susceptibility to quality childcare (Pluess \& Belsky, 2009). Additionally, links between negative emotionality, maternal and teacher caregiving, and behavior problems have primarily focused on children's externalizing or overall behavior problems, but not, to our knowledge, on internalizing behavior.

\section{The Present Study}

Despite the theorized importance of caregiving across multiple contexts of development (Bronfenbrenner \& Morris, 2006), relatively few studies have examined how children high in negative emotionality are influenced by multiple environments during their early development (for exception see: Pluess \& Belsky, 2010). Additionally, these studies have primarily emphasized children's externalizing or overall behavior problems (Bradely \& Corwyn, 2008; Pluess \& Belsky, 2009, 2010). Although commonalities exist for the development of internalizing and externalizing behavior problems, distinct precursors and contributors have been identified, making it important 
to examine whether similar patterns of differential susceptibility hold for both types of behavior problems. The present study addressed these gaps in the literature by examining how both early maternal sensitivity and subsequent preschool teacher sensitivity were moderated by children's early negative emotionality to predict kindergarten externalizing and internalizing behavior problems. Additionally, this study is longitudinal in nature, allowing us to examining the links between adult sensitivity in early childhood and behavior problems in kindergarten. Finally, this work benefits from a large and nationally representative sample.

First, we expected that children's negative emotionality would moderate the links between maternal sensitivity and children's behavior problems (externalizing and internalizing) and teacher sensitivity and children's behavior problems. Specifically, we expected the negative association between sensitivity and behavior problems to be stronger for children with higher negative emotionality. Further, for children with high negative emotionality, we expected that high levels of sensitivity in one context (i.e., home or school) would buffer or protect against the negative influence of low levels of sensitivity in another context. This three-way interaction was hypothesized based on literature indicating the importance of quality interactions across multiple developmental contexts (Bronfenbrenner \& Morris, 2006). We expected a similar pattern of findings for internalizing and externalizing behavior. This hypothesis is based on literature indicating that adult sensitivity buffers against both internalizing and externalizing behavior as well as prior research that found similar results for children's internalizing and externalizing behavior as separate outcomes, but examined different susceptibility factors and contextual influences than the present study (NICHD ECCRN, 1998, 2003; Obradović, 
Bush, \& Boyce, 2011). However, we anticipated that patterns in our findings would be stronger for externalizing than internalizing behavior given the more consistent support for the differential susceptibility hypothesis with externalizing behavior (Obradović et al., 2011; Pluess \& Belsky, 2010).

\section{Methods}

\section{Participants}

Early Childhood Longitudinal Study - Birth Cohort. The participants for the current study were from the Early Childhood Longitudinal Study - Birth Cohort (ECLSB), a large-scale study conducted through the National Center for Education Statistics (NCES) with collaboration and sponsorship from many agencies within the U.S. Department of Education, U.S. Department of Health and Human Services, and the U.S. Department of Agriculture. The ECLS-B is a longitudinal study of children's cognitive, social, emotional, and physical development observed in multiple contexts, including home, childcare, and school, and by multiple observers, including parents, caregivers, and teachers. The ECLS-B followed a nationally representative sample of children born in 2001 from 9 months through the transition to kindergarten (for additional information see http://nces.ed.gov/ecls/birth.asp). Weights were devised to translate the raw sample data into data that is nationally representative and generalizable to the population of children born in 2001 (Wheeless et al., 2009).

Children were sampled from the U.S. National Center for Health Statistics record of registered births (for details see Bethel, Green, Nord, Kalton, \& West, 2005). Children who died before the age of 9 months, were adopted before 9 months, and who were born to parents younger than 15 years old were excluded from the sample. Additionally, low 
and very low birth weight infants and twins were over sampled to increase analytic power (Bethel et al., 2005). Data collection for the ECLS-B took place across five time points: the nine-month assessment (Wave 1), the two-year assessment (Wave 2), the preschool assessment (Wave 3), and the kindergarten assessment (Waves 4 and 5). Approximately $75 \%$ of children entered kindergarten in 2006 during Wave 4 and the remaining $25 \%$ entered kindergarten in 2007 during Wave 5 (Flanagan \& McPhee, 2009). Assessments included measures of children's cognitive, social-emotional, and physical development (e.g., direct tests of cognitive and motor abilities, parent and teacher-report, coded observations), measures of parents' beliefs and parenting behavior (e.g., self-report, interviews, coded observations), and measures of caregivers' experience and interactions with children (e.g., self-report, interviews, coded observations). Procedures and measures relevant for the present analyses are described in detail.

Analysis Sample. Participants for the present study were the children, parents, and caregivers and/or teachers who participated in the ECLS-B study. This particular study is a secondary data analysis based on data collected during the two-year, preschool, and kindergarten assessments. More specifically, participants who completed the twoyear (Wave 2) parent questionnaire, two-year Two Bags task, who were selected to participate in the preschool assessment (Wave 3) Child Care Observation, who entered kindergarten in 2006 (Wave 4), and who had a completed kindergarten teacher questionnaire were included in the present analysis.

\section{Procedures}

Two-year Assessment (Wave 2). Parents (over 90\% mothers, 1.1\% non-parental relative or non-relative; Andreassen \& Fletcher, 2007; Nord, Edwards, Andreassen, 
Green, \& Wallner-Allen, 2006) were asked to report on their child's development as well as on characteristics of their families and themselves. Child temperament, race/ethnicity, gender, family socioeconomic status, mother's education, marital status, and household members were assessed through this parent report measure. Additionally, the dyadic interactions between mothers and their toddlers were observed and coded for maternal sensitivity (Two Bags Task). The majority of children completed the child assessment between 22 and 25 months of age (88\%), and all children completed the assessment between 16 and 39 months of age (Mulligan \& Flanagan, 2006). See Table 1 for sample demographic information collected during the two-year assessment wave.

Preschool Assessment (Wave 3). At the preschool assessment (Wave 3) children's non-parental caregivers and early education providers were asked to report on their education, training, and beliefs, characteristics of the childcare facility, and the development of the child with whom they worked. Additionally, a subsample of ECLS-B participants was selected for a Child Care Observation (see Attrition below for details on selection for this observation). During this observation preschool teacher sensitivity with the children in her classroom was observed and coded at the classroom level. The majority of children were assessed between 48 months and 57 months (75\%), 14\% were assessed before 48 months, and 11\% were assessed after 57 months (Jacobson-Chernoff, Flanagan, McPhee, \& Park, 2007).

Kindergarten Assessment (Wave 4). At the kindergarten assessment (Wave 4) kindergarten teachers were asked to report on the child's behavior problems as part of a larger questionnaire regarding the child's adjustment to school and characteristics of the teacher and he classroom. Only the children entering kindergarten in 2006 were included 
in the analyses. Using this subsample of children ensured that preschool observations of teacher sensitivity occurred in the year just prior to kindergarten entry. Most children $(81.9 \%)$ were between the ages of 5 and 6 years old when they were assessed in kindergarten; $16.4 \%$ were older than 6 years old and $1.7 \%$ were younger than 5 years old (Flanagan \& McPhee, 2009).

\section{Attrition}

Due to the large scale and longitudinal nature of this study attrition was expected. Of the 14,000 children originally sampled, 10,700 (weighted response rate of $74.1 \%$ ) participated in the first assessment at 9-months (as a requirement of using this data, all unweighted sample sizes are rounded to the nearest 50 to protect the identity of the ECLS-B participants). Most parents and children who participated in the 9-month assessment participated in the two-year assessment; 9850 parents completed the parent interview (93.1\% weighted response rate) and 9200 children participated in the direct assessments (94.2\% weighted response rate). At the preschool assessment, of the 7,300 children with completed parent interview (weighted response rate of 63.1\%), a small subset of children were selected to participate in a Child Care Observation (CCO). Based on the child's enrollment in out of home care and parents' consent, 6,000 childcare providers participated in the Early Care and Education Provider phone interview. Out of these children, 4,600 were eligible for a Child Care Observation (participants were excluded if the child spent less than 10 hours per week in childcare, if they were not awake in childcare for one 2.5-hour block, if they lived in Alaska or Hawaii, and if the primary setting language was neither English nor Spanish). Of those eligible, 3,000 children were sampled equally across three settings (Head Start, relative care, and non- 
Head Start centers) and three poverty levels (less than 100\% of poverty line, between $100 \%$ and $150 \%$ of poverty line, greater than $150 \%$ of poverty line) (Snow et al., 2007). A total of 1800 observations were completed (63.6\% weighted response rate for eligible children). The main reasons why CCOs were not completed were that children were no longer at the childcare placement, the childcare provider refused participation or did not complete the interview, and the care provider could not be observed (e.g., center closed for summer, provider not available) (Wheeless, Ault, Park, \& Mulligan, 2008). For the 2006 kindergarten assessment, of children who were eligible and selected to participate in the 2006 kindergarten $91.8 \%$ participated. A total of 3850 kindergarten teachers out of the 5200 that were contacted completed the questionnaire about the study child and their classroom. The weighted kindergarten teacher response rate for selected participants in the 2006 wave is $75.6 \%$. For the present study, of the 10,700 children who participated at the 9-month assessment and the subsample of 1800 for whom Child Care Observations were conducted, 1400 children were assigned a sampling weight accounting for their participation in the preschool Child Care Observation and in Wave 4. Of these children, 1100 entered kindergarten in 2006, which is the final unweighted sample size. It is important that a sampling weight was devised for this subsample so that analyses using this sequence of data could be generalized to children born in the United States in 2001 (see Sampling Weights below for details).

The attrition described above occurred for multiple reasons. Non-response occurred when participants were unable to be located, when they were not interested in participating, and for other reasons such as a language barrier. Extensive efforts were made to locate all participants and to maintain participation in the study. In order to be 
eligible for participation in an assessment wave, children had to have participated at the prior wave (Wheeless et al., 2009). Nonresponse bias analyses were conducted and reported in the methodology reports for each assessment wave (Wheeless et al., 2008; Wheeless et al., 2009). Significant differences between responders and nonresponders were found on a number of socio-demographic variables (e.g., ethnicity, family income, family size) with minority participants and participants experiencing more demographic risk (e.g., poverty) being more likely to be non-responders. Analytic sampling weights (described below) were created and applied to account for nonresponse and the sampling frame. As a result, differences between responders and nonresponders were very small and unlikely to result in bias (Wheeless et al., 2008; Wheeless et al., 2009).

\section{Sampling Weights}

Sampling weights (often used in population surveys) are employed to make a sample representative of the population from with the sample came and to account for nonresponse and noncoverage (Kalton \& Flores-Cervantes, 2003). In the ECLSB dataset, the sampling weights take into account the sampling design (e.g., the oversampling of some minority groups, selecting a sub-sample for certain parts of data collection, the child-care observation), non-response rates (described above), and the longitudinal nature of the data (e.g. data collected across multiple waves). For all of the regression analyses described below the W43P0 sampling weight was applied (see Snow et al., 2009 for further details on calculation of sampling weights). This sampling weight accounted for participant attrition and non-response through the kindergarten assessment as well as the sub-selection of participants for the preschool Child Care Observation (CCO). For the Confirmatory Factor Analysis conducted for our measure of negative emotionality, the 
W2CO sampling weight was applied in order to obtain the most accurate factor scores based on all children participating at the two-year assessment.

\section{Measures}

Negative Emotionality. Children's negative emotionality was assessed at the two-year assessment (Wave 2). Parents completed seven questions regarding their child's behavior (e.g. child is fussy or irritable) that were rated on a scale of 0 to 3 ("Never," "Used to Be," "Sometimes," "Most Times"). These items were selected from the Infant/Toddler Symptom Checklist (ITSC) based on their ability to identify children with self-regulatory difficulties that are associated with attention and behavior problems as well as the salience of the symptoms for parents (Andreassen \& Fletcher, 2007). An eighth question asked parents the overall difficulty raising the child on a five-point scale and the ninth question asked about the time spent calming the child on a 0 to 2 scale (Nord et al., 2006). A Confirmatory Factor Analysis was fit on these nine items in order to obtain a factor score reflecting children's negative emotionality. The W2CO sampling weight was applied to this analysis. Two items from the ITSC (needs help falling asleep and has difficulty shifting focus) had factor loadings below .4 and were subsequently removed from the CFA (Floyd \& Widaman, 1995). In the revised CFA with seven items, all factor loadings were then above .4 and the fit was good $\left(\chi^{2}=173.86, p<.001\right.$, RMSEA $=.049, \mathrm{CFI}=.916, \mathrm{SMRM}=.034)$.

Maternal Sensitivity. Maternal sensitivity was observed at the two-year assessment (Wave 2) during the Two Bags Task, which was adapted from the Three Bags Task used in prior longitudinal studies (e.g. the Early Head Start Research and Evaluation Project; EHSRE, i.e. Love et al., 2005 and NICHD SECC, i.e., NICHD ECCRN, 1999). 
In this 10-minute semi-structured play interaction, mothers were given one bag with a book and one with play materials. In order to elicit natural mother-child interactions, mothers were asked only to play with the book first and toys second and otherwise were free to play as they pleased. Maternal sensitivity, positive regard, stimulation of cognitive development, detachment, negative regard, and intrusiveness were coded on a scale from 1 (very low) to 7 (very high). All coders met the required $85 \%$ or higher agreement following training and maintained $85 \%$ agreement on a weekly reliability tape. Agreement was defined as assigning a code within one point of the consensus code. Coders' mean weekly percentage agreement was high (96.5\%) and ranged from $93-97 \%$ (Andreassen \& Fletcher, 2007). A maternal sensitivity composite, previously used by the EHSRE, was created for the ECLS-B sample. Behaviors in this composite include a mother's observation and child-centered responses to her child's cues (sensitivity), awareness of her child's cognitive level and efforts to bring the child to the next level (stimulation of cognitive development), and expression of love, respect, and warmth (positive regard) (Andreassen \& Fletcher, 2007; Love et al., 2005; Nord et al., 2006). The internal consistency of the maternal sensitivity composite was good in the present study $(\alpha=.82)$, consistent with previous studies that used this measure (Love et al., 2005; NICHD ECCRN, 1999).

Preschool Teacher Sensitivity. Preschool teacher sensitivity was assessed with the Arnett Scale of Caregiver Behavior, which contains some wording modifications from the original Arnett Scale of Caregiver Interaction (Arnett, 1989). These wording modifications and added behavior examples for clarity are similar to those used in several other large scale studies of early childhood development, including the Head Start Family 
and Child Experiences Survey (FACES) (Snow et al., 2007). Observers were trained to complete this measure as well as several other childcare observation measures. All observers obtained a minimum of $80 \%$ agreement to be considered reliable with their certification scores ranging from $85-100 \%$ and an average close to $97 \%$. Observers spent at least 2 hours observing the childcare environment before completing this 26 -item scale rating the frequency of teacher behaviors on a four-point scale from 1 (not at all) to 4 (very much). For analysis, items were reverse coded when necessary so that higher scores consistently represented more positive behavior and all items were recoded to a 0 to 3 scale (Snow et al., 2007). An overall score and four subscales are calculated from these items: sensitivity, harshness, detachment, and permissiveness. The sensitivity scale was used as our measure of preschool teacher sensitivity. This scale consists of the sum of 10 items, such as speaks warmly to children, seems to enjoy children, and talks to children on a level they can understand, and has high internal consistency (Cronbach's $\alpha$ $=.95 ;$ Snow et al., 2007).

Kindergarten Behavior Problems. Children's behavioral problems were assessed through a kindergarten teacher questionnaire regarding children's problem behaviors in the classroom. A factor analysis of the 22 items revealed four factors: Social Skills (example items include is accepted by other children and makes friends easily), Approaches to Learning (e.g., works well independently and keeps working until finished), Internalizing Behavior (e.g. acts shy, is sad and worries about things), and Externalizing Behavior (e.g., disrupts others and is physically aggressive). The Externalizing Behavior composite, made up of 7 items $(\alpha=.91)$, and Internalizing Behavior composite, containing 3 items $(\alpha=.69)$, were used in the present analyses. 
Items were rated on a 5-point scale from 1 (Never) to 5 (Very Often). The mean rating across items was calculated to compute the Internalizing and Externalizing Behavior composites. The items of these subscales were consistent with the items on other commonly used, norm-referenced rating scales from which these items were selected (e.g. Social Skills Rating System; SSRS, Gresham \& Elliot, 1990; Preschool and Kindergarten Behavior Scales $-2^{\text {nd }}$ Edition; PKBS-2, Merrell, 2002; Family and Child Experiences Study; FACES, Zill et al., 2003).

The correlation between internalizing and externalizing behavior was .111, which was lower than anticipated. However, as would be expected based on previous literature (Barkley, 2006; Dominguez et al., 2010; Fantuzzo et al., 2005; Raver \& Knitzer, 2002), internalizing and externalizing behavior were negatively associated with kindergarten teachers' report of children's social skills ( $r$ s $=-0.444,-0.378$, respectively) and approaches to learning ( $r \mathrm{~s}=-0.279,-0.572$, respectively) supporting the validity of this measure of behavior problems. Additionally, a content analysis of the three internalizing scale items was conducted to support the validity of this measure. Two expert raters cross-walked the individual items with commonly used teacher report measures of children's behavior problems (Child Behavior Checklist; CBCL, Achenbach, 1991; Behavior Assessment System for Children, $2^{\text {nd }}$ edition; BASC - II; Reynolds \& Kamphaus, 2004; Social Skills Rating System; SSRS, Gresham \& Elliot, 1990) and found that the items used in this study were included within these more comprehensive behavior rating scales. The items mapped on to subscales measuring anxious, depressed, and withdrawn behavior and onto overall internalizing behavior scales on these established measures. 
Covariates. In addition to the primary predictors of interest, child characteristics that have been linked to children's behavior problems and have typically been included as control variables in the developmental literature were included as covariates.

Children's age, gender, ethnicity and family socioeconomic status (quintiles based on parent education, occupation, and household income) were obtained through parent report at the two-year assessment. Younger children, boys, minority children, and children from a low socioeconomic status are frequently found to evidence higher levels of externalizing behavior (Raver \& Knitzer, 2002; Miner \& Clarke-Stewart, 2008). Girls, especially older girls, children from lower SES households, and Caucasian children tend to have greater internalizing behavior (Leve, Kim, \& Pears, 2005; Keily, Bates, Dodge, \& Pettit, 2000; Nguyen, Huang, Arganza, \& Liao, 2007). Consistent with our theoretical framework, the hours per week that children spent in childcare were also included as a covariate to account for the amount of exposure children had to childcare. Greater hours in care have been linked with children's behavior problems, particularly externalizing behavior (e.g., Belsky, Vandell et al., 2007). Finally, ratio of children to caregivers in the classroom is included as a covariate given its association with the quality of classroom interactions and positive child outcomes (Burchinal, Roberts et al., 2000; Mashburn, Hamre, Downer, \& Pianta, 2006).

\section{Data Analysis}

Regression analyses were conducted to examine the interaction between maternal and teacher sensitivity and child negative emotionality in predicting kindergarten behavior problems in Mplus Version 6 (Muthén \& Muthén, 2010). Previously described sampling weights (W43P0) were applied to all analyses to account for study attrition and 
to ensure nationally representative findings. The same regression model was fit for externalizing and internalizing behavior problems in a stepwise fashion. Child and preschool covariates were entered in Step 1 (child age, gender, ethnicity, socioeconomic status, child:caregiver ratio, and hours per week in care). The main effects for negative emotionality, maternal sensitivity, and teacher sensitivity were entered in Step 2. All twoway multiplicative interactions between negative emotionality, maternal sensitivity and teacher sensitivity were entered in Step 3. The three-way multiplicative interaction between negative emotionality, maternal sensitivity and teacher sensitivity was entered in Step 4. Nonsignificant steps of interaction terms were removed from the model in a backward elimination. We report the standardized model results. Following Pluess and Belsky (2009), we interpret interactions as significant when $\alpha=.10$ because of the statistical difficulty of detecting interaction effects in field studies (McClelland \& Judd, 1993). We plotted significant interactions with excel documents from stat-help.com. Interactions were graphed at one standard deviation above and below the means for the predictors and moderator (Aiken \& West, 1991) and illustrate the isolated effects of the interaction terms. Simple slopes for these interactions were tested using calculation tools from www.quantpsy.org (Preacher, Curran, \& Bauer, 2006).

\section{Results}

\section{Preliminary Analyses}

Correlations between the predictors (maternal and teacher sensitivity), moderator (negative emotionality), and outcomes (kindergarten internalizing and externalizing behavior problems) were small in magnitude and largely nonsignificant (see Table 2). The susceptibility factor (negative emotionality) was independent of the predictors 
(maternal sensitivity and preschool teacher sensitivity). Additionally, the correlation between the susceptibility factor (negative emotionality) and one outcome (internalizing behavior) was nonsignificant. However, negative emotionality was positively correlated with externalizing behavior problems $(r=.169, p<.01)$. See Table 2 for descriptive statistics for all predictors, moderator, and outcomes. The only significant main effect of the predictors of interest (negative emotionality, maternal sensitivity, and preschool teacher sensitivity) on kindergarten behavior problems was negative emotionality significantly predicting kindergarten externalizing behavior $(\beta=0.120, S E=0.054, p=$ .026). Following the procedures outlined by Pluess and Belsky (2009), we residualized externalizing behavior for the variance shared with negative emotionality and fit the model again using the residualized externalizing behavior variable as the outcome. The pattern of effects was the same as the non-residualized outcome. Thus, consistent with previous literature (Pluess \& Belsky, 2009) we report the findings for the original (nonresidualized) externalizing behavior model.

\section{Primary Analyses}

Models were fit for both externalizing and internalizing problems that included all two-way interactions (negative emotionality x maternal sensitivity, negative emotionality $\mathrm{x}$ teacher sensitivity, and maternal sensitivity $\mathrm{x}$ teacher sensitivity) and the three-way interaction term between negative emotionality, maternal sensitivity, and teacher sensitivity in the last step. Table 3 presents a summary of the findings including the $\beta$ and standard error for each term and the $R^{2}$ for each step and the full model. The standardized coefficients presented are from the first model in which the variable was entered (e.g., the coefficients for negative emotionality are reported from the model including covariates 
(Step 1) and all main effects (Step 2)) in order to provide the best representation of each effect. If the three-way interaction term did not significantly predict kindergarten behavior problems, it was removed from the model to interpret the two-way interactions most accurately.

\section{Negative Emotionality X Maternal Sensitivity X Preschool Teacher}

\section{Sensitivity.}

The 3-way interaction between child negative emotionality, maternal sensitivity and preschool teacher sensitivity predicted children's kindergarten internalizing behaviors $(\beta$ $=-0.109, S E=0.047, p=.020$; see Figure 1). For children high in negative emotionality, when they experienced high teacher sensitivity, as maternal sensitivity increased children's internalizing behaviors remained relatively stable $(-0.071, t=-0.688, p=\mathrm{ns})$. However, when children experienced low teacher sensitivity, maternal sensitivity was positively associated with children's internalizing behavior $(0.180, t=1.879, p=0.06)$, For children low in child negative emotionality, when they experienced high teacher sensitivity, as maternal sensitivity increased children's internalizing behaviors again remained stable $(-0.068, t=-0.864, p=\mathrm{ns})$. However, when they experienced low teacher sensitivity, maternal sensitivity was negatively associated with children's internalizing behavior $(-0.241, t=-1.688, p=0.09)$.

The three-way interaction between negative emotionality, maternal sensitivity, and preschool teacher sensitivity did not reach statistical significance in predicting children's kindergarten externalizing behavior. Thus, this interaction term was removed from the model and only significant two-way interactions are interpreted.

Maternal Sensitivity X Preschool Teacher Sensitivity. Teacher sensitivity 
significantly moderated the relation between maternal sensitivity and child externalizing behavior in kindergarten $(\beta=0.091, S E=0.049, p=.065$; see Figure 2$)$. Specifically, when children experienced high preschool teacher sensitivity, as maternal sensitivity increased their levels of externalizing behavior remained fairly stable $(0.066, t=0.810$, $p=$ ns). However, when children experienced low teacher sensitivity, maternal sensitivity was negatively associated with children's level of externalizing behavior $(-0.116, t=-$ $1.594, p=0.11$ ). Thus, teacher sensitivity appeared to buffer the effect of low maternal sensitivity on children's kindergarten externalizing behavior, such that when maternal sensitivity was low, children had lower levels of behavior problems when they experienced high teacher sensitivity compared to low teacher sensitivity.

\section{Discussion}

We examined the links between child negative emotionality, both maternal and preschool teacher sensitivity, and children's kindergarten behavior problems. We extended previous research by examining maternal and teacher sensitivity together, investigating internalizing and externalizing behavior problems separately, and by using a large, nationally representative sample from a comprehensive longitudinal study (ECLSB). We expected the relation between sensitivity (both maternal and teacher) and behavior problems to be stronger for children high in negative emotionality. Additionally, we expected that for children high in negative emotionality, high sensitivity in one context would protect against low sensitivity in another context.

Our predictions for this paper were informed by the bioecological model of human development (Bronfenbrenner \& Morris, 2006) and the differential susceptibility hypotheses (Belsky et al., 2007). In explaining how child behavior is shaped, the 
bioecological model emphasizes the importance of caregiving across multiple ecological contexts of development in combination with individual child characteristics. The differential susceptibility hypothesis proposes that children high in negative emotionality are more susceptible to both positive and negative environmental influences, including caregiving (Belsky et al., 2007). Thus, children characterized by higher negative emotionality have both the best and the worst outcomes, depending on their environment (Belsky et al., 2007).

Consistent with our hypothesis, we found a moderating effect of negative emotionality on the links between maternal sensitivity, teacher sensitivity, and children's internalizing behavior. However, this effect was in the opposite direction as hypothesized for children high in negative emotionality. Specifically, when children high in negative emotionality experienced low teacher sensitivity, high maternal sensitivity was associated with higher kindergarten internalizing behavior. In contrast, for children low in negativity experiencing low teacher sensitivity, high maternal sensitivity was associated with lower internalizing behavior. For children high or low in negativity, when they experienced high teacher sensitivity, their levels of internalizing behavior were comparable regardless of maternal sensitivity. Several possible explanations may account for the initially counterintuitive findings for children high in negative emotionality.

Our finding for kindergarten internalizing behavior is consistent with previous research on inhibited children, who may be considered high in negative emotionality as infants. Degnan, Almas, and Fox (2010) note that for inhibited children, sensitive parenting may "maintain inhibited behavior by catering to the child's fears and suggesting that extreme fearfulness is something one cannot change" (p.7). Although 
there are mixed findings, some research indicates that a lack of sensitivity can be protective for inhibited children. For example, Park, Belsky, Putnam, and Crnic (1997) found that for first-born boys, maternal intrusiveness, paternal lack of sensitivity, and paternal lack of positive affect were associated with lower inhibition at age 2. Maternal and paternal intrusiveness and paternal expressed negative emotion were associated with lower inhibition at age 3. Our findings suggest that for at least some children high in negative emotionality, sensitive maternal behavior may unintentionally serve to maintain or increase children's internalizing behavior.

For children low in negative emotionality, high maternal sensitivity appeared to buffer the negative influences of low teacher sensitivity for children's kindergarten internalizing behavior. This finding again stands in contrast to the differential susceptibility hypothesis, which suggests that children with low negative emotionality will have similar levels of behavior problems regardless of their experience. It may be that children's early experience of maternal sensitivity shapes their ability to regulate emotions and behavior, thereby preparing them to better cope with later experiences of low teacher sensitivity (Sroufe, 1996). Children low in negative emotionality may be more able to benefit from these early experiences of maternal sensitivity because they may become less distressed by their mother's gentle prompts to explore and try new things than children high in negative emotionality.

In the context of high teacher sensitivity, children's levels of internalizing behavior were similar regardless of child negative emotionality and maternal sensitivity. Thus, maternal and teacher sensitivity appear to operate in different ways for children's internalizing behavior, such that teacher sensitivity is protective for children and maternal 
sensitivity may exacerbate internalizing behavior for children high in negative emotionality. This finding indicates that teachers can serve as an emotional resource that children can access in the classroom when faced with challenges such as navigating early peer relationships, participating in school activities and persisting in new learning activities. Experiencing sensitive, responsive interactions with a teacher can support children's adaptive classroom behavior for children with different temperament styles and different experiences of previous caregiver sensitivity (Buyse et al., 2011; Curby, Rudasill, Edwards, \& Perez-Edgar, 2011).

With regard to externalizing problems, child negative emotionality did not moderate children's experience of maternal and teacher sensitivity regarding their externalizing behavior problems. Instead, there was a main effect of negative emotionality. Although in contrast to what we expected given the differential susceptibility hypothesis, it is in line with past temperament research that often finds this main effect (e.g., Eisenberg et al., 2005; Rothbart \& Bates, 2006; Sanson et al., 2004). Additionally, for all children, not just those high in negative emotionality, having a highly sensitive teacher buffered against the potentially negative influences of experiencing low maternal sensitivity. That is, when children experienced low maternal sensitivity, they had lower behavior problems if they experienced high teacher sensitivity. And, when children experienced high maternal sensitivity, they had comparable levels of externalizing behavior regardless of their teacher's sensitivity. These findings further underscore the importance of both maternal and teacher sensitivity for children with different types of temperaments and the significance of multiple ecological contexts for the development of children's behavior problems (Buyse et al., 2011). 
Several limitations deserve attention. Although this study was longitudinal, thereby permitting more support for causal inference than a cross-sectional design, the study design was correlational. Thus, in order to determine whether increasing maternal and teacher sensitivity leads to fewer kindergarten behavior problems for children high in negative emotionality, experimental study designs are needed in future research.

Additionally, it is important to note that the overall variance in internalizing behavior explained by our model is only about $6 \%$. And, when interaction effects were probed not all simple slopes attained statistical significance. Also, this study used a secondary data analysis approach - the data was not collected specifically to test our research questions. Therefore, the measurement of several constructs of interest was imprecise and not comprehensive. Our measure of teacher sensitivity was at the classroom level; therefore, this measure gives an estimate for the average sensitivity of the teacher with a student in the classroom, but it does not tell us about a particular child's unique experience of sensitivity. This sensitivity measure is also not directly comparable to our dyadic measure of maternal sensitivity. With respect to the measurement of negative emotionality, the nine items do not distinguish specific dimensions of negative emotionality (e.g., anger, distress to novelty) that may be differentially related to young children's outcomes (Rothbart \& Bates, 2006; Sanson et al., 2004). Although our measures for negative emotionality, internalizing behavior and externalizing behavior were constructed based on key items selected from widely used, validated measures by the ECLS-B project, these measures were not the full measures used previously. Thus, our findings are not directly comparable to studies that have employed the full measures.

The difference in our measures may account for some of the unexpected findings 
that are inconsistent with prior work on differential susceptibility, but the loss in precision in these measurements is balanced by the unique ability to examine these constructs in a nationally representative sample. Furthermore, the imprecise measurement of the constructs under examination likely reduced the magnitude of the relationship between these variables. Therefore our findings may actually be an underestimation of the association between child negative emotionality, maternal and preschool teacher sensitivity, and kindergarten behavior problems.

The results from the current study have important implications for both parents and teachers, as well as researchers aiming to understand how adult interactions over time contribute to children's development. Our findings underscore the importance of caregiver sensitivity across the home and early school settings to buffer against the influence of low sensitivity in different contexts. For parents, these findings reinforce prior work indicating that sensitive interactions in the first few years of life can prepare children to navigate later environments that may not be as positive (Sroufe, 1996). Our results also add to the empirical support that indicates the importance of providing children with early school experiences where they have access to sensitive teachers who support children's adaptive classroom behavior. In contrast to previous research suggesting that maternal behavior is more influential for children with internalizing behavior tendencies (e.g., social wariness, inhibition) than children with externalizing behavior tendencies (e.g., bold, uninhibited with novelty) (Early et al., 2002; Rubin, Burgess, \& Hastings, 2002) and that teacher sensitivity is more influential for externalizing behaviors (Rimm-Kaufman et al., 2002), we find that both maternal and teacher sensitivity were important contributors to children's internalizing and 
externalizing behavior.

Given that our findings are from a nationally representative sample of children and evidence different patterns of results than previous work, further research is needed to better understand how adult-child interactions across early childhood contribute to children's development. First, future research should address how the constructs of negative emotionality, maternal sensitivity, and teacher sensitivity in the present study were measured. The present study and prior work on differential susceptibility have employed global measures of negative emotionality or "difficult" temperament; future research could employ differentiated measures of negative emotionality to better understand children's susceptibility to internalizing versus externalizing behavior problems. It would also be informative to use the same observational measure for parentchild and teacher-child interactions to ensure a direct comparison of sensitivity as it is possible that the different measures employed in the present study may assess different aspects of maternal and teacher sensitivity.

Future research should also examine the interactions between child negative emotionality, maternal sensitivity, and teacher sensitivity for children's behavior problems within the cultural context of the child and caregiver. For instance, some evidence indicates that sensitive, responsive parenting behaviors are positively related to social development for Caucasian and African-American children, but not for Hispanic children (Whiteside-Mansell, Bradley, \& McKelvey, 2009). Additionally, the more authoritarian and intrusive parenting practices observed among minority parents may be adaptive to the context in which children live (Garcia Coll, Meyer, \& Brillon, 1995; Halgunseth, Ispa, \& Rudy, 2006). Parents from different ethnic and socioeconomic 
contexts have different values and attitudes about parenting, may make different attributions about the meaning of children's temperament, and in turn respond differently (Chess \& Thomas, 1991; Halgunseth et al., 2006). Similarly, interactions between child negative emotionality, maternal and teacher sensitivity should also be examined by child gender. Consistent with prior work indicating a higher prevalence of internalizing behavior among girls and externalizing behavior among boys (Leve et al., 2005; Miner \& Clarke-Stewart, 2009), male gender was the strongest predictor of kindergarten externalizing behavior in the present study. Thus, the processes by which child negative emotionality and caregiver sensitivity interact to influence behavior may differ by gender. Future research can further elucidate the nuances in how children's individual characteristics interact with their developmental contexts to influence child development, building on findings from the present study demonstrating the significance of caregiver sensitivity across developmental contexts. 


\section{References}

Achenbach, T. M. (1991). Integrative guide for the 1991 Child Behavior Checklist/4 18. Burlington, VT: University of Vermont, Department of Psychiatry.

Aiken, L. S., \& West, S. G. (1991). Multiple Regression: Testing and Interpreting Interactions. Newbury Park, CA.: Sage.

Andreassen, C. \& Fletcher, P. (2007). Early Childhood Longitudinal Study, Birth Cohort (ECLS-B) Psychometric Report for the 2-Year Data Collection (NCES 2007084). Washington, DC: National Center for Education Statistics, Institute of Education Sciences, U.S. Department of Education.

Arnett, J. (1989). Caregivers in day-care centers: Does training matter? Journal of Applied Developmental Psychology, 10, 541 - 552.

Barkley, R. (2006). Attention-Deficit Hyperactivity Disorder: A Handbookfor Diagnosis and Treatment. New York, NY: The Guilford Press.

Belsky, J., Vandell, D. L., Burchinal, M., Clarke-Stewart, K. A., McCartney, K., Owen, M. T. \& NICHD Early Childhood Research Network. (2007). Are there long-term effects of early child care? Child Development, 78(2), $681-701$.

Belsky, J., Bakermans-Kranenburg, M. J., \& van IJzendoorn, M. H. (2007). For better and for worse: Differential susceptibility to environmental influences. Current Directions in Psychological Science, 16(6), 300 - 304.

Bethel, J., Green, J. L., Nord, C., Kalton, G., West, J. (2005). Early Childhood Longitudinal Study, Birth Cohort (ECLS-B): Methodology Report for the 9-month data collection, 2001-02, (NCES 2005-147). Washington, DC: National Center for Education Statistics, Institute of Education Sciences, U.S. Department of Education.

Boyce, W. T., \& Ellis, B. J. (2005). Biological sensitivity to context: I. An evolutionarydevelopmental theory of the origins and functions of stress reactivity. Development and Psychopathology, 17, 271 - 301.

Bradley, R. H. \& Corwyn, R. F. (2008). Infant temperament, parenting, and externalizing behavior in first grade: A test of the differential susceptibility hypothesis. Journal of Child Psychology and Psychiatry, and Allied Disciplines, 49(2), 124 - 131.

Bronfenbrenner, U. \& Morris, P. A. (2006). The bioecological model of human development. In R. M. Learner \& W. Damon (Eds.) Handbook of child psychology (pp. 793-828). Hoboken, NJ, US: John Wiley \& Sons Inc.

Bub, K. L. (2009). Testing the effects of classroom supports on children's social and 
behavioral skills at key transition points using latent growth modeling. Applied Developmental Science, 13(3), 130 - 148.

Bub, K. L., McCartney, K., \& Willett, J. B. (2007). Behavior problem trajectories and first-grade cognitive ability and achievement skills: A latent growth curve analysis. Journal of Educational Psychology, 99, 653 - 670.

Bulotsky-Shearer, R. J. \& Fantuzzo, J. W. (2011). Preschool behavior problems in classroom learning situations and literacy outcomes in kindergarten and first grade. Early Childhood Research Quarterly, 26, 61 - 73.

Burchinal, M. R., Peisner-Feinberg, E., Bryant, D. M., \& Clifford, R. (2000). Children's social and cognitive development and child-care quality: Testing for differential associations related to poverty, gender, or ethnicity. Applied Developmental Science, 4(3), 149 - 165.

Burchinal, M. R., Roberts, J. E., Riggins, R., Zeisel, S. A., Neebe, E. \& Bryant, D. (2000). Relating quality of center-based child care to early cognitive and language development longitudinally. Child Development, 71(2), 339 - 357.

Buyse, E., Verschueren, K., \& Doumen, S. (2011). Preschoolers' attachment to mother and risk for adjustment problems in kindergarten: Can teachers make a difference? Social Development, 20(1), $33-50$.

Campbell, S. B. (2002). Behavior Problems In Preschool Children. New York, NY: The Guilford Press.

Chess, S. \& Thomas, A. (1991). Temperament and the concept of goodness of fit. In J. Strelau \& A. Angleitner (Eds.), Explorations in temperament: International perspectives on theory and measurement (pp. 15-28). New York, NY, US: Plenum Press.

Curby, T. W., Rudasill, K. M., Edwards, E. \& Perez-Edgar, K. (2011). The role of classroom quality in ameliorating the academic and social risks associated with difficult temperament. School Psychology Quarterly, 26(2), 175 - 188.

Deater-Deckard, K., Pinkerton, R., \& Scarr, S. (1996). Child care quality and children's behavioral adjustment: A four-year longitudinal study. Journal of Child Psychology and Psychiatry, and Allied Disciplines, 37(8), 937 - 948.

Degnan, K. A., Almas, A. N. \& Fox, N. A. (2010). Temperament and the environment in the etiology of childhood anxiety. Journal of Child Psychology and Psychiatry, $51(4), 497-517$.

Dobbs, J., Doctoroff, G. L., Fisher, P. H., \& Arnold, D. H. (2006). The association between preschool children's socio-emotional functioning and their mathematical skills. Journal of Applied Developmental Psychology, 27(2), 97 - 108. 
Dominguez, X., Vitiello, V. E., Maier, M. F., \& Greenfield, D. B. (2010). A longitudinal examination of young children's learning behavior: Child-level and classroomlevel predictors of change throughout the preschool year. School Psychology Review, 39(1), $29-47$.

Early, D. M., Rimm-Kaufman, S. E., Cox, M. J., Sulaja, G., Pianta, R. C., Bradley, R. H., \& Payne, C. C. (2002). Maternal sensitivity and child wariness in the transition to kindergarten. Parenting: Science and Practice, 2(4), 355 - 377.

Eisenberg, N., Valiente, C., Spinrad, T. L., Cumberland, A., Liew, J., Reiser, M., Zhou, Q., \& Losoya, S. H. (2009). Longitudinal relations of children's effortful control, impulsivity, and negative emotionality to their externalizing, internalizing, and co-occurring behavior problems. Developmental Psychology, 45(4), 988 - 1008.

Fanti, K. A. \& Henrich, C. C. (2010). Trajectories of pure and co-occurring internalizing and externalizing problems from age 2 to age 12: Findings from the national institute of child health and human development study of early child care. Developmental Psychology, 46(5), 1159 -1175.

Fantuzzo, J. W., Bulotsky-Shearer, R., Fusco, R. A., \& McWayne, C. (2005). An investigation of preschool classroom behavioral adjustment problems and social-emotional school readiness competencies. Early Childhood Research Quarterly, $20(3), 259-275$.

Flanagan, K. D., and McPhee, C. (2009). The Children Born in 2001 at Kindergarten Entry: First Findings From the Kindergarten Data Collections of the Early Childhood Longitudinal Study, Birth Cohort (ECLS-B) (NCES 2010-005). Washington, DC: National Center for Education Statistics, Institute of Education Sciences, U.S. Department of Education.

Floyd, F. J. \& Widaman, K. F. (1995). Factor analysis in the development and refinement of clinical assessment instruments. Psychological Assessment, 7(3), 286 - 299.

Garcia Coll, Meyer, Brillon, 1995). Ethnic and minority parenting. In M. H. Bornstein (Ed.), Handbook of Parenting Vol. 2: Biology and Ecology of Parenting (p.189209). Hillsdale, NJ: Lawrence Erlbaum Associates.

Gresham, F.M., \& Elliott, S.N. (1990). Social Skills Rating System. Circle Pines, MN: American Guidance Service.

Hinshaw, S. P. (1992) Externalizing behavior problems and academic underachievement in childhood and adolescence: Causal relationships and underlying mechanisms. Psychological Bulletin, 111(1), 127 - 155.

Halgunseth, L. C., Ispa, J. M., \& Rudy, D. (2006). Parental control in Latino families: An integrated review of the literature. Child Development, 77(5), $1282-1297$. 
Jacobson-Chernoff, J., \& Flanagan, K. D. McPhee, C., Park, J. (2007). Preschool: First Findings From the Third Follow-up of the Early Childhood Longitudinal Study, Birth Cohort (ECLS-B) (NCES 2008025). Washington, DC: National Center for Education Statistics, Institute of Education Sciences, U.S. Department of Education.

Kalton, G. \& Flores-Cervantes, I. (2003). Weighting Methods. Journal of Official Statistics, 19(2), $81-97$.

Kiff, C. J., Lengua, L. J., \& Zalewski, M. (2011). Nature and nurturing: Parenting in the context of child temperament. Clinical Child and Family Psychology Review, 14(3), $251-301$.

Leve, L.D., Hyoun K.K., \& Pears, K.C. Childhood Temperament and Family Environment As Predictors of Internalizing and Externalizing Trajectories From Ages 5 to 17. Journal of Abnormal Child Psychology, 33(5), 505 - 520.

Love, J. M., Kisker, E. E., Ross, C., Raikes, H., Constantine, J., Boller, K., Brooks-Gunn, J., Chazan-Cohen, R., Tarullo, L. B., Brady-Smith, C., Fuligni, A. S., Schochet, P. Z., Paulsell, D., Vogel, C. (2005). The effectiveness of early head start for 3-yearold children and their parents: Lessons for policy and programs. Developmental Psychology, 41(6), $885-901$.

Mashburn, A. J., Hamre, B. K., Downer, J. T., \& Pianta, R. C. (2006). Teacher and classroom characteristics associated with teachers' ratings of prekindergartners' relationships and behaviors. Journal of Psychoeducational Assessment, 24(4), 367 -380 .

Merrell, K.W. (2002). Preschool and Kindergarten Behavior Rating Scales (PKBS-2). Austin, TX: PRO-ED.

Miner, J.L. \& Clarke-Stewart, K.A. (2008). Trajectories of Externalizing Behavior From Age 2 to Age 9: Relations with Gender, Temperament, Ethnicity, Parenting, and Rater. Developmental Psychology, 44(3), 771 - 786.

Mitchell-Copeland, J., Denham, S.A., \& DeMulder, E.K. (1997). Teacher attachment relationships and social competence in preschool. Early Education and Development, 8(1), $27-39$.

Mulligan, G.M. \& Flanagan, K. D. (2006). Age 2: Findings From the 2-Year-Old Followup of the Early Childhood Longitudinal Study, Birth Cohort (ECLS-B) (NCES 2006043). Washington, DC : National Center for Education Statistics, Institute of Education Sciences, U.S. Department of Education. 
Muthén, B. O., \& Muthén, L. K. (2010). Mplus (Version 6). Los Angeles. CA: Muthen \& Muthen.

NICHD Early Child Care Research Network. (1998). Early child care and self-control, compliance, and problem behavior at twenty-four and thirty-six months. Child Development, 69(4), 1145 - 1170.

NICHD Early Child Care Research Network. (1999). Chronicity of maternal depressive symptoms, maternal sensitivity, and child functioning at 36 months.

Developmental Psychology, 35(5), 1297 - 1310.

NICHD Early Child Care Research Network. (2002). Early child care and children's development prior to school entry: Results from the NICHD ECCRN study of early child care. American Educational Research Journal, 39, 133 - 164.

NICHD Early Child Care Research Network. (2003). Social functioning in first grade: Association with earlier home and childcare predictors and with current classroom experiences. Child Development, 74(6), 1639 - 1662.

NICHD Early Child Care Research Network (2004). Fathers' and mothers' parenting behavior and beliefs as predictors of children's social adjustment in the transition to school. Journal of Family Psychology, 18(4), 628 - 638.

Nelson, B., Martin, R. P., Hodge, S., Havill, V. \& Kamphaus, R. (1999). Modeling the prediction of elementary school adjustment from preschool temperament. Personality and Individual Differences, 26(4), 687 - 700.

Nguyen, L., Huang, L.N., Arganza, G.F., \& Liao, Q.(2007). The Influence of Race and Ethnicity on Psychiatric Diagnoses and Clinical Characteristics of Children and Adolescents in Children's Services. Cultural Diversity \& Ethnic Minority Psychology, 13(1), $18-25$.

Nord, C., Edwards, B., Andreassen, C., Green, J. L., and Wallner-Allen, K. (2006). Early Childhood Longitudinal Study, Birth Cohort (ECLS-B) User's Manual for the ECLS-B Longitudinal 9-Month-2-Year Data File and Electronic Codebook (NCES 2006-046). Washington, DC: National Center for Education Statistics, Institute of Education Sciences, U.S. Department of Education.

Obradović, J., Bush, N. R., \& Boyce, W. T. (2011). The interactive effect of marital conflict and stress reactivity on externalizing and internalizing symptoms: The role of laboratory stressors. Development and Psychopathology, 23(1), $101-114$.

Park, S. Y., Belsky, J., Putnam, S. \& Crnic, K. (1997). Infant emotionality, parenting, and 3-year inhibition: Exploring stability and lawful discontinuity in a male sample. Developmental Psychology, 33(2), 218 - 227. 
Pedlow, R., Sanson, A., Prior, M., \& Oberklaid, F. (1993). Stability of maternally reported temperament from infancy to 8 years. Developmental Psychology, 29(6), $998-1007$.

Pianta, R. C., LaParo, K. M., Payne, C., Cox, M. J., \& Bradley, R. (2002). The relation of kindergarten classroom environment to teacher, family, and school characteristics and child outcomes. The Elementary School Journal, 102(3), 225 - 238.

Pianta, R. C., Nimetz, S. L. \& Bennett, E. (1997). Mother-child relationships, teacherchild relationships, and school outcomes in preschool and kindergarten. Early Childhood Research Quarterly, 12(3), 263 - 280.

Pluess, M. \& Belsky, J. (2009). Differential susceptibility to rearing experience: The case of childcare. Journal of Child Psychology and Psychiatry, 50(4), 396 - 404.

Pluess, M. \& Belsky, J. (2010). Differential susceptibility to parenting and quality child care. Developmental Psychology, 46(2), 379 - 390.

Preacher, K. J., Curran, P. J., \& Bauer, D. J. (2006). Computational tools for probing interaction effects in multiple linear regression, multilevel modeling, and latent curve analysis. Journal of Educational and Behavioral Statistics, 31, 437 - 448.

Rapport, M. D., Denney, C. B., Chung, K. M., \& Hustace, K. (2001). Internalizing behavior problems and scholastic achievement in children: Cognitive and behavioral pathways as mediators of outcome. Journal of Clinical Child Psychology, 30(4), $536-551$.

Raver, C. C. \& Knitzer, J. (2002). Ready to enter: What research tells policy makers about strategies to promote social and emotional school readiness among threeand four-year-olds. New York: Mailman School of Public Health, Columbia University, National Center for Children in Poverty.

Rimm-Kaufman, S. E., Pianta, R. C., \& Cox, M. J. (2000). Teachers' judgments of problems in the transition to kindergarten. Early Childhood Research Quarterly, $15(2), 147-166$.

Rimm-Kaufman, S.E., Early, D.M., Cox, M.J., Saluja, G., Pianta, R.C., Bradley, R.H., Payne, C. (2002). Early behavioral attributes and teachers' sensitivity as predictors of competent behavior in the kindergarten classroom. Applied Developmental Psychology, 23, $451-470$.

Reynolds, C.R. \& Kamphus, R.W. (2004). Behavior Assessment System for Children: Second Edition. Circle Pines, Minnesota: AGS Publishing.

Rothbart, M. K., \& Bates, J. E. (2006). Temperament. In W. Damon, R. Lerner, \& N. Eisenberg (Eds.), Handbook of child psychology: Social emotional and personality (6 ${ }^{\text {th }}$ ed., Vol. 3, pp. 99-166). New York: John Wiley \& Sons, Inc. 
Rubin, K. H., Burgess, K. B., \& Hastings, P. D. (2002). Stability and social-behavioral consequences of toddlers' inhibited temperament and parenting behaviors. Child Development, 73(2), $483-495$.

Sanson, A., Hemphill, S. A., Smart, D. (2004). Connections between temperament and social development: A review. Social Development, 13(1), 142 - 170.

Sanson, A., Letcher, P., Smart, D., Prior, M., Toumbourou, J. W., \& Oberklaid, F. (2011). Associations between early childhood temperament clusters and later psychosocial adjustment. Merrill-Palmer Quarterly, 55(1), 26 - 54.

Smith, K. E., Landry, S. H., \& Swank, P. R. (2000). The influence of early patterns of positive parenting on children's preschool outcomes. Early Education and Development, 11(2), 147 - 169.

Snow, K., Derecho, A., Wheeless, S., Lennon, J., Rosen, J., Rogers, J., Kinsey, S, Morgan, K., and Einaudi, P. (2009). Early Childhood Longitudinal Study, Birth Cohort (ECLS-B), Kindergarten 2006 and 2007 Data File User's Manual (NCES 2010-010). Washington, DC: National Center for Education Statistics, Institute of Education Sciences, U.S. Department of Education.

Snow, K., Thalji, L., Derecho, A., Wheeless, S., Lennon, J., Kinsey, S., Rogers, J., Raspa, M., Park, J. (2007). User's Manual for the ECLS-B Longitudinal 9-Month-Preschool Restricted-Use Data File and Electronic Codebook (NCES 2008024). Washington, DC: National Center for Education Statistics, Institute of Education Sciences, U.S. Department of Education.

Sroufe, L. A. (1996). Emotional Development; The Organization of Emotional Life in the Early Years. New York, NY: Cambridge University Press.

Straight, A. D., Gallagher, K. C. \& Kelly, K. (2008). Infant temperament moderates relations between maternal parenting in early childhood and children's adjustment in kindergarten. Child Development, 79(1), 186 - 200.

Wheeless, S., Ault, K., Copello, E., Black, S., Johnson, R., \& Mulligan, G. M. (2009). Early Childhood Longitudinal Study, Birth Cohort (ECLS-B): Methodology Report for the Kindergarten 2006 Data collection (2006-07), Volume II: Sampling. Washington, DC: National Center for Education Statistics, Institute of Education Sciences, U.S. Department of Education.

Wheeless, S., Ault, K., Park, J. \& Mulligan, G. (2008). Early Childhood Longitudinal Study, Birth Cohort (ECLS-B): Methodology report for the Preschool data collection (2005-06), Volume II: Sampling. Washington, DC: National Center for Education Statistics, Institute of Education Sciences, U.S. Department of Education. 
Whiteside-Mansell, L., Bradley, R. H. \& McKelvey, L. (2009). Parenting and preschool child development: Examination of three low-income US cultural groups. Journal of Child and Family Studies, 18(1), 48 - 60.

Zill, N., Resnick, G., Kim, K., O’Donnell, K., Sorongon, A., McKey, R., Pai-Samant, S., Clark, C., O'Brien, R., D'Elio, M. (2003). Head Start FACES 2000: A wholechild perspective on program performance. Fourth progress report. Alexandria, VA: Head Start Information and Publication Center. 
Table 1

2-year Assessment (Wave 2) Participant Characteristics

\begin{tabular}{lcc}
\hline \multicolumn{1}{c}{ Demographic Characteristic } & $N^{a}$ & Percent of Sample \\
\hline Child Race/Ethnicity & 1100 & \\
Caucasian & 450 & $52.0 \%$ \\
African-American & 250 & $16.6 \%$ \\
Hispanic & 200 & $25.1 \%$ \\
Asian & 100 & $2.5 \%$ \\
Native Hawaiian/American Indian & 0 & $0.5 \%$ \\
Multiracial & 100 & $3.2 \%$ \\
& & \\
Maternal Education & 1100 & \\
Did not complete high school & 200 & $16.8 \%$ \\
High School Diploma & 350 & $31.4 \%$ \\
Some College/Vocational Program & 300 & $25.3 \%$ \\
Bachelors Degree & 150 & $15.7 \%$ \\
Graduate School, no degree & 0 & $4.1 \%$ \\
Graduate Degree & 100 & $6.5 \%$ \\
Mother Married & \multicolumn{2}{c}{} \\
Child Gender (Female) & 650 & $64.7 \%$ \\
& 550 & $49.6 \%$ \\
& & \\
Child Age (months) & & Mean (range) \\
Mother (years) & 1100 & $24.52(22.5-38.2)$ \\
\hline
\end{tabular}

${ }^{a}$ All unweighted sample sizes are rounded to the nearest 50 to protect the privacy of the ECLS-B participants. 


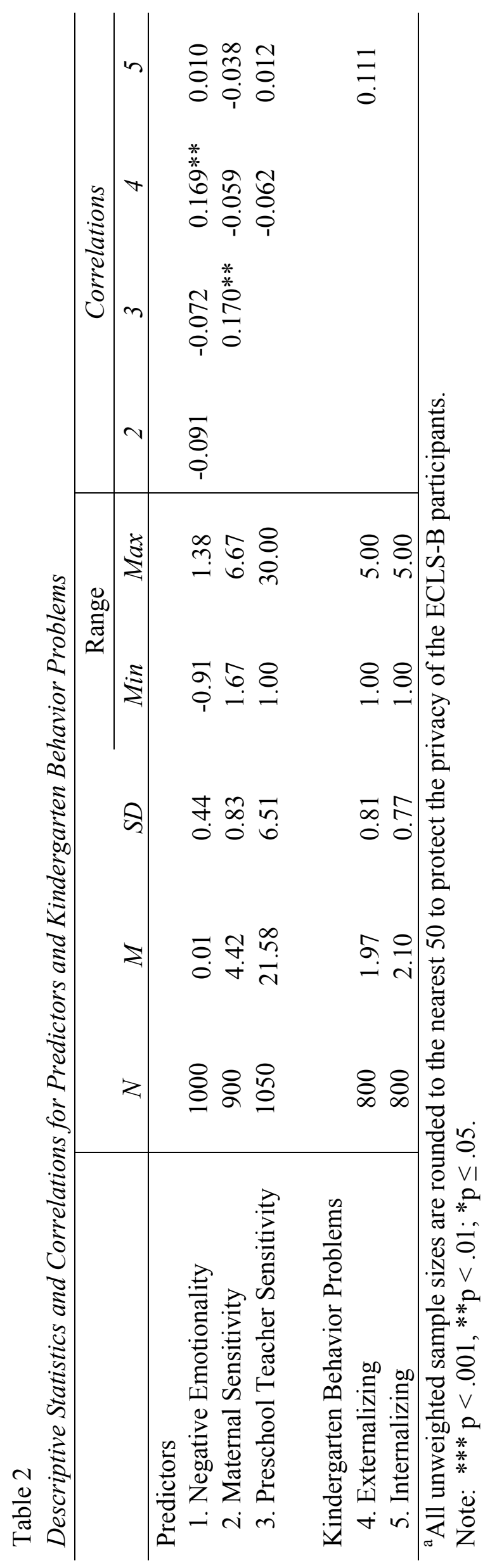


Table 3

Regression Analyses Predicting Kindergarten Behavior Problems

\begin{tabular}{|c|c|c|c|c|c|c|}
\hline & \multicolumn{3}{|c|}{ Externalizing Behavior } & \multicolumn{3}{|c|}{ Internalizing Behavior } \\
\hline & $\beta$ & $S E$ & $R^{2}$ & $\beta$ & $S E$ & $R^{2}$ \\
\hline Covariates & & & $.121 * * *$ & & & .031 \\
\hline Age at kindergarten & $-0.094^{\dagger}$ & 0.051 & & 0.014 & 0.070 & \\
\hline Male & $0.282 * * *$ & 0.047 & & 0.011 & 0.066 & \\
\hline Caucasian & 0.050 & 0.053 & & -0.028 & 0.066 & \\
\hline SES & $-0.133^{*}$ & 0.054 & & 0.020 & 0.054 & \\
\hline Child:Adult Ratio & -0.001 & 0.049 & & $-0.158 * *$ & 0.056 & \\
\hline Hours/week in childcare & $0.165 * *$ & 0.049 & & 0.076 & 0.070 & \\
\hline Main Effects & & & $.133 * * *$ & & & .035 \\
\hline Negative Emotionality & $0.120 *$ & 0.054 & & 0.000 & 0.063 & \\
\hline Maternal Sensitivity & -0.014 & 0.065 & & -0.053 & 0.067 & \\
\hline Teacher Sensitivity & -0.004 & 0.047 & & 0.042 & 0.060 & \\
\hline 2-way Interactions & & & $.140 * * *$ & & & $.046^{\dagger}$ \\
\hline NegEm*MSensitivity & -0.004 & 0.049 & & $0.099^{\dagger}$ & 0.058 & \\
\hline NegEm*TSensitivity & -0.022 & 0.054 & & -0.008 & 0.061 & \\
\hline MSensitivity*TSensitivity & $0.091^{\dagger}$ & 0.049 & & -0.032 & 0.055 & \\
\hline 3-way Interaction & & & $.140 * * *$ & & & $057^{*}$ \\
\hline NegEm*Msen*Tsen & 0.002 & 0.052 & & $-0.109 *$ & 0.047 & \\
\hline
\end{tabular}

Note: $* * * p<.001, * * p<.01 ; * p<.05^{\dagger} p<.10$.

$N=1100$ (rounded to the nearest 50 to protect the privacy of ECLS-B participants) 


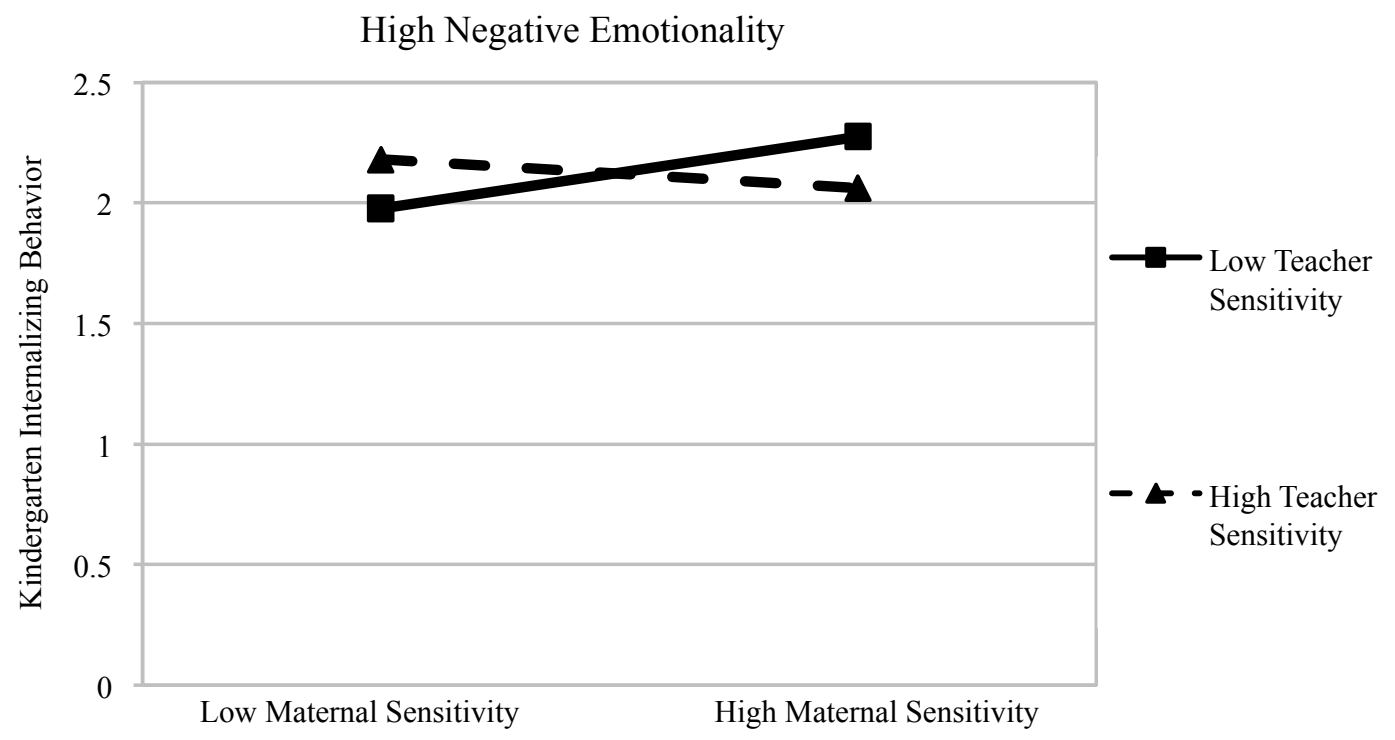

Figure 1a. Moderating influence of preschool teacher sensitivity in the relation between maternal sensitivity and kindergarten internalizing behavior under conditions of high negative emotionality.

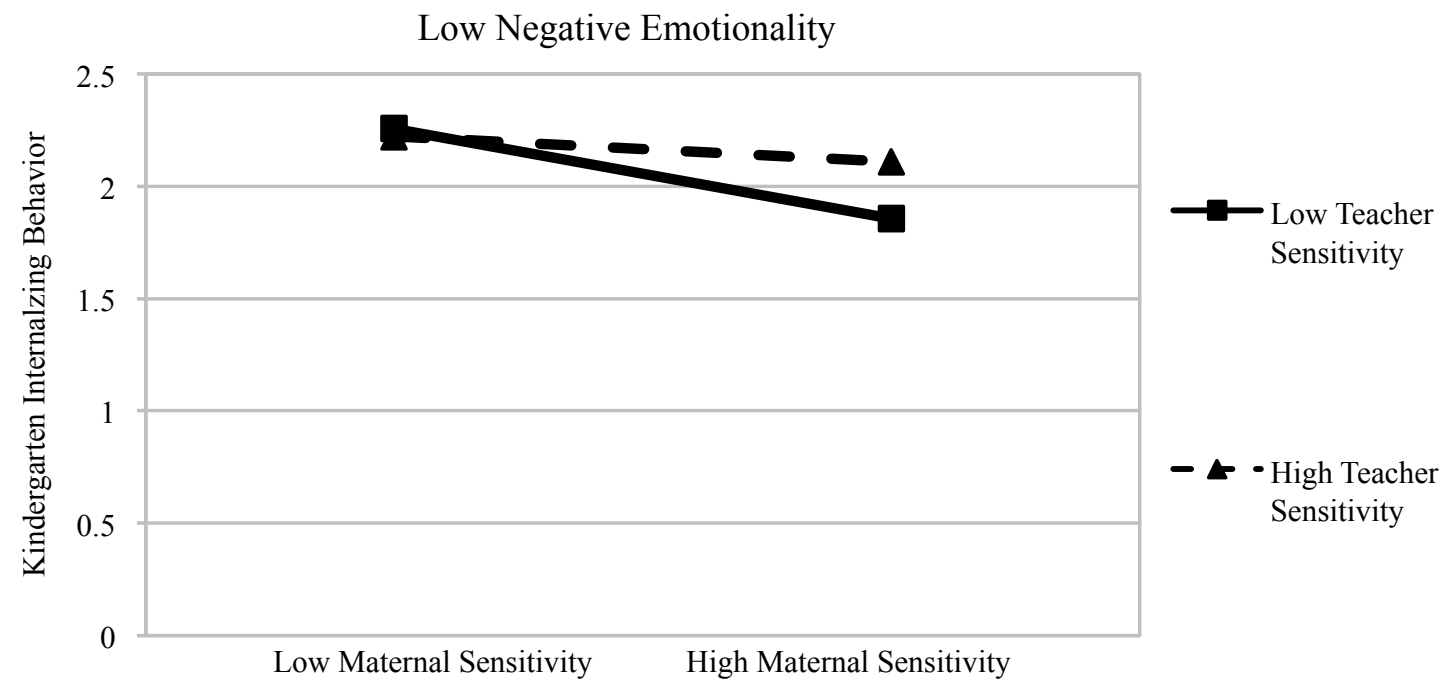

Figure $1 b$. Moderating influence of preschool teacher sensitivity in the relation between maternal sensitivity and kindergarten internalizing behavior under conditions of low negative emotionality. 


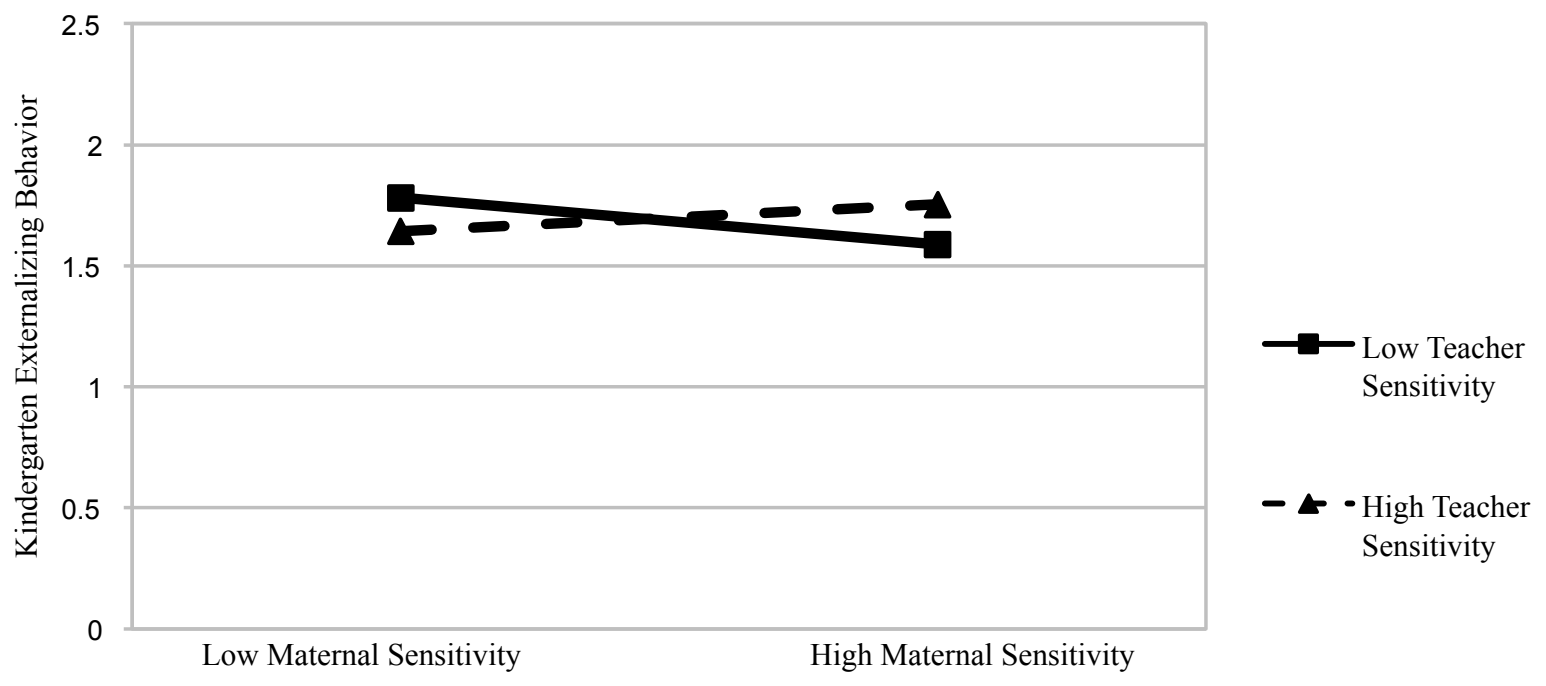

Figure 2. Moderating influence of preschool teacher sensitivity in the relation between maternal sensitivity and kindergarten externalizing behavior. 
Running Head: TEACHERS’ RELATIONSHIP PERCEPTIONS

Changes in Teachers' Perceptions of Teacher-Child Relationships: The Contribution of Children's Engagement and Teachers' Characteristics

Karyn A. Hartz ${ }^{\mathrm{a}}$, Amanda P. Williford ${ }^{\mathrm{a}}$, and Helma M. Y. Koomen ${ }^{\mathrm{b}}$

${ }^{\mathrm{a} U n i v e r s i t y ~ o f ~ V i r g i n i a ~}$

${ }^{\mathrm{b}}$ University of Amsterdam 


\begin{abstract}
The present study examines the contribution of children's classroom engagement and teachers' psychological characteristics to stability in teachers' perceptions of the teacher-child relationship with a particular child during one year of preschool. Teachers reported on their perceptions of closeness and conflict in the teacher-child relationship in the fall and spring. Children's classroom engagement (teacher, peer, task, negative) was observed midyear. Teachers also reported on their anxiety, anger, work-related stress, adult-centered beliefs and self-efficacy. Children positive engagement in classroom tasks predicted increases in teachers' perceptions of closeness. Children's negative engagement predicted increases in their teachers' perceived relational conflict. Children's positive engagement with their teacher and peers was not related to changes in teachers' relationship perceptions. Teachers' higher anxiety predicted decreases in their perceptions of closeness and their higher work related stress predicted increases in conflict. Teachers' anger, adult-centered beliefs and self-efficacy did not predict changes in relationship perceptions.
\end{abstract}

Keywords: teacher-child relationships, child engagement, teacher well-being, teacher stress 
Changes in Teachers' Perceptions of Teacher-Child Relationships: The Contribution of Children's Engagement and Teachers' Characteristics

\section{Introduction}

Teachers' perceptions of the quality of the teacher-child relationship are key predictors of children's academic, social, and behavior outcomes (Hamre \& Pianta, 2001; Hughes, 2011; Roorda, Koomen, Spilt \& Oort, 2011). Given the significance of these relationship perceptions for children, it is important to understand the factors that contribute to teachers' perceptions of their relationship with children and to changes in these perceptions over time. Teacher-child relationships are dynamic systems that develop over time based on contributions from both the teacher and the child (Pianta, 1999). Previous research shows that children's classroom behavior is related to teachers' perceptions of this relationship. However, most work has focused on associations with teacher-reported problem behavior (Birch \& Ladd, 1998; Ladd \& Burgess, 1999). Less work has examined what is actually happening in the classroom through independent observations of children's engagement in the classroom. Teachers' perceptions of the teacher-child relationship at a given time have also been related to teachers' psychological characteristics, including their classroom-related beliefs (e.g., selfefficacy) and their well-being (e.g., stress) (Hamre, Pianta, Downer \& Mashburn, 2008; Mashburn, Hamre, Downer, Pianta, 2006; Thijs \& Koomen, 2009; Yoon, 2002). Thus, these psychological characteristics may contribute to the ways that teachers' perceptions of the relationship change over time. The present study examines how aspects of children's classroom engagement and teachers' psychological characteristics contribute 
to changes in teachers' perceptions of the teacher-child relationship with a particular child over the course of one school year.

\section{Importance of Teachers' Perceptions of the Teacher-Child Relationship}

Teachers' perceptions of their relationships with the children in their classroom predict children's academic, behavioral and social outcomes (Baker, 2006; Birch \& Ladd, 1997; Hamre \& Pianta, 2001; Hughes, 2011; Hughes, Cavell \& Jackson, 1999; Palermo, Hanish, Martin, Fabes \& Reiser, 2007; Roorda et al., 2011). When a teacher reports having a close relationship with a child, one that is characterized by warmth, connection, and openness, that child is more likely to perceive and demonstrate higher academic competence, and to like school (Birch \& Ladd, 1997; Hughes, 2011; Hughes \& Kwok, 2007; Maldonado-Carreno \& Votruba-Drzal, 2011). In contrast, when a teacher reports conflict in his/her relationship with a child, that child is more likely to evidence escalating behavior problems, lower academic achievement, lower school liking, and more school avoidance (Birch \& Ladd, 1997; Doumen et al., 2008; O’Connor \& McCartney, 2007). The importance of teachers' perceptions of teacher-child relationships is underscored by the protective influence a close relationship has been shown to have for children who are at-risk for poor school outcomes because of early behavior or academic problems, demographic and family characteristics (Baker, 2006; Burchinal, PeisnerFeinberg, Pianta, Howes, 2002; Buyse, Verschueren \& Doumen, 2011; Hughes, Gleason, \& Zhang, 2005; O’Connor \& MCartney, 2007; Sabol \& Pianta, 2012; Silver, Measelle, Armstrong, \& Essex, 2005).

Although teacher-reported relationship quality reflects teachers' perceptions, which may contain reporter bias, these perceptions have proven to be highly influential 
for children. For instance, a teacher's report of his or her relationship with a child has been linked with how he or she is observed to interact with that child in the classroom (Stuhlman \& Pianta, 2002). The quality of these interactions in turn affect how children interact with other children and adults in the classroom, learn, and achieve in school (Hughes \& Kwok, 2007; O’Connor \& McCartney, 2007). Furthermore, teachers assign grades, make recommendations for grade retention or promotion, and refer children for school services such as special education. This makes teachers' perceptions of children and their relationship contributors to children's school success. And, when teachers perceive less positive relationships with their students, they tend to rate children's academic competence lower even when controlling for students measured ability (Hughes et al., 2005). Thus, it is important to understand factors related to changes in teachers' perceptions of their relationships with children in order to gain insight into improving teacher-child relationships so as to support children's success in school.

\section{Change in Teachers' Perceptions of Their Relationships with Children}

Most research examining child and teacher characteristics as predictors of teacher-child relationships has been conducted using an assessment of the teacher-child relationship at a single point in time (e.g., Birch \& Ladd, 1998; Yoon, 2002). However, research examining the stability of the teacher-child relationship is also important because the trajectories of change in children's relationship quality have also been associated with children's academic success and behavioral adjustment (MaldonadoCarreno \& Votruba-Drzal, 2011; Spilt, Hughes, Wu, \& Kwok, 2012). As described by Pianta (1999), teacher-child relationships are dynamic systems that develop over time and are amenable to change. For example, teachers' negative perceptions about their 
relationship with a student affect their behavior toward that child (Pianta, 1999; Stuhlman \& Pianta, 2002) and can become a self-fulfilling prophecy. Existing research examining the stability of teacher-child relationship quality across multiple years with different teachers indicates that teacher-child relationship quality is modestly stable across the preschool and elementary school years (Howes, Phillipsen \& Peisner-Feinberg, 2000; Jerome, Hamre \& Pianta, 2009). Two recent studies examined how children's behavior problems contribute to stability in teachers' perceptions of relationships with the same students within a single school year and found that teachers' perceptions of closeness and conflict in their relationships with children are moderately to highly stable over one school year in early childhood (Doumen et al., 2008; Zhang \& Sun, 2011). Although teachers' perceptions seem to be fairly stable overall, they are not fixed. In the present study, we extend recent research by examining how both teacher and child characteristics predict change in a teacher's perception of his/her relationship with a child during a single year of school in a sample of preschool children who are at risk for negative school outcomes because they come from low-income households.

\section{The Role of Children's Classroom Engagement}

A considerable body of work has identified many child attributes that affect teachers' report of the teacher-child relationship, including age, gender, behavioral style, language abilities, temperament (Birch \& Ladd, 1998; Ewing \& Taylor, 2009; Murray \& Murray, 2004, Rudasill, Rimm-Kaufman, Justice, \& Pence, 2006; Saft \& Pianta, 2001). Again, much of this work has examined the teacher-child relationship at a single point in time. Children's behavior problems have also been found to relate to changes in teachers' perceptions of the relationship over one school year (Doumen et al., 2008; Zhang \& Sun, 
2011). Examinations of the association between children's classroom behavior and the teacher-child relationship primarily employ teachers' report of both the relationship (outcome) and behavior (predictor) (Baker, Grant \& Morlock, 2008; Birch \& Ladd, 1997; Doumen et al., 2008; Ewing \& Taylor, 2009; Ladd \& Burgess, 1999). This use of primarily teacher reports has been a limitation of this body of research (Sabol \& Pianta, 2012). Teachers' perceptions of a child are likely to influence both their reports of relationship quality and children's behavior, thereby introducing a problem with shared method variance. Some authors have used parent report of behavior problems to avoid employing the same rater (e.g., NICHD ECCRN, 2003); however, these child behaviors are then out of the context of the classroom and may not reflect the behavior a child displays in the classroom setting. Children's behavior in the classroom is most proximal to teachers and therefore likely to be predictive of stability and change in teachers' perceptions of the teacher-child relationship. Thus, observations in the classroom can provide an assessment of children's behavior that is relevant for teachers' perceptions and free of potential rater bias. Little work has utilized independent classroom observations of children's behavior to examine how what actually happens in the classroom relates to teachers perceptions of the teacher-child relationship (for exceptions see: Doumen, Koomen, Buyse, Wouters \& Verschueren, 2012; Doumen et al., 2009; Stuhlman \& Pianta, 2002). The present study will address this limitation by employing independent observations of children's classroom engagement to predict changes in teachers' perceptions of teacher-child relationships.

Additionally, much of the work that has established the relation between children's behavior in the classroom and teachers' perceptions of the relationship has 
asked teachers to report on children's discrete behavior occurrences (e.g., difficulty following directions, hits/kicks other students, avoids children) out of context from how children are engaged in interactions with their teachers, peers, and classroom tasks and activities (e.g., Birch \& Ladd, 1998; O’Connor, Dearing \& Collins, 2011; Doumen et al., 2008; Hamre et al., 2008). Although children's disruptive behavior in the classroom is salient for teachers and highly related to their perceptions of conflict in the teacher-child relationship (Campbell 2002; Hamre et al., 2008), this is only one aspect of children's classroom behavior. Recent work provides empirical support of the usefulness of employing a global, multidimensional assessment of children's engagement in the classroom, which is related in important ways to children's social-emotional development (Williford, Whittaker, Vitiello \& Downer, 2013). This measure of children's engagement is consistent with how McWillam and Casey (2008) define this construct: children's developmentally and contextually appropriate interactions with teachers, peers, and materials in the classroom environment. In the present study we examine how children's positive and negative classroom engagement with teacher, peers, and tasks relates to stability in teachers' perceptions of the teacher-child relationship.

\section{The Role of Teacher Characteristics in Perceptions of Teacher-Child Relationships}

Researchers have repeatedly found that teachers' perceptions of teacher-child relationships at a single point in time are influenced by teachers' own personal characteristics, past relationship experiences, and/or current stressors (Doumen et al., 2012; Doumen et al., 2009; Mashburn et al., 2006; Hamre et al., 2008; Jennings \& Greenberg, 2009; Spilt, Koomen, Thijs, van der Leij, 2012). The association between teachers' personal characteristics and their perceptions of teacher-child relationships is 
highlighted by research showing that up to one-third of the variance in teachers' reports of the relationship may be attributed to individual differences between teachers (Mashburn et al., 2006) and that teacher characteristics may account for more variation in teachers' reports of the teacher-child relationship than children's characteristics and behavior (Rudasill et al., 2006). Several aspects of teachers' classroom-related beliefs have been predictive of their perceptions of the teacher-child relationship. For instance, teachers' higher self-efficacy is related to their more positive perceptions of the teacherchild relationship (Hamre et al., 2008; Mashburn et al., 2006; Spilt, Koomen et al., 2012). When teachers have more authoritarian rather than child-centered beliefs, they tend to have lower quality interactions with their students (Pianta et al., 2005), which is likely to affect their perceptions of the teacher-child relationship. Teachers' emotional well-being also influences their classroom interactions and perceptions of the teacher-child relationship (Hamre et al., 2008; Kesner, 2000; Jennings \& Greenberg, 2009). When teachers' experience negative emotions that are difficult to manage, this may contribute to negative patterns of interaction (Jennings \& Greenberg, 2009). Teachers' higher stress is predictive of teachers' perceptions of more negative relationships with students (Yoon, 2002). Additionally, teachers' depression, which often includes feelings of anxiety and anger/irritability in addition to sadness, is related to perceptions of less positive relationships with students (Hamre \& Pianta, 2004; Hamre et al., 2008). The classroom composition (e.g., student misbehavior) and broader school context in which teachers work (e.g., workload, time pressures, climate, and support) contribute to teachers' workrelated stress, experience of negative emotions, and perceptions of their efficacy (Chang, 2009; Kelly \& Berthelsen, 1995; Kryiacou, 2001; Lambert, O’Donnell, Kusherman \& 
McCartney, 2006; van Dick \& Wager, 2001; Skaalvik \& Skaalvik, 2008; Smith \& Bourke, 1992). Thus, teachers' classroom beliefs and emotional well-being are likely to be fairly consistent in the short-term when they remain in same teaching environment. Teachers' patterns of well-being relative to other teachers tend to be fairly stable over time (Kinnuhen \& Saloa, 1994). Teachers' authoritarian beliefs also tend to be consistent over time (Roach, Kim \& Riley, 2006). This emerging body of research on teacher characteristics and teacher-child relationships provides insight into how teachers' psychological characteristics affect their relationship perceptions at a given time. We extend this research by examining how teachers' psychological characteristics contribute to changes in their perceptions of their relationships with students.

\section{Present Study}

In the present study we examine changes in teachers' perceptions of the teacherchild relationship across one year of preschool by investigating the contribution of children's observed classroom engagement and teachers' classroom beliefs and emotional well-being to this change. With regard to children's observed classroom behaviors, we used an assessment that examined how children engaged both positively and negatively with teachers, peers, and tasks within the classroom. Two primary research questions were addressed. (1) To what extent do children's observed positive and negative engagement with their teacher, peers, and tasks predict changes in their teachers' perceptions of closeness and conflict in the teacher-child relationship across one year of preschool? We hypothesized that children's positive engagement would be linked with gains in teachers' perceptions of closeness. Conversely, we expected that children's negative engagement would predict increases in teachers' perceptions of conflict. 
We were also interested in (2) the extent to which teachers' classroom-related beliefs (self-efficacy, adult-centered beliefs) and emotional well-being (work related stress, anger and anxiety) predicted changes in their perceptions of the teacher-child relationship (closeness and conflict). We hypothesized that teachers' psychological characteristics would contribute to changes in their reports of closeness and conflict such that teachers with greater anger, anxiety, and stress and with less efficacy and childcentered beliefs would report less positive relationships (more conflict, less closeness). As a secondary research question related to how teacher characteristics may contribute to change in the teacher's perception of the relationship, we were interested in whether teacher characteristics might moderate the association between children's observed behavior in the classroom and change in the teacher-child relationship. Based on prior research (Spilt, Koomen et al., 2012; Isen, 1990; Jennings \& Greenberg, 2009; Runhaar, Sanders, \& Yang, 2010), we expected teachers who evidenced higher self-efficacy and lower levels of adult-centered beliefs, work-related stress, anger and anxiety to be more flexible to change in their teacher-child relationship perceptions. Thus, for these teachers, children's observed engagement would be more highly associated with change in the teacher-child relationship compared to teachers who displayed lower self efficacy, and higher levels of adult-centered beliefs, work stress, anger and anxiety.

\section{Method}

\section{Participants and Selection}

Data were collected as part of the National Center for Research on Early Childhood Education's (NCRECE) Professional Development Study, an 18-month study testing the combination of two forms of professional development aimed to improve 
everyday teacher-child and instructional interactions focused on promoting children's language and literacy skills: (1) a 14-week course (Phase I) and/or (2) yearlong coaching using the MyTeachingPartner (MTP) approach, which includes individualized, webmediated coaching (Phase II). Teachers were followed with the new students in their classroom the year after their participation in the professional development study (Phase III). The impact of the intervention was not of interest in the current study but was controlled for in the analysis.

The NCRECE Professional Development Study targeted large community preschool and Head Start programs in 10 sites in eight states across the country. Teachers were eligible for participation in the study if they were the lead teacher in a classroom in which the majority of children were eligible for kindergarten the following school year. Eligible teachers also conducted instruction in English for the majority of the school day and had high-speed Internet access available for their use. Before Phase I began, teachers were randomized within each site at the classroom level into the course or control group. After Phase I, remaining Phase I teachers and newly recruited teachers were randomized into coaching or control group conditions for Phase II. Thus, four groups were created by crossing the Phase I Course/Control groups with the Phase II Coaching/Control groups. A full description of the intervention, study design, sample, and results can be found in Hamre et al. (2012) and Downer et al. (in press).

Participants for the present study included the teachers and children who participated in the follow-up year of the professional development study (Phase III). A total of 223 teachers were eligible, agreed to participate, and had at least one child in their classroom selected to participate in this Phase. During Phase III, four children, two boys 
and two girls when possible, were randomly selected from each classroom to participate in the study. Children were eligible to be selected if they were not in the teacher's classroom the prior year during Phase II, did not have an IEP and had a primary language of English or Spanish. The majority of the teachers were female (92\%) with a mean age of $42.56(S D=10.55)$. Almost half of teachers were African American $(47 \%)$ and about a third were Caucasian (33\%), 12\% of teachers were Hispanic, 4\% were Asian, $5 \%$ were multiracial or of another racial/ethnic background. Teachers had an average of 15.81 years of education $(S D=1.62)$. Just over half of the teachers taught in Head Start classrooms (55\%) and on average $87 \%$ of children in the classroom had an income to needs ratio of less than 2.0, indicating that on average classrooms contained a high percentage of children living in poverty.

A total of 895 children (443 female) participated in Phase III of the NCRECE Professional Development Study and the present study. On average children were 4.12 years old ( $S D=0.50$ years) at the beginning of the school year. Children were ethnically diverse with the majority of children being African American (42\%) or Hispanic (35\%) and the remainder were Caucasian (14\%), Asian (4\%), multiracial or of another race/ethnicity $(5 \%)$. On average children's mothers' had 12.70 years of education $(S D=$ 2.35). Please see Table 1 for a summary of child, teacher, and classroom demographic information.

\section{Procedures}

Data Collection. In the fall of Phase III, teachers completed a demographic questionnaire about their classroom and parents completed a demographic survey about their child and family. In the fall and at the end of the school year, teachers completed a 
series of questionnaires about each child, including the teacher's perception of the teacher-child relationship. Children were observed in the classroom during one visit in the middle of the school year. Teachers completed a series of questionnaires asking teachers about their demographic information (i.e., age, gender, race/ethnicity, income, and education) as well as their beliefs about teaching and children, and their personal characteristics at the beginning of Phase1. This information was only collected once during the study in an effort to not overburden teachers by asking them to repeatedly report self-characteristics that are likely to be stable over time. We examined the extent to which the context that teachers were teaching in remained stable during their participation by comparing aspects of teachers' classroom composition from Phase I to Phase III. We found no significant differences with respect to educational setting, whether a teacher assistant was present, percentage of children with Limited English Proficiency, percentage of children with an Individualized Education Plan, or level of behavior problems. The only significant difference found was with respect to children's age where over time the composition of the classroom contained a larger portion of younger children (i.e., \% of 5-year-olds in teachers' Phase III classrooms compared to Phase I; $t(167)=-3.650, p<.001)$.

Classroom Observations. Data collectors participated in a two-day training on a measure of children's classroom engagement, the Individualized Classroom Assessment Scoring System (inCLASS; Downer, Booren, Hamre, Pianta \& Williford, 2011), followed by a reliability assessment. The training included instruction in the content of the inCLASS and observation protocol, and watching, coding, and discussing five 10minute training video segments. At the end of the training data collectors completed a 
reliability assessment, which consisted of independently (no discussion or instruction) watching and coding 5 master-coded video segments. Data collectors were considered reliable if $80 \%$ of their codes were within one point of the master-code across the 5 assessment additional segments. If they were not initially reliable, data collectors received individual feedback and coded another set of 5 video segments. All data collectors became reliable on the inCLASS with final reliability scores ranging from 9094\%. The last step of training was a live observation in a classroom with an inCLASS master coder. Data collectors maintained reliability via weekly calibration meetings where they were required to independently watch and code inCLASS reliability clips and discuss (via group conference call) how their scores compared with mastercodes.

inCLASS observations were conducted during one visit in the winter during the middle of the school year. Observations occurred in the morning and typically lasted four hours and across almost all classroom settings and activities. Data collectors observed selected children in the classroom on alternating cycles. An inCLASS cycle consists of 10 minutes of observation followed by 5 minutes of coding. These cycles alternated between selected children being observed and with another observation tool, the Classroom Assessment Scorning System (CLASS; Pianta, LaParo, Hamre, 2008). Data collectors completed an average of 3.16 cycles per child with a range of 1 to 6 during Phase III.

\section{Measures}

Children's Demographic Characteristics. Parents reported on children’s age, gender, and ethnicity, along with parents' income and education levels in a demographic questionnaire. The demographic characteristics have previously been found to relate to 
teachers' perceptions of the teacher-child relationship and are therefore included in the analyses as control variables (Hamre \& Pianta, 2001; Hamre et al., 2008; Murray \& Murray, 2004).

Teachers' Perceptions of the Teacher-Child Relationship. Teachers' perceptions of the teacher-child relationship were measured through their report on the Student Teacher Relationship Scale (STRS; Pianta, 2001). In the present study, the STRS consisted of 15 items (Hamre et al., 2008, Mashburn et al., 2006) that a teacher rates on a 5-point scale from 1 (definitely does not apply) to 5 (definitely applies) about her relationship with a particular child. The items comprise two scales: closeness, which reflects the warmth, affection, and openness the teacher perceives in the relationship (e.g., I share an affectionate, warm relationship with this child), and conflict, which reflects the negativity a teacher perceives in the relationship (e.g, This child remains angry or is resistant after being disciplined). The STRS is a widely used measure of the teacher-child relationship that has demonstrated good internal consistency for both scales (e.g., Koomen, Verschueren, van Schooten, Jak, \& Pianta, 2012; Thijs \& Koomen, 2009; Silver et al., 2005). In line with previous studies, the internal consistency for closeness and conflict in the present were high $(\alpha=.82, .88)$. Additionally, teachers' ratings of closeness and conflict on the STRS consistently predict children's outcomes concurrently and longitudinally including their behavior, social-emotional skills and academic achievement (Hamre \& Pianta, 2001; Pianta \& Stuhlman, 2004).

Children's Observed Classroom Engagement. Children's engagement in the classroom was observed with the Individualized Classroom Assessment Scoring System (inCLASS; Downer et al., 2011). The inCLASS consists of 10 dimensions of children's 
engagement in their interactions with peers, teachers, and tasks: Positive Engagement with Teachers (attunement to the teacher, proximity seeking, and shared positive affect), Teacher Communication (initiates conversations, sustains conversations, and varied purposes of speech), Teacher Conflict (aggression, noncompliance, negative affect, and attention-seeking directed toward the teacher), Peer Sociability (proximity seeking, shared positive affect, popularity, and cooperation), Peer Assertiveness (positive initiations with peers, leadership, and self-advocacy), Peer Communication (initiates conversations, sustains conversations, and varied purposes of speech), Peer Conflict (aggression, confrontation, negative affect, and attention-seeking directed toward peers), Engagement with Tasks (sustained attention and active engagement), Self-Reliance (personal initiative and independence), and Behavior Control (patience, matches classroom expectations, and physical awareness). These 10 dimensions in turn comprise 4 domains of classroom engagement, empirically-derived through factor analysis: Positive Teacher Engagement (Positive Engagement with Teacher, Teacher Communication), Positive Peer Engagement (Peer Sociability, Peer Communication, Peer Assertiveness), Task Engagement (Engagement with Tasks, Self-Reliance), and Negative Engagement (Teacher Conflict, Peer Conflict, Behavior Control - reversed) (Downer et al., 2010; Vitiello, Booren, Downer \& Williford, 2012).

After 10 minutes of observing a child, trained observers code each dimension on a seven-point scale using a detailed manual. Higher codes indicate higher quality and/or more frequent positive engagement for most dimensions. Teacher and Peer Conflict codes indicate the reverse, with higher ratings indicating more negative engagement. The four domain scores are calculated by averaging the dimension scores that comprise the 
domain. In the present study, for each dimension, the codes assigned during the observation cycles across one morning $(M=3.16$ cycles, range: $1-6)$ were averaged to create an estimate of children's engagement across the observation. Two observers double-coded approximately $20 \%$ of observation cycles and their interrater reliability was high for Teacher Engagement $(\mathrm{ICC}=.925)$ and Peer Engagement $(\mathrm{ICC}=.906)$ and good for Task Engagement $(\mathrm{ICC}=.780)$ and Negative Engagement $(\mathrm{ICC}=.755)$. The construct and criterion-related validity of the inCLASS were demonstrated in a validation paper of the measure (Downer et al., 2010). Children's engagement, as measured by the inCLASS, is also predictive of children's gains in social-emotional skills (e.g., selfregulation, social skills, emotion regulation) over one year of preschool (Downer et al., 2011; Williford et al., 2013).

\section{Teacher's Classroom-Related Beliefs.}

Self-efficacy. Teachers' beliefs about their efficacy in the classroom were measured with the Teachers' Sense of Self Efficacy measure; a 12-item scale that assesses teachers' perceptions about their ability to accomplish the tasks involved in teaching, including facilitating student engagement, appropriate behavior, and learning (Tschannen-Moran \& Hoy, 2001). This measures contains three subscales: (1) efficacy for instructional strategies (e.g., To what extent can you use a variety of assessment strategies?), (2) efficacy for classroom management (e.g., How much can you do to control disruptive behavior in the classroom?), and (3) efficacy for student engagement (e.g., How much can you do to help your students value learning?). Teachers rated these items on a scale from 1 (nothing) to 9 (a great deal). Internal consistencies for the subscales were high in the present study, ranging from .85 to .87 and the total scale 
internal consistency was .932 . This is consistent with a previous use of this measure (Tschannen-Moran \& Hoy, 2001). The total scale is used in the present study as a measure of teachers' overall sense of efficacy in the classroom.

Adult-Centered Beliefs. The Modernity Scale (Schaefer \& Edgerton, 1985) was used to measure teacher's adult-centered versus child-centered beliefs about interactions with children. This scale assesses teachers' traditional or more adultcentered, authoritarian perspectives of interactions with children (e.g., It is important to teach children absolute obedience to authority) versus more progressive or modern childcentered perspectives (e.g., Children learn best by doing things themselves). Teachers rated 16 items on a scale from 1 (strongly disagree) to 5 (strongly agree). Child-centered belief items are reversed scored and the 16 items are averaged to create an overall score with higher scores indicating more adult-centered beliefs. The internal consistency for this scale in the present study was acceptable $(\alpha=.78)$ and comparable to prior studies that have used this measure with teachers (Hamre et al., 2008; Mashburn et al., 2006).

\section{Teachers' Well-Being.}

Work Related Stress. The Teacher Stress Inventory (Fimian \& Fastenau, 1990) assesses several dimensions of occupational stress specific to teaching. The 6-item work-related stressors subscale is used in the present study. Teachers rated items on this subscale such as, "There is little time to prepare for my lessons/responsibilities" and "Too much work to do" on a response scale from 0 (no stress) to 5 (highly stressful). The internal consistency for the work-related stressors subscale was good $(\alpha=.799)$ and comparable to prior use by the authors (Fimian \& Fastenau, 1990). 
Anger and Anxiety. State of Anxiety and Anger Expression Inventories

are 10-item scales that assess how much teachers' emotional state during the previous week was characterized by feelings of anger and anxiety (Spielberger, 1983; Spielberger, 1988). Teachers reported their feelings of tension and worry indicative of their anxiety (e.g., Ifeel tense) and the intensity of their anger (e.g., I was furious) on a 4-point scale from 0 (not at all) to 3 (very much) (Spielberger \& Sydeman, 1999). The internal consistencies for the current study were .80 and .83 for the Anxiety and Anger scales, respectively, and are consistent with prior use of this measure (Barnes, Harp \& Jung, 2002; Kroner \& Reddon, 1992). The state inventories are intended to assess an individual's feelings of anger and anxiety at a given time versus their trait-levels of these emotions (Spielberger \& Sydeman, 1999). Nonetheless test-retest reliability for the state inventories are often quite high (.70 on average in meta-analysis; Barnes et al., 2002), indicating that individual's experience of anger and anxiety at a given time may be fairly consistent over time (Barnes et al., 2002; Kroner \& Reddon, 1992).

\section{Missing Data and Data Imputation}

All 223 teachers and 895 children selected to participate in the present study were included in the analyses, and multiple imputation was employed to account for missing data. Of these 223 teachers, 175 completed a series of questionnaires to obtain information about teachers' characteristics in Phase I. Of the 895 children selected to participate in Phase III, 714 were observed using the inCLASS, 703 have teacher-ratings of the teacher-child relationship in the fall and 749 have teacher-ratings in the spring. In order to make use of all available data and handle missing data, multiple imputation was employed. This method of handling missing data avoids listwise deletion and can 
provide better estimates of effects by employing all available data (Schafer \& Graham, 2002). Using Mplus software (Muthen \& Muthen, 2012) 100 data sets were imputed. The regression analyses described below were then conducted in each of the datasets and the results presented reflect the estimates based on the compiled results. These estimates are automatically generated in Mplus when the data type is specified as imputed.

\section{Data Analysis Plan}

Regression analyses were conducted in a multilevel framework using Mplus software (Muthen \& Muthen, 2012) in order to account for the nesting of children within teachers/classrooms. We tested the main effects of children's classroom engagement (teachers, peers, task, negative) and teachers' characteristics (adult centered beliefs, self efficacy, work related stress, anger and anxiety) on changes in teachers' perceptions of the teacher child relationship (closeness and conflict) from the beginning to end of the school year. Next, interactions between children's classroom engagement and teachers' characteristics were tested.

The outcomes of interest were teachers' perceptions of closeness and conflict in their relationship with a particular child in the spring of preschool, controlling for their perceptions of this relationship in the fall; therefore results reflect changes in teachers' perceptions of closeness and conflict across the preschool year. Closeness and conflict were included in one model in order to account for the correlation between these two outcomes. The main effects model included the following key teacher and classroom predictors as control variables at the between (teacher) level: classroom in poverty (percent of children), teacher's education (years), Head Start classroom (Yes/No), professional development course intervention participation (Yes/No), professional 
development consultancy intervention participation (Yes/No), and indicator variables for the geographic location of the preschool center. The key predictors of interest at the between level were teacher characteristics: self-efficacy, adult-centered beliefs, workrelated stress, anger, and anxiety. Covariates at the within (child) level include the child's age, gender, ethnicity (indicators for Black, Hispanic, or other ethnicity), and maternal education (years). The predictors of interest at the child (within) level were the four domains of children's classroom engagement (Positive Teacher Engagement, Positive Peer Engagement, Task Engagement, and Negative Engagement), which were entered concurrently.

Next, the moderating influence of teachers' characteristics for the relation between children's classroom engagement and changes in teachers' perceptions of closeness and conflict were examined. The interactions between children's classroom engagement (teachers, peers, tasks, and negative engagement) and teachers' characteristics (adult centered beliefs, self efficacy, work related stress, anger and anxiety) were tested for teachers' perceptions of closeness and conflict. Each moderator was examined in a separate model (i.e., five separate interaction models).

\section{Results}

\section{Preliminary Analyses}

Table 2 provides descriptive statistics of all predictors and outcome variables. Teachers' perceptions across one year of school were moderately stable, but evidenced some change. The correlations between teachers' fall ratings of the teacher-child relationship and spring ratings were moderate for closeness and conflict $(r \mathrm{~s}=.527, .620)$. See Table 3 for a correlation summary. 
Change in the teacher-child relationship over the preschool year was also examined descriptively. Considerable variability was observed in teacher-child relationships change during the school year. On average, closeness increased $(M=.17$ on a 5-point scale); however, teachers' report of closeness in some relationships increased by as much as $65 \%$ (3.25 points) whereas in others it decreased by as much as $48 \%$ ( 2.38 points) with the SD being $9 \%$. Similarly, although the average change in conflict was close to zero $(M=.02)$, teachers reported as much as a $54 \%$ ( 2.71 points) increase in conflict and others reported as much as a $66 \%$ (3.29 points) decrease with a SD of $11 \%$.

\section{Child Engagement and Teacher-Child Relationship: Main Effects}

When children were positively engaged in classroom tasks, their teachers reported an increase in closeness at the end of the year $(\beta=0.103, S E=0.035, p<.01)$; however, children's task engagement was not related to changes in teachers' perceptions of conflict $(\beta=0.004, S E=0.046, p=\mathrm{ns})$. When children were negatively engaged in the classroom, their teachers reported experiencing increases in conflict in the teacher-child relationship over the school year $(\beta=0.448, S E=0.088, p<.001)$. Children's negative classroom engagement was not related to changes in how close teachers reported feeling to their students $(\beta=0.059, S E=0.060, p=\mathrm{ns})$. Children's positive engagement with their teacher was not related to changes in teachers' perceptions of closeness $(\beta=0.026$, $S E=0.024, p=\mathrm{ns})$ or conflict $(\beta=0.009, S E=0.033, p=\mathrm{ns})$ during the school year. Similarly, children's positive peer engagement was not related changes in teachers' perceptions of closeness $(\beta=0.006, S E=0.030, p=\mathrm{ns})$ or conflict $(\beta=0.021, S E=$ $0.039, p=\mathrm{ns})$. See Table 4 for a summary. 
Post Hoc Analyses. As described in the Methods section, each of the four global domains of children's classroom engagement (teacher, peer, task, negative) are comprised of two or three dimensions of engagement. Therefore, tests of the main effects of the four domains provide an omnibus test for the dimensions of engagement comprising the domains. In order to understand at a more detailed level the types of child engagement that are related to changes in teachers' relationship perceptions, we conducted post hoc analyses at the dimensions level for each domain that significantly predicted changes in teachers' perceptions. This was done by conducting the same main effects model presented in Table 4, but replacing the domain (i.e., negative engagement) with the dimensions comprising the domain (i.e., impulsivity, peer conflict, teacher conflict).

Task Engagement and teacher-reported closeness. The domain of Task Engagement is comprised of the following dimensions: Self Reliance (personal initiative, independence) and Engagement with tasks (sustained attention, active engagement). When children were observed to demonstrate higher Self Reliance, their teachers reported increases in closeness $(\beta=0.052, S E=0.024, p<.05)$. However, children's engagement with tasks was not related to how close teachers reported feeling to that child ( $\beta=0.049$, $S E=0.031, p=\mathrm{ns})$.

Negative Engagement and teacher-reported conflict. The domain of Negative Engagement is comprised of the following dimensions: Teacher Conflict, Peer Conflict, and Behavior Control - Reversed). When children evidenced higher impulsivity, their teachers' tended to report increases in their perceptions of conflict from the beginning to the end of the year $(\beta=0.131, S E=0.048, p<.01)$. When children were observed to 
have higher levels of conflict with their teachers, their teachers tended to report increases in their perceptions of conflict across the school year $(\beta=0.296, S E=0.144, p<.05)$. Children's conflict with their peers was not related to changes teachers' report of conflict $(\beta=0.117, \mathrm{SE}=0.116, p=\mathrm{ns})$

\section{Teacher Psychological Characteristics and the Teacher-Child Relationship: Main}

\section{Effects}

Table 4 presents a summary of the main effects of teachers' psychological characteristics on changes in teachers' perceptions of the teacher-child relationship. Teachers who reported experiencing more anxiety reported decreases in their perceptions of closeness in their relationships with the children in their classroom from the beginning to the end of the year $(\beta=-0.138, S E=0.069, p<.05)$. Additionally, when teachers reported higher work related stress, they reported increases their perceptions of conflict in their teacher-child relationships $(\beta=0.124, S E=0.046, p<.01)$. Teachers' reports of expressed anger, adult-centered beliefs, and self-efficacy were not related to changes in their perceptions of closeness or conflict in the teacher-child relationship.

\section{Teacher Psychological Characteristics as a Moderator of the Relation Between Children's Engagement and Changes in the Teacher-Child Relationship}

The interactions between children's classroom engagement (teachers, peers, tasks, and negative engagement) and teachers' characteristics (adult centered beliefs, self efficacy, work related stress, anger and anxiety) were tested for teachers' perceptions of closeness and conflict. None of the interactions were significant. 


\section{Discussion}

Teachers' perceptions of the teacher-child relationship are important for the wellbeing of both teachers and children as well as for children's school adjustment and academic success (Hamre \& Pianta, 2001; Pianta \& Stuhlman, 2004; Koomen \& Spilt, 2012; Spilt, Koomen, \& Thijs, 2011). The present study aimed to better understand how certain child and teacher characteristics are linked with changes in teachers' relationship perceptions of a particular student over the course of one year of preschool. We did this by examining how teachers' classroom-related beliefs and emotional well-being and children's observed engagement were related to changes in teachers' perceptions of closeness and conflict in the teacher-child relationship.

The present study had several strengths. First, by using independent observers' ratings of children's classroom engagement, rather than teacher ratings for both predictors and outcomes, this study addresses a key limitation in the literature and direction for future work identified by Sabol and Pianta (2012). That is, the research focused on examining the associations between children's behavior and teacher-child relationships often suffers from primarily employing a single rater (teachers), rather than multiple raters of the teacher-child relationship and children behavior (Sabol and Pianta, 2012). Secondly, we examined children's positive and negative classroom engagement across teachers, peers, and task rather than looking only at children's behavior problems. Other measures that assess children's classroom behavior by examining only the presence or absence of certain behaviors do not account for the multidimensionality of children's engagement in the classroom. Further, disruptive behaviors (e.g., aggression) occur at a low base-rate even for children who have or are at-risk for a disruptive behavior disorder 
(Pelham, Fabiano \& Massetti, 2005). Finally, the present study benefited from a diverse sample of preschool children from low-socioeconomic status families who are at-risk for difficulty at school (Ryan, Fauth, Brooks-Gunn, 2006) and their teachers.

Teachers' perceptions of closeness and conflict in the present study were moderately stable across one year of preschool $(r \mathrm{~s}=.53, .62$, respectively), consistent with recent findings demonstrating moderate to high stability across one school year $(r \mathrm{~s}=$ $.57, .47$, respectively; Zhang \& Sun, 2011; conflict $r=.74$, Doumen et al., 2008).

Although we did not test the differences in stability between closeness and conflict, in the present study the correlation for conflict was higher than closeness. This pattern is in line with previous work across multiple school years that found higher stability for conflict than closeness (Howes, Phillipsen \& Peisner-Feinberg, 2000; Jerome, Hamre \& Pianta, 2009). Nonetheless, considerable variability in teachers' perceptions of closeness and conflict was observed. We then attempted to predict this variability using child and teacher characteristics.

Consistent with our hypotheses, we found that children's observed classroom engagement was related to changes in teachers' relationship perceptions. When a child was more appropriately engaged in the tasks in the classroom, teachers' perceptions of closeness tended to increase during the school year. Specifically, when children engaged in more self-reliant behaviors, teachers' perceptions of closeness increased during the school year. Contrary to our expectations, children's observed positive engagement with teachers and peers was not uniquely related to changes in teachers' perceptions of closeness. As expected, when children engaged negatively in the classroom, teachers perceived more conflict in those relationships from the beginning to the end of the school 
year. Specifically, teachers' reported increases in relational conflict when children had higher impulsivity and engaged in greater conflict with their teacher.

Our finding that children's positive task engagement, self reliance in particular, was related to increases in teachers' perceptions of closeness points to teachers' values regarding their relationships with children and their beliefs about their role in the classroom. Preschool children's self-reliant behavior is characterized by independence, taking learning into their own hands, persisting with difficult tasks, and using classroom resources (including the teacher) when needed (Downer et al., 2010; Pianta, 1999). Preschool teachers value this developmentally appropriate autonomy and see their role, in part, as supporting children's growing independence (Killen, Ardila-Rey, Barakkatz, \& Wang, 2000). Particularly with the current policy focus on children's academic performance, teachers feel increased pressure for children to be competent, engaged learners who can meet academic standards (Stipek, 2006). Therefore, when children demonstrate appropriate independence with learning opportunities in the classroom, teachers may view students more positively overall and in turn report feeling increasingly close to them.

We were surprised that children's positive engagement with the teacher was not uniquely related to changes in teachers' relationship perceptions. This domain of children's classroom engagement consists of their attunement to the teacher, proximity seeking, and shared positive affect, as well as initiating and sustaining conversation with the teacher for varied purposes. One would expect these aspects of children's engagement to be related to gains in teachers' perceptions of closeness because theoretical work indicates that shared experiences, positivity, and attunement contribute to relational 
closeness (Pianta, 1999). Additionally, prior empirical work found that children's positive teacher engagement was related to teachers' perceptions of closeness at a single time point (Downer et al., 2010). Our null findings may be attributable to low overall mean levels of children's positive teacher engagement $(M=2.21, S D=0.84)$ for both the scale range (1 'Rarely or never positively engaged with teacher' to 7 'Consistent, high positive engagement with teacher') and in comparison to prior work $(M=3.20, S D=$ 0.85) (Downer et al., 2010). The low levels of positive teacher engagement suggest that children in our sample, who were at-risk for poor school outcomes and could benefit from a positive relationship with a teacher, were in classrooms where they spent little time engaging with their teachers and experienced minimal positivity in these interactions.

Consistent with our hypotheses, we found that when children were negatively engaged in the classroom, or more specifically, engaged in negative interactions with the teacher and displaying impulsive behaviors, teachers perceived increases in conflict during the school year. Our findings are consistent with recent work demonstrating that the stress teachers experience from children's problem behavior is fully accounted for by the interpersonal conflict teachers' perceive in the teacher-child relationship (Koomen \& Spilt, 2012). Children's ability to control their behavior may have been related to decreases in teachers' perceptions of conflict because when children are better able regulate their behavior in the classroom, this may lead to less interpersonal conflict with the teacher (Birch \& Ladd, 1998; Ladd \& Burgess, 1999). For instance, when a child is consistently matching the expectations set by the teacher, being patient (i.e., walking, waiting their turn), and respecting others personal space, the teacher may need to correct 
the child's behavior less, feel less drained, and feel less like the child is disobeying his/her classroom rules. Teachers may also perceive less conflict in the relationship when they observe that children are accomplishing the developmental task of self- regulating their emotions and behaviors, skills that are valued by teachers as important for success in kindergarten (Kowalskia, Pretti-Frontczakb \& Johnsonc, 2001; Rimm-Kaufman, Pianta, Cox, 2000).

Perhaps not as surprising as the null positive teacher engagement findings, children's positive peer engagement was not uniquely related to changes in teachers' perceptions of their relationships with children. Within children's negative engagement, peer conflict was also not related to changes in teachers' perceptions of conflict. Thus, how children engage with their peers does not appear to influence how teachers perceive their relationships with children. Intuitively, children's engagement with their peers is more distally related to children's direct interactions with teachers, and therefore one would hypothesize that interactions with teachers, rather than peers, would be most closely associated with relationship perceptions.

Consistent with our hypotheses, aspects of teachers' well-being were also related to changes in their perceptions of the quality of their relationships with students in their classroom. Specifically, teachers' work-related stress predicted increases in teachers' perceptions of conflict. Teachers' reports of higher levels of anxiety were related to decreases in perceptions of closeness during the school year. Teachers' reports of anger and their classroom-related beliefs (adult-centered beliefs and self-efficacy) were not related to changes in teachers' perceptions of their relationships with children. 
Our findings regarding the relation of teachers' psychological characteristics to changes in their perceptions of the teacher-child relationship add to a growing body of literature demonstrating the importance of teachers' social-emotional competence in the classroom (Jennings \& Greenberg, 2009). We found that when teachers reported higher teacher stress, their perceptions of conflict in their relationships with student tended to increase during the school year. The stress associated with job demands (e.g., a challenging classroom composition, a lack of structural support) may contribute to teachers’ stress (Boyle, Borg, Falzon, Baglioni, 1995; Smith \& Bourke, 1992) and practically limit the amount of time teachers have to develop teacher-child relationships. Stress may also drain teachers' emotional resources, which can contribute to increased frustration and reactivity to children's challenging behavior (Jennings \& Greenberg, 2009), in turn contributing to relational conflict. We also found that when teachers' reported higher levels of anxiety they experienced decreases in the closeness they felt in their relationships with children. Together, these findings point to the importance of teachers' emotional experience for the quality of their relationships with children, as aspects of teachers' emotional well-being (stress and anxiety), rather than classroomrelated beliefs, contributed to their relationship perceptions. These findings are consistent with work that has highlighted the importance of emotions in teachers' daily interactions with the children in their classroom and in their motivation to teach (Hargreaves, 2000; Jennings \& Greenberg, 2009; Spilt et al., 2011).

Our findings about the relation between teachers' well-being and their perceptions of the teacher-child relationship also underscore the importance of providing support to teachers to improve their well-being and their ability to establish and maintain positive 
relationships with students in their classroom. Teachers' representations of relationships are theorized to guide their emotions and behavior with the children in their classroom (Pianta, Hamre \& Stuhlman, 2003). Additionally, teachers' emotions are thought to play a critical role in their daily interactions with children that contribute to their representations of the relationship (Spilt et al., 2011). Our findings indicate that teacher stress and anxiety may be aspects of teachers' emotional well-being that are important targets for intervention. Helping teachers form closer and less conflictual relationships could have important benefits for teachers and students alike. Conflict in the teacherchild relationship has been consistently linked to poor academic, behavioral, and social outcomes for children (Hamre \& Pianta, 2001; Hughes, 2011). Close relationships have been linked to more positive school adjustment, especially for children at risk for school difficulty (Baker, 2006; Hughes et al., 1999). Additionally, positive teacher-child relationships contribute to teachers' well-being and job satisfaction (Spilt et al., 2011; Hargreaves, 2000).

We did not find differences in the flexibility of teachers' relationship perceptions (i.e., teachers' psychological characteristics did not moderate relation between children's engagement and changes in relationship perceptions). Recent evidence suggests that teachers' psychological characteristics (i.e., self-efficacy) contribute to increased flexibility in their beliefs about teaching (Runhaar et al., 2010). Thus, one might hypothesize that these psychological characteristics could also influence teachers' flexibility in their perceptions about relationships with students (some teachers may be more open to change based on the child's behavior than others); however, we did not find support for this hypothesis in the present study. 
Several limitations also deserve attention. First, this was a correlational study, and therefore we cannot infer causation about the relations between children's engagement, teachers' psychological characteristics and changes in teachers' perceptions of the teacher-child relationship. Second, teachers' psychological characteristics were measured in a prior school year, not concurrently with children's classroom engagement and teachers' perceptions of the teacher-child relationship. Although it is possible that these teacher characteristics changed between the school years, they are considered to be fairly consistent psychological characteristics (e.g., Barnes et al.; 2002, Kinnuhen \& Saloa, 1994) and contextual factors that have been related to these characteristics, such as student behavior in the classroom, support, and educational setting were consistent across the school years. Third, we only had observations of children's classroom engagement at one time during the middle of the school year. Recent evidence indicates that teachers' relationship perceptions and teachers' perceptions of student's behavior problems are reciprocally related to each other across one school year (Doumen et al., 2008; Zhang, 2011). It is possible that teachers' initial relationship perceptions had an effect on children's engagement. However, because we only measured engagement at one time point half-way through the school-year, we were not able to test the reciprocal relations in the changes in teachers' relationship perceptions and children's engagement across the school year. Finally, we included children's teacher, peer, task, and negative engagement in the same model; therefore, we did not find unique associations between children's positive teacher and peer engagement and changes in teachers' relationship perceptions. Given the moderate correlations among the engagement domains, the results could differ if each domain was examined in a separate model. 
Several directions for future research may be helpful for furthering our knowledge about changes in teachers' perceptions of their relationships with their students. First, the continued use of multiple reporters and independent observations of classrooms can help separate individual perceptions from what is actually happening in the classroom. This will help to better understand the dynamics of relationships in the classroom. Second, future study designs could address the limitations of the present study by including observations of children's engagement and teacher-reported relationship quality concurrently at multiple times during the school year in order to examine reciprocal relations between child engagement and teachers' relationship perceptions over time. Additionally, because the present study was correlational, we cannot infer causation from our findings. Future research could examine the associations between children's engagement, teachers' psychological characteristics and changes in teachers' relationship perceptions in an experimental study that would allow for causal inferences. For instance, an intervention could target reductions in teachers' work-related stress and test whether perceptions of conflict in the teacher-child relationships subsequently decreased.

Our findings have several implications for understanding teacher-child relationships and how to best support teachers and children. Our findings provide further evidence of the dyadic and dynamic nature of teacher-child relationships (Pianta, 1999). The results of this study contribute to increasing evidence that both teacher (Hamre et al., 2008; Mashburn et al., 2006; Yoon, 2002) and child characteristics (Birch \& Ladd, 1998; Ewing \& Taylor, 2009; Murray \& Murray, 2004, Rudasill et al., 2006; Saft \& Pianta, 2001) contribute to the course and quality of the teacher-child relationship and that these relationships can change over time (Doumen et al., 2008; Zhang, 2011). Our findings 
also add to growing evidence of the importance of teachers' social-emotional competence and well-being for their positive teaching practices (i.e., forming positive teacher-child relationships) and suggest that one way to improve teacher-child relationship quality would be to intervene with teachers to reduce their stress and anxiety. 


\section{References}

Baker, J. A. (2006). Contributions of teacher-child relationships to positive school adjustment during elementary school. Journal of School Psychology, 44(3), 211229.

Baker, J. A., Grant, S., \& Morlock, L. (2008). The teacher-student relationship as a developmental context for children with internalizing or externalizing behavior problems. School Psychology Quarterly, 23(1), 3-15.

Barnes, L. L. B., Harp, D., \& Jung, W. S. (2002). Reliability generalization of scores on the Spielberger state-trait anxiety inventory. Educational and Psychological Measurement, 62(4), 603-618.

Birch, S. H. \& Ladd, G. W. (1997). The teacher-child relationship and children's early school adjustment. Journal of School Psychology, 35(1), 61-79.

Birch, S. H. \& Ladd, G. W. (1998). Children's interpersonal behaviors and the teacher-child relationship. Developmental Psychology, 34(5), 934.

Boyle, G. J., Borg, M. G., Falzon, J. M. and Baglioni, A. J. (1995), A structural model of the dimensions of teacher stress. British Journal of Educational Psychology, $65,49-67$.

Burchinal, M. R., Peisner-Feinberg, E., Pianta, R., Howes, C. (2002). Development of academic skills from preschool through second grade: Family and classroom predictors of developmental trajectories. Journal of School Psychology, 40(5), $415-436$.

Buyse, E., Verschueren, K., \& Doumen, S. (2011). Preschoolers' attachment to mother and risk for adjustment problems in kindergarten: Can teachers make a difference? Social Development, 20(1), 33-50.

Campbell, S. B. (2002). Behavior Problems In Preschool Children. New York, NY: The Guilford Press.

Chang, M. (2009). An appraisal perspective of teacher burnout: Examining the emotional work of teachers. Educational Psychology Review, 21, 193 - 218.

Doumen, S., Koomen, H. M., Buyse, E., Wouters, S., \& Verschueren, K. (2012). Teacher and observer views on student-teacher relationships: Convergence across kindergarten and relations with student engagement. Journal of School Psychology, 50(1), 61-76.

Doumen, S., Verschueren, K., Buyse, E., De Munter, S., Max, K., \& Moens, L. (2009). Further examination of the convergent and discriminant validity of the student-- 
teacher relationship scale. Infant and Child Development, 18(6), 502-520.

Doumen, S., Verschueren, K., Buyse, E., Germeijs, V., Luyckx, K., \& Soenens, B. (2008). Reciprocal relations between teacher-child conflict and aggressive behavior in kindergarten: A three-wave longitudinal study. Journal of Clinical Child and Adolescent Psychology, 37(3), 588-99.

Downer, J. T., Booren, L. M., Hamre, B., Pianta, R. C., \& Williford, A. (2011). The Individualized Classroom Assessment Scoring (inCLASS). Unpublished technical manual, University of Virginia.

Downer, J. T., Booren, L. M., Lima, O. K., Luckner, A. E., \& Pianta, R. C. (2010). The individualized classroom assessment scoring system (inCLASS): Preliminary reliability and validity of a system for observing preschoolers' competence in classroom interactions. Early Childhood Research Quarterly, 25(1), 1-16.

Downer, J. T., Pianta, R. C., Burchinal, M., Field, S., Hamre, B. K., Locasale-Crouch, J. L., ..., Scott-Little, C. (in press). Coaching and coursework focused on teacherchild interactions during language/literacy instruction: Effects on teacher beliefs, knowledge, skills, and practice. Early Childhood Research Quarterly.

Ewing, A. R. \& Taylor, A. R. (2009). The role of child gender and ethnicity in teacherchild relationship quality and children's behavioral adjustment in preschool. Early Childhood Research Quarterly, 24(1), 92-105.

Fimian, M. J. \& Fastenau, P. S. (1990). The validity and reliability of the teacher stress inventory: A re-analysis of aggregate data. Journal of Organizational Behavior, 11(2), 151-157.

Hamre, B. K. \& Pianta, R. C. (2001). Early teacher-child relationships and the trajectory of children's school outcomes through eighth grade. Child Development, 72(2), $625-38$.

Hamre, B. K. \& Pianta, R. C. (2004). Self-Reported depression in nonfamilial caregivers: Prevalence and associations with caregiver behavior in child-care settings. Early Childhood Research Quarterly, 19(2), 297-318.

Hamre, B. K., Pianta, R. C., Burchinal, M, Field, S., LoCasale-Crouch, J., Downer, J. T., Howes, C., LaParo, K., \& Scott-Little, C. (2012). A Course on Effective TeacherChild Interactions: Effects on Teacher Beliefs, Knowledge, and Observed Practice. American Educational Research Journal, 49(1), 88 - 123.

Hamre, B. K., Pianta, R. C., Downer, J. T., \& Mashburn, A. J. (2008). Teachers' perceptions of conflict with young students: Looking beyond problem behaviors. Social Development, 17(1), 115-136. 
Hargreaves, A. (2000). Mixed emotions: teachers' perceptions of their interactions with students. Teaching and Teacher Education, 16(8), $811-826$.

Howes, C., Phillipsen, L. C., \& Peisner-Feinberg, E. (2000). The consistency of perceived teacher--child relationships between preschool and kindergarten. Journal of School Psychology, 38(2), 113-132.

Hughes, J. \& Kwok, O. M. (2007). Influence of student-teacher and parent-teacher relationships on lower achieving readers' engagement and achievement in the primary grades. Journal of Educational Psychology, 99(1), 39-51.

Hughes, J. N. (2011). Longitudinal effects of teacher and student perceptions of teacherstudent relationship qualities on academic adjustment. The Elementary School Journal, 112(1), 38-60.

Hughes, J. N., Cavell, T. A., \& Jackson, T. (1999). Influence of the teacher-student relationship on childhood conduct problems: A prospective study. Journal of Clinical Child Psychology, 28(2), 173-84.

Hughes, J. N., Gleason, K. A., \& Zhang, D. (2005). Relationship influences on teachers' perceptions of academic competence in academically at-risk minority and majority first grade students. Journal of School Psychology, 43(4), 303-320.

Isen, A. M. (1990). The influence of positive and negative affect on cognitive organization: Some implications for development. In N. Stein, B. Leventhal, \& T. Trabasso (Eds.), Psychological and biological approaches to emotion (pp. 75-94). Hillsdale, NJ: Erlbaum.

Jennings, P. A. \& Greenberg, M. T. (2009). The prosocial classroom: Teacher social and emotional competence in relation to student and classroom outcomes. Review of Educational Research, 79(1), 491-525.

Jerome, E. M., Hamre, B. K., \& Pianta, R. C. (2009). Teacher--Child relationships from kindergarten to sixth grade: Early childhood predictors of teacher-perceived conflict and closeness. Social Development, 18(4), 915-945.

Kelly, A. L. \& Bethelsen, D. C. (1995). Preschool teachers' experiences of stress. Teaching \& Teacher Education, 11(4), 345 - 357.

Kesner, J. E. (2000). Teacher characteristics and the quality of child--teacher relationships. Journal of School Psychology, 38(2), 133-149.

Killen, M. Ardila-Rey, A., Barakkatz, M. \& Wang, P. (2000). Preschool Teachers' Perceptions about Conflict Resolution, Autonomy, and the Group in Four Countries: United States, Colombia, El Salvador, and Taiwan. Early Education \& Development, 11(1), 73-92. 
Kinnehen, U. \& Saloa, K. (1994). Teacher stress: An eight-year follow-up study on teachers' work, stress, and health. Anxiety, Stress \& Coping, 7(4), $319-337$.

Koomen, H. M. Y., \& Spilt, J. L. (2012). Student behavior problems and teacher wellbeing: The role of teacher-student relationships. Paper 2e International Conference on Interpersonal Relationships in Education (ICIRE) - April 11-12, 2012 - Vancouver, Canada.

Koomen, H. M. Y., Verschueren, K., van Schooten, E., Jak, S. \& Pianta, R. C. (2012). Validating the Student-Teacher Relationship Scale: Testing factor structure and measurement invariance across child gender and age in a Dutch sample. Journal of School Psychology, 50, 215-234.

Kowalskia, K., Pretti-Frontczakb, K. \& Johnsonc, L. (2001). Preschool Teachers' Beliefs Concerning the Importance of Various Developmental Skills and Abilities. Journal of Research in Early Childhood Education, 16(1), 5 - 14.

Kroner, D. G. \& Reddon, J. R. (1992). The anger expression scale and state-trait anger scale. Criminal Justice and Behavior, 19(4), 397-408.

Kryiacou, C. (2001). Teacher stress: Directions for future research. Educational Review, $53(1), 28-35$.

Ladd, G. W. \& Burgess, K. B. (1999). Charting the relationship trajectories of aggressive, withdrawn, and aggressive/withdrawn children during early grade school. Child Development, 70(4), 910-29.

Lambert, R. G., O’Donnell, M., Kusherman, J. \& McCartney, C. J., (2006). Teacher stress and classroom structural characteristics in preschool settings. In R. G. Lambert \& C. J. McCartney (Eds.), Understanding teacher stress in and age of accountability. Greenwich, CT: Information Age Publishing.

Maldonado-Carreño, C. \& Votruba-Drzal, E. (2011). Teacher-Child relationships and the development of academic and behavioral skills during elementary school: A within- and between-child analysis. Child Development, 82(2), 601-16.

Mashburn, A. J., Hamre, B. K., Downer, J. T., \& Pianta, R. C. (2006). Teacher and classroom characteristics associated with teachers' ratings of prekindergartners' relationships and behaviors. Journal of Psychoeducational Assessment, 24(4), 367 -380 .

McWilliams, R. A. \& Casey, A. M. (2008). Engagement of every child in the preschool classroom. Baltimore, MD: Brooks Publishing Company.

Murray, C. \& Murray, K. M. (2004). Child level correlates of teacher--student 
relationships: An examination of demographic characteristics, academic orientations, and behavioral orientations. Psychology in the Schools, 41(7), 751762.

Muthén, L. K., \& Muthén, B. O. (1998-2012). Mplus user's guide (6th ed.). Los Angeles, CA: Muthén \& Muthén.

NICHD Early Child Care Research Network. (2003). Social functioning in first grade: Association with earlier home and childcare predictors and with current classroom experiences. Child Development, 74(6), 1639 - 1662.

O'Connor, E. E., Dearing, E., \& Collins, B. A. (2011). Teacher-Child relationship and behavior problem trajectories in elementary school. American Educational Research Journal, 48(1), 43.

O’Connor, E. \& McCartney, K. (2007). Examining teacher--child relationships and achievement as part of an ecological model of development. American Educational Research Journal, 44(2), 340-369.

Palermo, F., Hanish, L. D., Martin, C. L., Fabes, R. A., \& Reiser, M. (2007). Preschoolers' academic readiness: What role does the teacher-child relationship play? Early Childhood Research Quarterly, 22(4), 407-422.

Pelham Jr, W. E., Fabiano, G. A., \& Massetti, G. M. (2005). Evidence-Based assessment of attention deficit hyperactivity disorder in children and adolescents. Journal of Clinical Child and Adolescent Psychology, 34(3), 449-476.

Pianta, R. C. (2001). Student Teacher Relationship Scale. Lutz, FL: Psychological Assessment Resources, Inc.

Pianta, R. C. (1999). Enhancing Relationships Between Teachers and Children. Washington, DC: American Psychological Association.

Pianta, R., Hamre, B., Stuhlman, M. (2003). Relationships between teachers and children. In W.M. Reynolds, G.E. Miller, \& I.B. Weiner (Eds.), Handbook of psychology. Vol. 7. Educational psychology (pp. 199-234). Hoboken, NJ: Wiley.

Pianta, R. C., La Paro, K. M., \& Hamre, B. K. (2008). Classroom Assessment Scoring System [CLASS] Manual: Pre-K. Baltimore, MD: Brookes Publishing.

Pianta, R., Howes, C., Burchinal, M., Bryant, D., Clifford, R., Early, D., et al. (2005). Features of pre-kindergarten programs, classrooms, and teachers: Do they predict observed classroom quality and child-teacher interactions? Applied Developmental Science, 9(3), 144-159.

Pianta, R. C. \& Stuhlman, M. W. (2004). Teacher-child relationships and children's 
success in the first years of school. School Psychology Review, 33, 444-458.

Rimm-Kaufman, Pianta, Cox (2000). Teachers' judgments of problems in the transition to kindergarten. Early Childhood Research Quarterly, 15(2), 147 - 166.

Roorda, D. L., Koomen, H. M. Y., Spilt, J. L., \& Oort, F. J. (2011). The influence of affective teacher--student relationships on students' school engagement and achievement. Review of Educational Research, 81(4), 493-529.

Roach, M. A., Kim, Y. B. \& Riley, D. A. (2006). Once attained, can quality child care be maintained? Early Education and Development, 19(4), 553 - 570.

Rudasill, K. M., Rimm-Kaufman, S. E., Justice, L. M., \& Pence, K. (2006). Temperament and language skills as predictors of teacher-child relationship quality in preschool. Early Education and Development, 17(2), 271-291.

Runhaar, P., Sanders, K., \& Yang, H. (2010). Stimulating teachers' reflection and feedback asking: An interplay of self-efficacy. Teaching and Teacher Education, 26, 1154-1161.

Ryan, R. M., Fauth, R. C., Brooks-Gunn, J. (2006). Childhood poverty: Implications for school readiness and early childhood education. In B. Spodeck \& O. N. Saracho (Eds.) Handbook of Research on the Education of Young Children $2^{\text {nd }}$ Ed. Mahwah, NJ: Lawrence Erlbaum Associates.

Sabol, T. J. \& Pianta, R. C. (2012). Recent trends in research on teacher-child relationships. Attachment \& Human Development, 14(3), 213-31.

Saft, E. W. \& Pianta, R. C. (2001). Teachers' perceptions of their relationships with students: Effects of child age, gender, and ethnicity of teachers and children. School Psychology Quarterly, 16(2), 125.

Schaefer, E. S., \& Edgerton,M. (1985). Parent and child correlates of parental modernity. In I. E. Sigel (Ed.), Parental belief systems: Psychological consequences for children (pp. 287-318). Hillsdale, NJ: Lawrence Erlbaum.

Schafer, J. L. \& Graham, J. W. (2002). Missing data: Our view of the state of the art. Psychological Methods, 7(2), $147-177$.

Silver, R. B., Measelle, J. R., Armstrong, J. M., \& Essex, M. J. (2005). Trajectories of classroom externalizing behavior: Contributions of child characteristics, family characteristics, and the teacher-child relationship during the school transition. Journal of School Psychology, 43(1), 39-60.

Skaalvik, E. M. \& Skaalvik, S. (2008). Teacher self efficacy: Conceptual analysis and relations with teacher burnout and perceived school context. In H. W. Marsh, R. 
G. Cravern, D. M. McInerney (Eds.), Self-Processes, Learning, and Enabling Human Potential: Dynamic New Approaches. Charlotte, NC: Information Age Publishing.

Smith, M. \& Bourke, S. (1992). Teacher stress: Examining a model based on context, workload, and satisfaction. Teaching and Teacher Education, 8(1), 31 - 46.

Spielberger, C. D. (1983). Manual for the Stat-Trait Anxiety Inventory: STAI (Form Y). Palo Alto, CA: Consulting Psychologists Press.

Spielberger, C. D. (1988). Manual for the State-Trait Anger Expression Inventory (STAXI). Odessa, FL: Psychological Assessment Resources.

Spielberger, C. D. \& Sydeman, S. J. (1999). State-Trait Anxiety Inventory and State-Trait Anger Expression Inventory. In M. E. Maruish (Ed.) The Use of Psychological Testing for Treatment Planning and Outcome Assessment. Hillsdale, NJ: Lawrence Erlbaum Associates.

Spilt, J. L., Hughes, J. N., Wu, J. Y., \& Kwok, O. M. (2012). Dynamics of teacherstudent relationships: Stability and change across elementary school and the influence on children's academic success. Child Development, 83(4), 1180-95.

Spilt, J. L., Koomen, H. M. Y., Thijs, J. T., van der Leij, A. (2012). Supporting teachers relationships with disruptive children: The potential of relationship-focused reflection. Attachment \& Human Development, 14(3), 305 - 318.

Spilt, J. L., Koomen, H. M. Y. \& Thijs, J. T. (2011). Teacher well-being: The importance of teacher-student relationships. Educational Psychology Review, 23(4), 457 477.

Stipek, D. (2006, May). No child left behind comes to preschool. The Elementary School Journal, 106(5), 455-466.

Stuhlman, M. W. \& Pianta, R. C. (2002). Teachers' narratives about their relationships with children: Associations with behavior in classrooms. School Psychology Review.

Tschannen-Moran, M. \& Hoy, A. W. (2001). Teacher efficacy: Capturing an elusive construct. Teaching and Teacher Education, 17(7), 783-805.

Thijs, J. \& Koomen, H. M. Y. (2009). Toward a further understanding of teachers' reports of early teacher-child relationships: Examining the roles of behavior appraisals and attributions. Early Childhood Research Quarterly, 24(2), 186-197.

van Dick, R. \& Wagner, U. (2001). Stress and strain in teaching: A structural equation approach. British Journal of Educational Psychology, 71, 243 - 259. 
Vitiello, V. E., Booren, L. M., Downer, J. T., \& Williford, A. (2012). Variation in children's classroom engagement throughout a day in preschool: Relations to classroom and child factors. Early Childhood Research Quarterly, 27, 210 - 220.

Williford, A. P., Whittaker, J. E. V., Vitiello, V. E. \& Downer, J. T. (2013). Children's engagement within the preschool classroom and their development of selfregulation. Early Education and Development, 24(2), 162 - 187.

Yoon, J. S. (2002). Teacher characteristics as predictors of teacher-student relationships: Stress, negative affect, and self-efficacy. Social Behavior and Personality: An International Journal, 30(5), 485-493.

Zhang, X. \& Sun, J. (2011). The reciprocal relations between teachers' perceptions of children's behavior problems and teacher-child relationships in the first preschool year. The Journal of Genetic Psychology, 172(2), 176-98. 
Table 1

Teacher, Classroom, and Child Demographics

\begin{tabular}{|c|c|c|c|}
\hline & $N$ & Mean & $S D$ \\
\hline \multicolumn{4}{|l|}{ Teacher demographics } \\
\hline Male & 214 & 0.04 & 0.19 \\
\hline Age & 214 & 42.56 & 10.55 \\
\hline White & 214 & 0.33 & 0.47 \\
\hline Black & 214 & 0.47 & 0.50 \\
\hline Hispanic & 214 & 0.12 & 0.32 \\
\hline Asian & 214 & 0.04 & 0.19 \\
\hline Multi-ethnic & 214 & 0.05 & 0.21 \\
\hline Total years teaching experience & 211 & 14.55 & 9.14 \\
\hline Years of education & 214 & 15.81 & 1.62 \\
\hline \multicolumn{4}{|l|}{ Classroom demographics } \\
\hline Head Start & 213 & 0.55 & 0.50 \\
\hline Proportion classroom in poverty & 222 & 0.87 & 0.23 \\
\hline \multicolumn{4}{|l|}{ Child demographics } \\
\hline Age (in months) & 895 & 4.12 & 0.50 \\
\hline Male & 895 & 0.51 & 0.50 \\
\hline Income to needs & 773 & 1.07 & 1.04 \\
\hline Maternal education & 854 & 12.70 & 2.35 \\
\hline White & 872 & 0.14 & 0.34 \\
\hline Black & 872 & 0.42 & 0.49 \\
\hline Hispanic & 872 & 0.35 & 0.48 \\
\hline Asian & 872 & 0.04 & 0.20 \\
\hline Native American & 872 & 0.001 & 0.03 \\
\hline Other & 872 & 0.003 & 0.06 \\
\hline Multi-ethnic & 872 & 0.04 & 0.21 \\
\hline
\end{tabular}

Note: The current study sample included 895 children and 223 teachers 


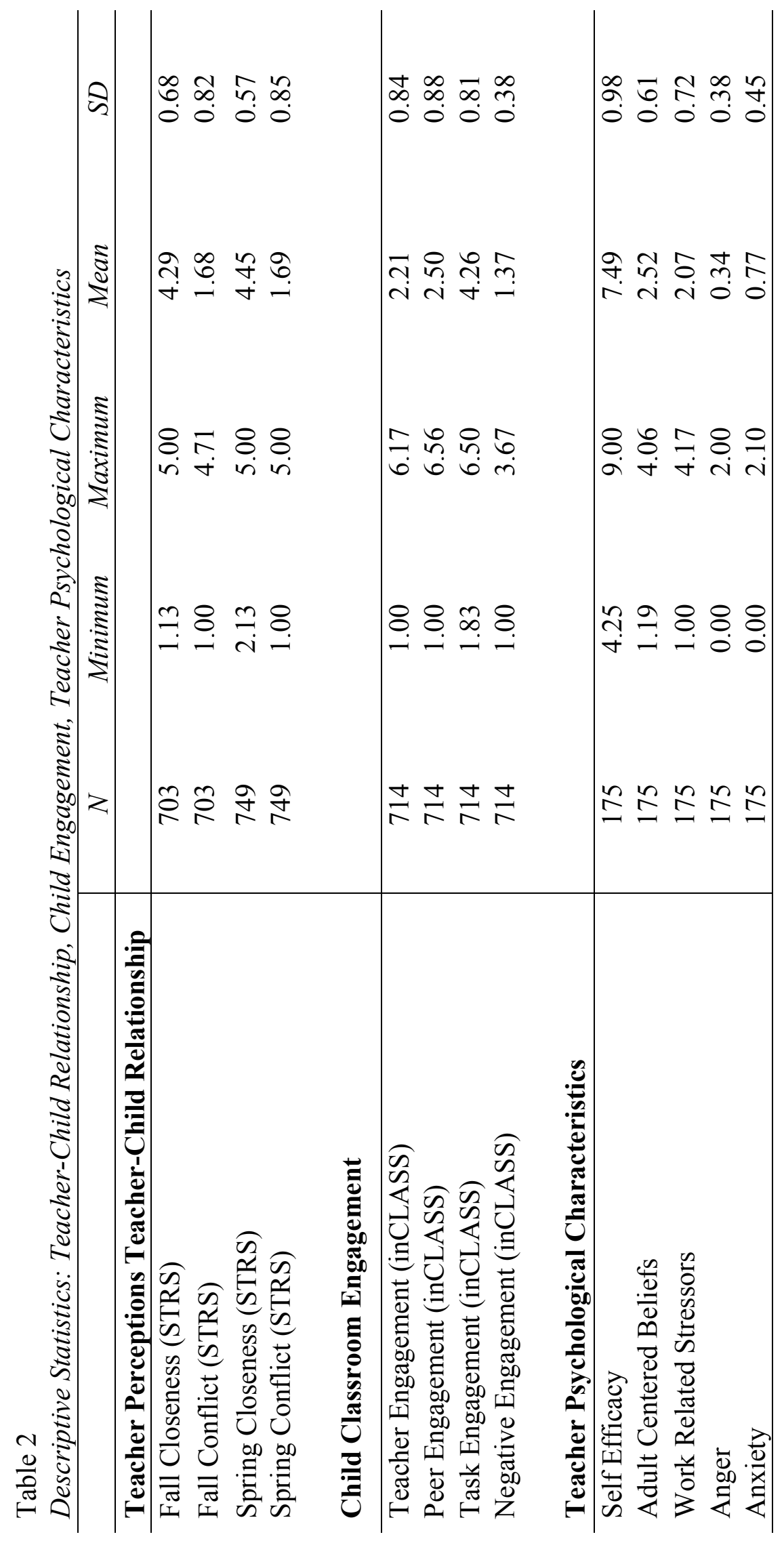




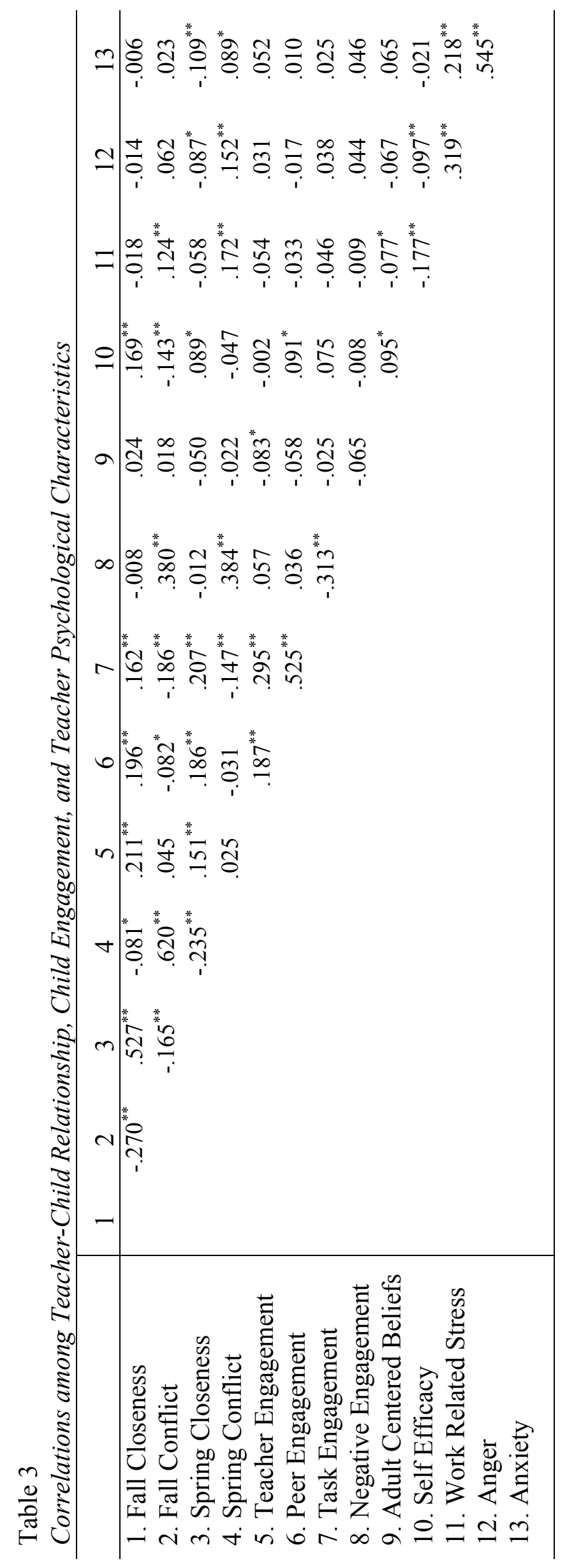


Table 4

Child Engagement and Teacher Psychological Characteristics predicting Teacher-Child Relationship Quality Stability

\begin{tabular}{|c|c|c|c|c|}
\hline \multirow[b]{2}{*}{ Within Model } & \multicolumn{2}{|c|}{ Closeness } & \multicolumn{2}{|c|}{ Conflict } \\
\hline & $\beta$ & $S E$ & $\beta$ & $S E$ \\
\hline Child Age & 0.043 & 0.041 & -0.044 & 0.061 \\
\hline Male & $-0.084^{*}$ & 0.034 & 0.043 & 0.045 \\
\hline Black & -0.044 & 0.068 & $0.209^{*}$ & 0.088 \\
\hline Hispanic & -0.021 & 0.074 & -0.005 & 0.089 \\
\hline Other Ethnicity & -0.048 & 0.080 & -0.054 & 0.104 \\
\hline Maternal Education & 0.000 & 0.010 & 0.002 & 0.011 \\
\hline Fall Closeness/Conflict & $0.392 * * *$ & 0.038 & $0.533 * * *$ & 0.041 \\
\hline Teacher Engagement & 0.026 & 0.024 & 0.009 & 0.033 \\
\hline Peer Engagement & 0.006 & 0.030 & 0.021 & 0.039 \\
\hline Task Engagement & $0.103 * *$ & 0.035 & 0.004 & 0.046 \\
\hline Negative Engagement & 0.059 & 0.060 & $0.448 * * *$ & 0.088 \\
\hline \multicolumn{5}{|l|}{ Between Model } \\
\hline$\%$ class poverty & 0.024 & 0.126 & 0.080 & 0.169 \\
\hline Teacher Years Education & -0.024 & 0.018 & 0.013 & 0.024 \\
\hline Head Start Classroom & -0.021 & 0.064 & -0.034 & 0.080 \\
\hline Course Intervention & 0.008 & 0.051 & 0.031 & 0.061 \\
\hline Cousultancy Intervention & 0.000 & 0.046 & 0.048 & 0.056 \\
\hline Site 2 & -0.025 & 0.115 & -0.051 & 0.144 \\
\hline Site 3 & -0.036 & 0.099 & -0.229 & 0.129 \\
\hline Site 6 & -0.047 & 0.096 & -0.169 & 0.133 \\
\hline Site 7 & 0.085 & 0.117 & 0.039 & 0.157 \\
\hline Site 8 & 0.082 & 0.081 & -0.173 & 0.110 \\
\hline Site 9 & -0.079 & 0.111 & 0.006 & 0.134 \\
\hline Site 10 & 0.166 & 0.124 & 0.032 & 0.148 \\
\hline Site 11 & -0.042 & 0.112 & 0.024 & 0.174 \\
\hline Site 12 & 0.032 & 0.112 & 0.059 & 0.146 \\
\hline Self Efficacy & 0.007 & 0.031 & -0.002 & 0.037 \\
\hline Adult Centered Beliefs & -0.053 & 0.051 & -0.034 & 0.057 \\
\hline Work Related Stress & -0.001 & 0.039 & $0.124 * *$ & 0.046 \\
\hline Anger & -0.021 & 0.085 & 0.159 & 0.106 \\
\hline Anxiety & $-0.138 *$ & 0.069 & 0.040 & 0.085 \\
\hline
\end{tabular}

Note: ${ }^{*} p<.05,{ }^{* *} p<.01,{ }^{* * *} p<.001$ 
RUNNING HEAD: Children's Relationship Perceptions

Children's Perceptions of the Teacher-Child Relationship: Associations with Teachers' Relationship Perceptions, Independent Observations, and Child Characteristics

Karyn Hartz and Amanda Williford

University of Virginia 


\begin{abstract}
The present study extends the very limited research on children's relationship perceptions during preschool. We examined the reliability and validity of preschool children's relationship perceptions in a sample of children with disruptive behavior problems who are at-risk for forming negative teacher-child relationships. Children' relationship perceptions were obtained through two measures: a structured interview and a representational drawing. Children's interactions with their teacher and teachers' emotionally supportive practices were observed. Teachers reported on their perceptions of the teacher-child relationship. Parents reported on children's demographic characteristics, teachers rated children's behavior problems, and children's receptive language was directly assessed. Results indicate in our sample of children as young as three years old with behavior problems, the measure structures were consistent with prior uses with slightly older children. Children's perceptions on two measures were associated with each other in the expected directions. Children who were younger, male, AfricanAmerican and who had lower verbal ability, parents with less education, and a lower income-to-needs ratio perceived less positive teacher-child relationships. Children's perceptions were not associated with teachers' relationship perceptions. More warmth and less conflict in the teacher-child relationship reported by children were associated with teachers' emotionally supportive practices. Less relational negativity in children's drawings was associated with children's observed positive interactions with their teacher. Less child-reported warmth and more child-reported conflict were associated with children's observed conflictual interactions. Findings indicate that we can reliably and accurately assess preschool children's perceptions of the teacher-child relationship.
\end{abstract}


Children's Perceptions of the Teacher-Child Relationship: Associations with Teachers' Relationship Perceptions, Independent Observations, and Child Characteristics

Warm, sensitive, and responsive teacher-child relationships are a key contributor to children's social, emotional, and academic development (Hamre \& Pianta, 2001; Roorda, Koomen, Spilt, \& Oort, 2011). For the 10 to 20 percent of children with early behavior problems, a high quality teacher-child relationship offers an opportunity to foster positive school-related outcomes (Baker, 2006; Hamre \& Pianta, 2001; Palermo, Hanish, Martin, Fabes, \& Reiser, 2007; Sabol \& Pianta, 2012). The extensive work demonstrating the importance of teacher-child relationships has focused on teachers' report of this relationship (e.g., Hamre \& Pianta, 2001). In fact, little work has examined children's perception of the teacher-child relationship, especially among preschool children (for an exception see Mantzicopoulos \& Neuharth-Pritchett, 2003). We know surprisingly little about preschool children's perceptions of the teacher-child relationship, particularly given the developmental significance of these early relationships.

Understanding children's perceptions of the teacher-child relationship may help us better understand this relationship and the mechanisms by which the quality of teacher child relationships longitudinally predict children's outcomes. The present study is among the first to comprehensively assess preschool children's perception of their relationship with their teachers. Specifically, this work examines the reliability and validity of preschool children's report of these relationships using two different measures in a sample of children who display early disruptive behavior in the classroom.

\section{Importance and Measurement of Teacher-Child Relationships}

Children's early relationships with their teachers play a critical role in their 
academic success as well as their social and behavioral competencies (O'Connor, Dearing, \& Collins, 2011; Hamre \& Pianta, 2001; Palermo et al., 2007; Peisner-Feinberg et al., 2001; Pianta, Steinberg, \& Rollins, 1995; Roorda et al., 2011). Children whose relationships with their teachers are characterized by closeness tend to have higher academic achievement, better school adjustment and fewer behavior problems (Birch \& Ladd, 1997; Pianta \& Stuhlman, 2004). In contrast, when children's relationships with their teachers are high in negativity, children have lower academic performance, are less well adjusted to school and are more likely to evidence behavior problems (Birch \& Ladd, 1997; Hamre \& Pianta, 2001; Pianta \& Stuhlman, 2004). These associations between relationship quality and children's adjustment are observed concurrently as well as longitudinally (Hamre \& Pianta, 2001; Pianta \& Stuhlman, 2004) as well as in both within-child analysis and between child analyses across elementary school (MaldonadoCarreño \& Votruba-Drzal, 2011). Children's early relationships with their teachers have long lasting influences for their academic and social-emotional functioning. Specifically, negativity in these early relationships predicts lower academic achievement and more behavior problems for children through eighth grade (Hamre \& Pianta, 2001).

Teacher-child relationships are particularly important for children with early behavior problems, as these children are less likely to form positive, close relationships with their teachers (Baker, 2006; Birch \& Ladd, 1998; Hughes, Cavell, \& Jackson, 1999). When children with disruptive behavior problems form a positive relationship with their teacher, this relationship can be a protective factor for children's behavior problems and academic performance (Baker, 2006; Silver, Measelle, Armstrong, \& Essex, 2005). However, when children with behavior problems experience a negative relationship with 
their teacher, it can exacerbate their behavior problems and contribute to lower academic achievement (Hamre \& Pianta, 2001; Silver et al., 2005). The quality of these teacherchild relationships in preschool is also linked to the quality of children's relationships with subsequent teachers (Howes, Phillipsen, \& Peisner-Feinberg, 2000).

This research supporting the importance of early teacher-child relationships has typically measured the quality of early teacher-child relationships through teachers' selfreport measures, which reflect teachers' perceptions of this relationship (e.g., Baker, 2006; Silver et al., 2005). Researchers have also examined observed interactions between teachers and children, which are proximally related to the development of relationships. Specifically, observations of teachers' emotional support, which consists of their warmth, sensitivity, and responsiveness to children, is thought to be a critical component in the development of teacher-child relationships (Buyse et al., 2008; Hamre \& Pianta, 2005; Howes, Galinsky, \& Kontos, 1998; NICHD ECCRN, 2002a; Verschueren \& Koomen, 2012). Both the emotional support provided by teachers in the classroom and teachers' perceptions of the teacher-child relationship have been consistently linked longitudinally with children's positive social, behavioral, and academic outcomes (Hamre \& Pianta, 2001; NICHD ECCRN, 2003, 2005; Peisner-Feinberg et al., 2001).

\section{Significance of Children's Perceptions of the Teacher-Child Relationship}

Although the importance of teacher-child relationships has been well established, these relationships have primarily been studied through teachers' report (e.g., Birch \& Ladd, 1997; Hamre \& Pianta, 2001). However, these dyadic relationships may be more fully understood by also examining children's perceptions. Little work has examined young children's perceptions of the teacher-child relationship. Some researchers have 
examined kindergarten and early elementary school age children's perceptions of the teacher-child relationship (Henricsson \& Rydell, 2004; Harrison, Clarke, \& Ungerer, 2007; Hughes, 2011; Murray, Murray, \& Wass, 2008; Rey, Smith, Yoon, Somers, \& Barnett, 2007; Spilt, Koomen, \& Mantzicopoulos, 2010) and very few researchers have examined preschool children's relationship perceptions (e.g., Mantzicopoulos \& Neuharth-Pritchett, 2003). Yet, early relationships are particularly formative, underscoring the importance of understanding children's perceptions of the teacher-child relationship during the preschool years. Children's relationship with their preschool teacher is one of the first such relationships they have, which can form the basis for subsequent relationships (Bowlby, 1988; Pianta, 1999).

Because the quality of an early teacher-child relationship continues to predict children's academic achievement and behavioral adjustment long after the child is no longer directly in a relationship with that particular teacher (Hamre \& Pianta, 2001), these early relationships presumably influence internal child characteristics that continue to affect the child's academic performance and behavior. One child characteristic that may be influenced by their early relationships with teachers is their internal working model, or mental representation, of the teacher-child relationship (Bretherton, 1999; Bowlby, 1988). Children's application of their internal working model to later relationships with teachers may influence their behavior and interactions in the classroom. If a child experiences an early conflictual relationship with their teacher, they are more likely to expect that later relationships with teachers will function in the same manner. These children are less likely to see the teacher as a resource who can help them with difficulties navigating peer interactions and academic tasks. Children with a 
conflictual, less secure relationship receive more attention from the teacher, attention that is often negatively valenced in response their disruptive or attention-seeking behavior (O’Conner \& McCartney, 2007; Pianta, 1999). In contrast, when children have a close relationship with their teacher, they tend to be proactively engaged in the learning opportunities in the classroom, using their teacher as a secure base from which to explore and be engaged in the classroom environment (O’Conner \& McCartney, 2007; Pianta, 1999). Provided that this theory of children's internal working models of teacher-child relationships and their association with children's classroom behavior is true, and if we can accurately and reliability assess young children's perceptions of the teacher-child relationship, then we may be able to better target early intervention for children with less positive internal working models and their teachers. This targeted intervention may be able to help these children develop more positive perceptions of the teacher-child relationship. In this study, we measured preschool children's perceptions of the teacherchild relationship in a sample of young children who displayed elevated levels of disruptive behaviors and are thus more likely to experience lower quality teacher-child relationships. Then, we examined the reliability and validity of these preschool children's report of the teacher-child relationship.

\section{Measuring Young Children's Perceptions of the Teacher-Child Relationship}

For very young children, preliminary work has measured children's perceptions of the teacher-child relationship differently than older elementary school children's perceptions and teachers' perceptions. Older children and teachers are often administered self-report rating scales that have a number of items on a likert scale (e.g., 'Some kids have a hard time talking to their teachers, but other kids don't. Do you have a hard time 
talking to your teachers?'), which children rate on a five-point scale from 'always' to 'never' (Dubow, Tisak, Causey, Hryshko, \& Reid, 1991 as cited in Rey et al., 2007). On the other hand, younger children's perceptions have been obtained through playful structured interviews or drawing tasks (Harrison et al., 2007; Mantzicopoulos \& Neuharth-Pritchett, 2003; Murray et al., 2008). In structured interviews, children are often asked a series of focused questions to which they respond verbally or nonverbally. These interviews are conducted with hands-on materials in addition to the verbal statements from the examiner to maintain children's engagement in the task (Mantzicopoulos \& Neuharth-Pritchett, 2003). Another approach to understanding children's perceptions of relationships is through representational measures, including drawing tasks, in which children symbolically portray their relationship representations or internal working models (Fury, Carlson \& Sroufe, 1997; Harrison et al., 2007). Representational drawing measures have often been used in attachment research to understand children's perceptions of their relationships with their family, especially mothers (Dallaire, Ciccone, \& Wilson, 2012; Fury et al., 1997), and more recently, their relationship with their teacher (Harrison et al., 2007). Children are asked to draw a picture of themselves with their teacher, and then the drawings are coded for several indicators of relational negativity between the child and the teacher (Harrison et al., 2007). The feelings and understanding of the relationship that children portray in their drawings can be reliably coded and these codes have been linked to multiple indicators of relationship quality (Fury et al., 1997; Harrison et al., 2007; Madigan, Ladd, \& Goldgerg, 2003).

Initial work indicates that preschool, kindergarten and first grade children are able 
to reliably self-report their perceptions through structured interviews (Mantzicopoulos \& Neuharth-Pritchett, 2003; Spilt et al., 2010) and that kindergarten children can reliably portray their representations of the teacher-child relationship in drawings (Harrison et al., 2007). Preliminary evidence for the construct validity of these measures comes from the associations of children's relationship perceptions with teachers' relationship perceptions in the expected direction and support for predictive validity comes from children's relationship perceptions prediction of children's classroom behavior. With respect to construct validity, children's report of warmth on the Young Children's Appraisals of Teacher Support in a population of children who were or had been in Head Start (YCATS; Mantzicopoulos \& Neuharth-Pritchett, 2003) has been associated with teachers' report of a secure and improved relationship, whereas child-reported conflict was associated with teachers' report of more dependency and less improvement in relationship quality (Mantzicopoulos \& Neuharth-Pritchett, 2003). Similarly, more relational negativity in children's drawings was associated with less teacher-reported closeness and more teacher-perceived conflict among kindergarten children whose mothers had previously been recruited for participation in a larger study (Harrison et al., 2007). Additionally, children's relationship perceptions have been concurrently associated with their classroom behavior and achievement. Higher child-reported conflict on the YCATS has been associated with teachers' report of more behavior problems, lower social skills as well as lower achievement for children, whereas child-reported warmth has been associated with children's greater self-control and less negative emotionality (Mantzicopoulos, 2005; Mantzicopoulos \& Neuharth-Pritchett, 2003; Spilt et al., 2010). With respect to predictive validity, low child-reported warmth on the 
YCATS also predicted less teacher-reported aggression for boys and more teacherreported social inhibition for girls in a sample of kindergarten children who were randomly selected from the classrooms of teachers participating in the study (Spilt et al., 2010). Children's representations of relational negativity also predicted less positive school adjustment as well as more learning and behavior problems (Harrison et al., 2007). Furthermore, the relational negativity represented in children's drawings was more strongly predictive of children's behavior problems than was children's self-report of the teacher-child relationship through a structured interview (Harrison et al., 2007). However, to our knowledge, these measures of children's relationship perceptions have not been used together in a single study and have not been validated with independent observations of children's classroom interactions and teachers' practice in the classroom. Additionally, we examine children's perceptions of the teacher-child relationship in a sample of children with high levels of disruptive behavior, as these children are at particular risk for having a negative teacher-child relationship. And, the children in our sample are demographically diverse, coming from a wide variety of preschool and childcare programs that serve children who are younger than have been included in previous studies.

Teachers' and young children's reports of their relationships in previous research were found to be moderately concordant, indicating a shared experience (Mantzicopoulos \& Neuharth-Pritchett, 2003; Murray et al., 2008; Spilt et al., 2010) and providing support for the validity of children's report of teacher-child relationship. However, work with kindergarten and elementary school children indicates that these reports are not perfectly aligned, reflecting the different experiences of the relationship that students and teachers 
may have (Murray et al., 2008; Rey et al., 2007). Among elementary school children (grades $2-6$ ), students' and teachers' perceptions of their relationship are uniquely and differentially predictive of children's academic achievement and school adjustment (Hughes, 2011; Rey et al., 2007). Thus, both teachers' and children's perceptions of the teacher-child relationship provide unique contributions to our understanding of children's

development. In the present study, we examined the association of children's relationship perceptions with teachers' relationship perceptions, in line with prior research employing the measures used in the present study (Mantzicopoulos \& Neuharth-Pritchett, 2003; Murray et al., 2008; Spilt et al., 2010), as an indication of the validity of children's reports. We also extended prior research by examining associations with children's characteristics as well as independent observations of teachers' classroom practice and children's classroom interactions as additional indications of the validity of children's report of teacher-child relationship quality.

\section{Child Characteristics Associated with the Quality of the Teacher-Child Relationship}

The quality of teacher-child relationships and how a child perceives his or her relationship with the teacher may be related to a child's individual characteristics. Several characteristics have been consistently associated with the quality of the teacher-child relationship, as perceived by teachers' and children alike. Finding similar associations in the present study would provide additional support for the validity of the measures being examined as well as information about which children may be most likely to have negative perceptions of this relationship. Prior research indicates that among preschool and elementary school aged children, boys tend to have less positive relationships with their teachers; these relationships are characterized by more conflict and less closeness 
than girls' relationships with their teachers according to both teachers' (Baker, 2006; Birch \& Ladd, 1997; Ewing \& Taylor, 2009; Hamre \& Pianta, 2001; Kesner, 2000; Murray \& Murray, 2004; Murray et al., 2008; Silver et al., 2005) and children's reports (Harrison et al., 2007; Mantzicopoulos \& Neuharth-Pritchett, 2003). African-American elementary school children tend to have less positive teacher-child relationships as reported by their teachers than do Caucasian or Hispanic children (Hamre \& Pianta, 2001; Hughes, Gleason, \& Zhang, 2005; Murray \& Murray, 2004) and African-American preschool boys report having less positive relationships with their teachers than Caucasian children and African-American girls (Mantzicopoulos \& Neuharth-Pritchett, 2003). There is some indication that teachers report more positive relationships with Hispanic kindergarten children than Caucasian or African-American children (Murray et al., 2008). Child age has also been associated with teacher-child relationship quality, though the pattern of association is less clear. Among kindergarten-aged children, older children tend to report more positive perceptions of their relationship with their teacher (Harrison et al., 2007). However, some researchers have found the opposite association when teachers report on relationship quality. That is, teachers tend to perceive less closeness with children in higher elementary school grades than kindergarten children (Baker, 2006) and more conflict with older preschool children, but only after controlling for child behavior problems (Hamre, Pianta, Downer, \& Mashburn, 2008). Children's behavior problems have been consistently associated with teachers' perceptions of less positive teacher-child relationships for children in elementary school and preschool (Baker, 2006; Baker, Grant, \& Morlock, 2008; Hamre \& Pianta, 2001; Hamre et al., 2008; Hughes et al., 1999). Children from families of lower SES are at-risk for poor 
adjustment to school, including behavior problems and lower academic achievement (Bradley \& Corwyn, 2002), which could affect the quality of the relationship with their teacher. Additionally, in combination with behavioral traits, children's language ability has been related to teacher-reported relationship quality (Rudasill, Rimm-Kaufman, Justice, \& Pence, 2006). Children's verbal ability is an important characteristic to examine in relation to their own perceptions, as it may affect the child's ability to accurately report on their perceptions of the teacher-child relationship. Children's verbal ability may also contribute a child's ability to communicate with their teacher and develop a positive, reciprocal relationship. The present study examined whether children's age, gender, ethnicity, verbal ability, behavior problems, family income, and parent education were associated with preschool children's perceptions of the teacherchild relationship. We also investigated if the directionality of these associations was aligned with previous research, much of which has been conducted with older children and has assessed the teacher-child relationship from the teacher's perspective.

\section{Present Study}

The present study contributes to the literature on teacher-child relationships in several ways. First, we add to the limited literature examining children's perceptions of the teacher-child relationship by examining two approaches to measuring children's relationship perceptions. Second, we extend prior research with the YCATS by using this measure with a sample of preschool children who have elevated disruptive behavior and who are younger than samples from previous studies - to our knowledge, we are the first to examine these perceptions in a sample inclusive of three-year-old children. Third, we extend research with representational drawings of the teacher-child relationship, which 
has previously only been used with typically developing kindergarten children. Finally, in addition to examining the validity of these measures through associations between children's perceptions of the teacher-child relationship, teacher's perceptions of the teacher-child relationship, and child characteristics, we included associations with independent observations of teachers' emotionally supportive practices and children's classroom interactions, which have not been included in previous work.

The present study addressed two research questions. First we asked if the previously established reliability of children's self-report of the teacher-child relationship on the Young Children's Appraisals of Teacher Support (YCATS) and children's representations of relational negativity with teachers in their drawings held in the current study with preschool children. We hypothesized that (a) the data from our sample would fit the previous two-factor solution for the YCATS (Warmth and Conflict) and would replicate the Relational Negativity composite for the drawing measure, and (b) all subscale scores would evidence adequate internal consistency. Second, we asked if preschool children's perceptions of the teacher-child relationship on two measures (YCATS Warmth and Conflict, Drawing Relational Negativity) were valid. Specifically, we expected that (a) Relational Negativity in children's drawings would be negatively associated with children's self-report of YCATS Warmth and positively associated with YCATS Conflict; (b) children who were older, male, evidenced lower language, lower SES and more behavior problems would perceive less positive relationships with their teachers (less YCATS Warmth, greater YCATS Conflict and Drawing Relational Negativity); (c) YCATS Warmth would be positively associated with teacher-reported closeness, and YCATS Conflict and Drawing Relational Negativity would be positively 
associated with teacher-reported conflict; (d) YCATS Warmth would be positively associated with teachers' emotionally supportive practices and YCATS Conflict and Drawing Relational Negativity would be negatively associated with emotional support; and (e) YCATS Warmth would be positively associated with independent observations of children's positive interactions with their teacher, whereas YCATS Conflict and Drawing Relational Negativity would be positively associated with children's observed classroom conflict.

\section{Method}

\section{Participants}

Participants were preschool children with disruptive behavior problems who were part of a larger intervention study. The data collected for the current study was added as a subcomponent of the larger study for Cohorts 2 and 3 of the study. The intervention was not of interest in the present study. The sample for the present study consisted of 158 children (52 female) between the ages of 3.45 and 6.12 years $(M=4.88, S D=0.54)$. Children in this sample were nested within classrooms with 3 children on average selected per classroom. Children attended a variety of preschool programs: Head Start $(34.2 \%)$, state-funded prekindergarten $(16.5 \%)$, private with state prekindergarten funding (10.1\%), private for-profit (13.9\%), and private not-for-profit preschool classrooms (25.3\%). Participants were racially diverse: 44\% were African American, $32 \%$ were Caucasian, $9 \%$ were Hispanic, $1 \%$ were Asian, $14 \%$ were Multiracial, and 1\% were another ethnicity. Participants' mothers had a wide range of educational backgrounds: 5.8\% did not graduate from high school, $12.3 \%$ obtained a high school degree or equivalent, $43.3 \%$ received some education or training beyond high school, 
$25.2 \%$ obtained a bachelor's degree, and $13.6 \%$ obtained a graduate degree. Many children came from low-income backgrounds and the average income to needs ratio for participants was 1.78 (range: $0.22-5.16, S D=1.51$ ).

Recruitment. State-funded, Head Start and private preschool programs in two Mid-Atlantic States were invited to participate. The preschool programs were located in rural, suburban, and small urban areas. Permission was first obtained from program directors and principals. Once a program agreed to participate, teachers were invited to participate in the study. Teachers who agreed to participate gave their informed consent for classroom observations, completed personal and classroom demographic surveys as well as surveys about the children in their classroom, and assisted with obtaining consent from parents for their children's participation. Consented teachers/classrooms were randomly assigned to one of three intervention conditions, which were controlled for in this study. Teachers helped obtain parental consent for the children in their classroom at the beginning of the school year. Parents/guardians of all children in each participating classroom were given a letter explaining the study, an informed consent form, and a family demographic survey. The average classroom consent rate was $76 \%$.

Selection. After children had been in the classroom for several weeks, teachers completed the ADHD Rating Scale (DuPaul, Power, \& Anastopoulos, 1998) and ODD Rating Scale (Anastopoulos, 1998) for each child in their classroom. The three children ( 2 boys and 1 girl) with the highest levels of teacher-reported disruptive behaviors and whose parents consented to be in the study were selected. Children who were typically developing and whose disruptive behavior was not accounted for by another disorder 
(e.g., Intellectual Disability, Pervasive Developmental Disorder) were eligible to participate.

Attrition. A total of 158 children completed the child interview, which was $67 \%$ of children who were initially enrolled in the study at the beginning of the year and who had consented to participate in this subcomponent of data collection. The majority of attrition resulted because the teacher or child left the participating school or classroom (68\%). The remaining attrition occurred because a teacher withdrew from the study (21\%), a child was no longer eligible (3\%), a child withdrew from the study (1\%), and because of repeated absence, refusal or other reason (7\%). Two additional interviews were not obtained for children still participating in the study; one due to a data collection error and one because the child could not complete the task. Analyses were conducted to determine if children who completed the child interview differed from children who did not complete the interview at our baseline assessment. There were no significant differences in maternal education, family income, family income-to-needs ratio, whether the child had and Individualized Education Plan (IEP), child gender, or child age. There were also no differences in teachers' ratings of children's behavior problems at baseline (symptoms of inattention, hyperactivity, and oppositional behavior). There was a higher proportion of ethnic minority children among the children who completed the interview compared to those who did not complete the interview $(\mathrm{t}(226)=1.414, p<.05)$.

\section{Procedures}

Study Procedures. The data used in the present study is a subset of the data collected as part of the larger intervention efficacy trial. The trial occurred over three years with different teachers and children participating in each year of the study. Due to 
the nature of the intervention, children were assigned to one of three treatment/assessment windows (fall, winter, spring). Within each window children were assessed at pre and post. Additionally, all children were assessed at the beginning of the year and end-of-year. Children's baseline and pre data collection are the same for children in the fall treatment/assessment window and the post and end-of-year data collection were the same for children in the spring treatment/assessment window (three total assessments). Intervention condition status was not related to the outcome measures of children's perceptions of the teacher-child relationship and thus is not included in the present study. Procedures relevant to the proposed study are described in further detail below.

Data Collection. At the beginning of the school year, parents and teachers completed questionnaires about children's behavior and development, along with personal and classroom demographic questionnaires, and children's receptive verbal skills were assessed. After completing the intervention with each child, teachers completed a survey assessing their perceptions of the teacher-child relationship. At the end of the school year, classroom observations of the child's interactions in the classroom and teacher's practice were conducted and children's perceptions of their relationship with their teacher was assessed through an interview and drawing.

Observation Training and Protocol. Data collectors attended a two-day intensive training with a certified trainer for the observational measure of children's interactions in the classroom (Individualized Classroom Assessment Scoring System; inCLASS, Downer, Booren, Hamre, Pianta, \& Williford, 2011) and for the observational measure of teachers' emotional support (CLASS; Pianta, LaParo, \& Hamre, 2008). The 
trainings included detailed descriptions and brief video examples of the measure content as well as watching, coding and discussing training videos. After completing training, data collectors were required to score $80 \%$ of their codes within one point of the mastercode across 5 video segments in order to be reliable on this measure. Data collectors' reliability scores were good and ranged from $80-94 \%$ for inCLASS and $80-$ 96\% for CLASS. Additionally, data collectors were required to maintain their reliability ( $80 \%$ of codes within one point of master code) through regular calibration meetings. During these meetings, data collectors coded video segments and discussed the mastercodes with a certified inCLASS trainer and CLASS trainer, similar to the format of the original training.

Observations were scheduled at a time that was convenient for the teacher during the end-of-year assessment window. The observations typically occurred in the morning and lasted about four hours across a variety of classroom setting and activities.

Observations occurred in 15-minute cycles during which data collectors observed the child for 10 minutes and coded the observation for 5 minutes. Data collectors rotated through observing up to three children on alternate cycles of the inCLASS. Additionally, inCLASS observations were alternated with observations of the classroom context using the CLASS. Data collectors typically obtained 4 inCLASS cycles per child and 2 CLASS cycles on two different days for a total of 8 inCLASS and 4 CLASS observation cycles. However, additional observation days were sometimes required to obtain 8 observation cycles for each child. The mean number of inCLASS cycles per child for children in the present study at the end-of-year assessment window was $8.99(S D=1.93$; range $=4$ to 18$)$ collected over an average of 3.12 days $(S D=0.84$; range $=1$ to 6$)$. The 
mean number of CLASS cycles was $5.55(\mathrm{SD}=2.19$; range $=3-14)$.

Direct Child Assessments. These direct assessments were administered in a quiet, private location, typically just outside of the classroom in the hallway, in another room at the center, or in a quiet corner of the classroom. During the baseline observation window, data collectors administered the Peabody Picture Vocabulary Test $4^{\text {th }}$ edition (Dunn \& Dunn, 2007), a direct assessment of children's receptive vocabulary. During the end-of-year assessment window, children participated in a playful interview about their perception of the teacher-child relationship, which included the Young Children's Appraisals of Teacher Support (YCATS; Mantzicopoulos \& Neuharth-Pritchett, 2003) and drawing a picture of themselves with their teacher (Harrison et al., 2007; Fury et al., 1997). The child interview was conducted on a day when the study teacher was present in order for the child to identify her/him as the focus of the interview. Data collectors attended a training on the procedures to administer the YCATS and drawing task, which included a detailed description of each measure, scripts to conduct each assessment, a detailed procedural manual, and practice conducting each assessment. Data collectors were observed by the trainer during practice to assure their fidelity with procedures. The procedures for the YCATS and drawing task are described in detail in the methods section.

\section{Measures}

\section{Children's perception of the teacher-child relationship.}

Young Children's Appraisals of Teacher Support (YCATS). The Young Children's Appraisals of Teacher Support (YCATS) assesses children's perception of their relationship with their teachers (Mantzicopoulos \& Neuharth-Pritchett, 2003). 
Children answer a series of yes/no questions that assess three dimensions of the teacherchild relationship: warmth, conflict, and autonomy. Only the warmth and conflict subscales were used in the present study. The warmth scale consists of 12 items (11 items from the original validation and 1 item that originally loaded on the autonomy scale, but in a later study loaded on the warmth scale; Spilt et al., 2010) that reflect the affection and closeness a child perceives in their relationship. The conflict scale consists of 10 items that assess the tension and negativity that a child perceives in their relationship with their teacher. In previous validations of the YCATS, internal consistency ranged from acceptable to good for warmth $(\alpha=.80, .65)$ and conflict $(.78, .72)$ (Mantzicopoulos \& Neuharth-Pritchett, 2003; Spilt et al., 2010). Test-retest reliability over a 3-week interval for warmth and conflict was acceptable ( $r \mathrm{~s}=.67$ and .62) (Spilt et al., 2010). This measure was validated for use with preschool, kindergarten, and first grade students (Mantzicopoulos \& Neuharth-Pritchett, 2003).

The interview was conducted using procedures described by the authors and researchers who previously used the measures reported in the original validation (Mantzicopoulos \& Neuharth-Pritchett, 2003; Spilt et al., 2010). Verbal assent was obtained from children to participate in the YCATS; then they were asked to identify their teacher. If they identified an adult in their classroom that was not their primary teacher, such as an assistant teacher or paraprofessional, the person conducting the assessment pointed out their teacher and told the child that this was whom they would be answering questions about. Children were assured of the confidentiality of their responses, and if the teacher was in the room during the interview, it was conducted in a location where the teacher would not be able to overhear. Children were read a statement 
about their teacher (e.g., My teacher likes me) and handed a small card with the item on it. Children were asked to put the card in a green bucket if he/she agreed that the statement was like their teacher. If the statement was not like their teacher, they were asked to put the item card in the red bucket. Green and red buckets were used instead of the mailbox and trashcan employed in a previous study (Mantzicopoulos \& NeuharthPritchett, 2003) to increase the simplicity of the task since all children in the sample were preschool aged. Three practice items were administered to teach children how to complete the task - one affirmative (My teacher is older than me), one negative (My teacher has blue hair), and one negatively worded (My teacher tells me I do not have teeth). The negatively worded practice item was added because the sentence structure including "not" may be particularly difficult for young children to understand. Children's answers were documented on a record form as children answered each item.

Drawing Task. Children's perceptions of the teacher-child relationship were also measured through a drawing task. We replicated procedures used by Harrison and colleagues (2007), who adapted family drawing procedures used by Fury and colleagues (1997) to a teacher drawing task. After completing the YCATS, children were asked to "draw a picture of you and your teacher at school." Children were given a blank sheet of white paper and a set of markers. If children did not initially include the teacher in their drawing, they were reminded that their drawing should include their teacher, but no other instructions were given. Children were asked to identify themselves, their teacher, and any other objects after they completed their drawing.

Teacher-child drawings were coded for relationship quality using a coding system developed by Fury and colleagues (1997) for children's family drawings, which has also 
been successfully applied to coding young children's teacher-child drawings (Harrison et al., 2007). We used the manual developed by Dallarie and colleagues (2012) to rate the following eight indicators of relationship quality on a 7-point scale from 1 (very low) to 7 (very high): Creativity/Vitality, Pride/Happiness, Vulnerability, Emotional

Distance/Isolation, Tension/Anger, Role Reversal, Bizarreness/Dissociation, Global Pathology. We used the same modifications to the coding system as Harrison et al. (2007): Emotional Distance/Isolation was given the highest rating when the teacher was left out of the drawing, Tension/Anger was given high ratings when the teacher's face was scribbled over or left blank, and Role Reversal was not coded when the teacher was left out of the drawing. Given the young age of the children in the present study, a few additional rules regarding whether drawings could be coded were added. Some children did not draw recognizable human figures even though they reported that they and their teachers were included in the drawing. In these cases, the majority of codes could be assigned based on drawing indicators other than the figures; however, Emotional Distance/Isolation and Role Reversal were determined to be uncodable because of the importance of the figures for these codes. If a child included neither themselves nor their teacher, even after being prompted, drawings were not coded. Based on principal component analysis (PCA) results, Harrison and colleagues (2007) computed a "relational negativity" composite by taking the mean of the Pride/Happiness (reversed), Emotional Distance, Tension, Bizarreness and Global Pathology codes, for which the internal consistency was very high $(\alpha=.96)$. Similarly, Dallaire and colleagues $(2012)$ computed a global composite score, based on PCA results, using all codes except Creativity/Vitality with high internal consistency $(\alpha=.87)$. 
Three coders were two undergraduate research assistants and one graduate student, who was the lead coder. Coder reliability was maintained through weekly coding meetings during which one or more drawings were discussed and consensus codes were assigned. All drawings were coded independently by two coders. The intraclass correlations were very good for all relationship quality codes indicating a high degree of interrater reliability; Creativity/Vitality $\mathrm{ICC}=.82$, Pride/Happiness $\mathrm{ICC}=.87$, Vulnerability $\mathrm{ICC}=.82$, Emotional Distance/Isolation $\mathrm{ICC}=.91$, Tension/Anger ICC $=$ .84 , Role Reversal ICC $=.82$, Bizarreness/Dissociation ICC $=.82$, Global Pathology ICC $=.86)$. For data analysis, the two independent ratings of the eight indicators of relationship quality were averaged.

Children's demographic characteristics. Children's age, gender, family income and level of maternal education were obtained from a parent report measure on family demographics that parent completed at the beginning of the school year.

Children's verbal ability. Children's receptive language ability was measured with the Peabody Picture Vocabulary Test $-4^{\text {th }}$ Edition (PPVT-4; Dunn \& Dunn, 2007). The PPVT demonstrates excellent reliability with high internal consistency for $3-5$ year old children $(\alpha \mathrm{s}=.95-.97)$ and high test-retest reliability $(r \mathrm{~s}=.91-.94)$ over approximately one month (range $14-42$ days) (Dunn \& Dunn, 2007). The PPVT also demonstrates good validity with other measures of children's verbal abilities (Dunn \& Dunn, 2007). The PPVT consists of a series of cards with four pictures that are shown to the child as the examiner reads a word that matches one of the pictures. The child identifies which picture corresponds to the word, which becomes increasingly challenging. Children's scores were standardized by age so that a child's score represents 
their verbal ability relative to their same-age peers.

Teacher-Rated Behavior Problems. Children's classroom behavior problems were measured with their teachers' report on the Sutter-Eyberg Student Behavior Inventory - Revised (SESBI-R) (Eyberg \& Pincus, 1999; Querido \& Eyberg, 2004). The SESBI-R consists of 38 items. For each item, teachers are asked to rate the frequency of children's behavior problems ( 1 never to 7 always) and whether this behavior is a problem for the teacher (Yes/No). The frequency ratings are summed to create the Intensity Scale and the problem ratings are summed to from the Problem Scale. The Intensity Scale is used in the present study. The intensity scale has good internal consistency in the present study $(\alpha=.96)$.

Teacher's perception of the teacher-child relationship. Teachers' perceptions of the teacher-child relationship were measured through their report on the Student Teacher Relationship Scale (STRS; Pianta, 2001). The STRS consists of 15 items that a teacher rates on a 5-point scale from 1 (definitely does not apply) to 5 (definitely applies) about his/her relationship with a particular child. Eight items are averaged to create the closeness scale (e.g., I share an affectionate, warm relationship with this child), which indicates the degree of warmth, affection, and openness the teacher perceives in the relationship. The remaining 7-items comprise the conflict scale (e.g, This child remains angry or is resistant after being disciplined), which reflects teachers' perception of negativity in the teacher-child relationship. The STRS is a widely used measure of the teacher-child relationship with good internal consistency for the closeness $(\alpha=.82)$ and conflict ( $\alpha=.88)$ scales in the present study and prior work (e.g., Thijs \& Koomen, 2009; Silver et al., 2005). Teacher's ratings of closeness and conflict on the STRS predict 
children's outcomes including their social, behavioral, and academic competencies (Hamre \& Pianta, 2001; Pianta \& Stuhlman, 2004).

Independent Observations of Teachers' Emotional Support. The emotional support provided by teachers' in children's classrooms was observed using the Classroom Assessment Scoring System (CLASS; Pianta, LaParo, \& Hamre, 2008). The CLASS is an observational measure of teachers' interactions with children in the classroom, comprised of 10 dimensions: Positive Climate, Negative Climate, Teacher Sensitivity, Regard for Student Perspectives, Behavior Management, Productivity, Instructional Learning Format, Concept Development, Quality of Feedback, and Language Modeling. These 10 dimensions in turn comprise 3 domains: Emotional Support (Positive Climate, Negative Climate - Reversed, Teacher Sensitivity, Regard for Student Perspectives), Classroom Management (Behavior Management, Productivity, Instructional Learning Formats), and Instructional Support (Concept Development, Quality of Feedback, and Language Modeling). In the present study the Emotional Support domain was used as our measure of the observed positive emotional climate and support teachers provided in children's classrooms.

The ten dimensions are rated on a seven-point scale with higher ratings indicating higher quality and/or more frequent positive interactions. Negative Climate is coded so that higher ratings indicate lower quality interactions. The codes assigned during each observation cycle were averaged to create a reliable estimate of teachers' practice. Two observers coded approximately $20 \%$ of observation cycles. Interrater reliability was good for the Emotional Support domain $(\mathrm{ICC}=.82)$. The CLASS is a widely used measure of teachers' practice and interaction quality and Emotional Support has been linked with 
children's social competence and academic achievement (Curby et al., 2009; Mashburn et al., 2008; Rudasill, Gallagher, \& White, 2010).

Observed teacher-child interactions. Children's interactions in the classroom were observed with the Individualized Classroom Assessment Scoring System (inCLASS; Downer et al., 2011). The inCLASS is an observational assessment of children's classroom interactions with peers, teachers and tasks, and is comprised of ten dimensions: Positive Engagement with the Teacher, Teacher Communication, Teacher Conflict, Peer Sociability, Peer Assertiveness, Peer Communication, Peer Conflict, Engagement with Tasks, Self-Reliance, and Behavior Control. These ten dimensions comprise four empirically-derived domains of classroom interactions: Positive Teacher Interactions (Positive Engagement with Teacher, Teacher Communication), Positive Peer Interactions (Peer Sociability, Peer Communication, Peer Assertiveness), Task Interactions (Engagement with Tasks, Self-Reliance), and Conflict Interactions (Teacher Conflict, Peer Conflict, Behavior Control - reversed) (Downer et al., 2010; Vitiello, Booren, Downer, \& Williford, 2012). In the present study, the Positive Teacher Interactions and Conflict Interactions domains were used as our measure of the observed quality of teacher-child interactions.

The ten dimensions are each rated on a seven-point scale with higher ratings indicating higher quality and/or more frequent positive interactions. Teacher and Peer Conflict are coded so that higher ratings indicate lower quality interactions. The codes assigned during each observation cycle were averaged to create a reliable estimate of children's interactions in the classroom. Two observers coded approximately $20 \%$ of observation cycles. Interrater reliability was good for both Positive Teacher Interactions 
$(\mathrm{ICC}=.87)$ and Conflict Interactions $(\mathrm{ICC}=.78)$

The inCLASS demonstrates construct and criterion-related validity. Children's conflict interactions are positively associated with teachers' report of conflict and behavior problems and negatively associated with teacher-reported social communication, frustration tolerance, task orientation, and social skills (Downer et al., 2010). Children's conflictual interactions as measured by the inCLASS also predict greater teacher-reported conflict and less social communication, assertiveness, task orientation, social skills, and emotional regulation across one year of preschool (Downer et al., 2011).

\section{Data Analysis}

First, the range, means, and standard deviations for the YCATS items, each of the drawing codes, and the composite scores for each measure were compared to prior work to further examine the validity of these measures with this population. Next, a series of Confirmatory Factor Analyses (CFAs) were performed for the measures of children's perceptions of the teacher-child relationship in Mplus (Muthen \& Muthen, 2013). The maximum likelihood estimator (ML) was used for the drawing task CFA, which consisted of continuous observed variables. For the YCATS, which consists of binary variables, the robust weighted least squares estimator (WLSMV) was used and all variables were specified as categorical. Modification indices were requested and the CFA models were modified accordingly to maximize the goodness-of-fit of each model. Items with factor loadings of .3 or greater were retained (Floyd \& Widaman, 1995). Correlations between items with a modification index of 10.0 or greater were added to the model. If an item cross-loaded on another factor with a modification index of 10.0 or 
greater, this item was removed from the factor analysis. Model fit was examined with the Comparative Fit Index and the Tucker-Lewis-Index (good fit: $\geq .95$, acceptable fit: $\geq$ $.90)$, and the Root Mean Square Error of Approximation (RMSEA) (good fit: < .06, acceptable fit: $<.08 ; \mathrm{Hu} \&$ Bentler, 1999). The internal consistency of the factors was examined with Cronbach's alphas (acceptable fit: <.70; Nunnally \& Bernstein, 1994).

A series of correlation analyses were conducted in SPSS 21 to examine the associations between reports of the teacher-child relationship from multiple reporters. Associations were examined for children's perceptions of the teacher-child relationship on two measures (YCATS, drawing). Then, associations between children's relationship perceptions (YCATS Warmth and Conflict and Drawing Negativity) and child characteristics (child age, gender, race, verbal ability, teacher-rated behavior problems, income-to-needs ratio, maternal education) were examined. Next, associations between children's report on both of these measures and teachers' perceptions of the relationship (STRS closeness and conflict) were examined. Finally, associations between children's perceptions and independent observations of emotional support provided by teachers (CLASS emotional support) and of children's interactions in the classroom (inCLASS positive engagement with teacher and teacher conflict) were examined.

A series of post hoc partial correlation analyses were then conducted to examine the associations between children's perceptions of the teacher-child relationship and teachers' perceptions of the teacher-child relationship, independent observations of emotional support provide by teachers, and independent observations of children's classroom interactions in the classroom after controlling for children's age and verbal ability. 


\section{Results}

\section{Young Children's Appraisals of Teacher Support}

A confirmatory factor analysis was fit for the 22 items included on the YCATS. The factors were warmth (12 items) and conflict (10 items), which were factors established by two previous exploratory factor analyses (Mantzicopoulos \& NeuharthPritchett, 2003; Spilt et al., 2010). Few differences in factor loadings were observed when the CFA was fit as a two-level model to account for the nesting of children within classroom. Therefore, the final CFA was fit only at the child level. All items had factor loadings that were .40 or higher. Modification indices indicated that one warmth item (My teacher helps me when I do not understand) also loaded on the conflict factor, thus this item was removed and the CFA was fit again. The final CFA including 11 warmth items and 10 conflict items had a good fit $\left(\chi^{2}(188)=211.291, N=158, n s ;\right.$ RMSEA $=$ $.028 ; \mathrm{CFI}=.963 ; \mathrm{TLI}=.958)$. Consistent with prior uses of this scale (Mantzicopoulos \& Neuharth-Pritchett, 2003; Spilt et al., 2010), items comprising a factor were averaged to create one score for each scale. Both the warmth and conflict factors had good internal consistency $(\alpha=.78, .77$, respectively).

The mean warmth composite score was $.85(S D=.20)$ and the mean conflict score was $.35(S D=.28)($ See Table 2$)$. This central tendency and variability were similar with to two prior uses of this scale (Warmth $M=.89, .85 \mathrm{SD}=.16, .20$, Conflict $M=.39, .37$, $S D=.26,26$; Mantzicopoulos \& Neuharth-Pritchett, 2003; Spilt et al., 2010).

\section{Teacher-Child Drawing Task}

A confirmatory factor analysis (CFA) was fit for the seven relationship quality codes that have been used in prior work as indicators of relational negativity. 
Creativity/Vitality was not included, as previous authors have reported that it is a separate factor that indicates a child's engagement with the task rather than the negativity in their relationship with their teacher (Harrison et al., 2007; Fury et al., 1997). The intraclass correlations (ICCs) for each of the seven drawing codes were 0.000 when the model was fit as a two-level model to account for the nesting of children within classroom. Therefore, the final CFA was fit only at the child level. All seven (Pride/Happiness reversed, Vulnerability, Emotional Distance/Isolation, Tension/Anger, Role Reversal, Bizarreness/Dissociation, Global Pathology) codes had factor loadings greater than .40. Based on modification indices, three correlations were added to the model (Emotional Distance and Vulnerability, Emotional Distance and Pride/Happiness (reversed), Bizarreness \& Dissociation and Role Reversal). The resulting model had a good fit $\left(\chi^{2}\right.$ $(11)=19.259, N=151, n s ; \mathrm{RMSEA}=.071 ; \mathrm{CFI}=.994 ; \mathrm{TLI}=.988)$. The internal consistency was very high $(\alpha=.96)$. In line with the prior work in which a composite was computed (Harrison et al., 2007; Fury et al., 1997), the mean of the seven items was calculated for our measure of relational negativity.

The mean for children's perceived relational negativity was $4.75(S D=1.14)$ (see Table 2). Overall, the mean and variability of the relational negativity composite were comparable to that reported by Harrison et al. (2007) $(M=4.10 ; S D=1.18)$; however, the mean relational negativity was somewhat higher in the present study. See Table 3 for means, ranges, standard deviations, and correlations for the seven items included in the relational negativity composite.

\section{Associations with children's perceptions of the teacher-child relationship} Associations between measures of children's relationship perceptions. 
Children's perceptions of relational negativity portrayed in their drawings were associated with their report of warmth and conflict on the YCATS in the expected directions (See Table 4). Relational negativity was negatively associated with YCATS Warmth $(r=-.255, p=.022)$ and positively associated with YCATS Conflict $(r=.259, p$ $=.001)$. Children's reports of warmth and conflict on the YCATS were not significantly related $(r=-.124, p=\mathrm{ns})$.

Associations with child characteristics. Older preschool children tended to report more positive perceptions of the teacher-child relationship, including more YCATS Warmth $(r=.279, p<.001$, see Table 4$)$ and less Drawing Relational Negativity $(\beta=-.401, p<.001)$. Boys tended to reported more YCATS Conflict $(r=.171, p=.032)$ and more Drawing Relational Negativity $(r=.189, p=.020)$. African-American children reported less positive relationships with their teachers than Caucasian children, including less YCATS Warmth $(r=-.181, p=.024)$, more YCATS Conflict $(r=.190, p=.017)$, and more Drawing Relational Negativity $(\beta=.258, p<.001)$. Caucasian children reported less YCATS Conflict $(r=-.212, p=.008)$ and Hispanic children reported less Drawing Relational Negativity $(r=-.186, p=.023)$. Children with higher receptive language abilities were associated with less reported YCATS Conflict $(r=-.233, p=$ $.004)$, and Drawing Relational Negativity $(r=-.249, p=.003)$. More years of maternal education and a greater income to needs ratio were both associated with lower childreported YCATS conflict $(r=-.248, p=.002 ; r=-.273, p<.001)$. Child disruptive behavior as rated by the teacher was not associated with children's teacher-child relationship perceptions.

Associations with teachers' relationship perceptions. Children's report of the 
teacher-child relationship was not significantly associated with teachers' report of the relationship on the STRS (See Table 4). YCATS Warmth was not associated with closeness $(r=-.010, p=\mathrm{ns})$ or conflict $(r=.031, p=\mathrm{ns})$, nor was child-reported YCATS Conflict associated with teacher-reported conflict $(r=-.073, p=\mathrm{ns})$ or closeness $(r=$ $.088, p=\mathrm{ns})$. Similarly, relational negativity in children's drawings was not related to teachers' report of closeness $(r=-.130, p=\mathrm{ns})$ or conflict $(r=.089, p=\mathrm{ns})$.

\section{Associations with independent observations of classroom emotional support.}

Children's report of warmth in the teacher-child relationship on the YCATS was positively associated with independent observations of teachers' emotional support in the classroom as measured by the CLASS $(r=.194, p=.014)$. Child-reported YCATS conflict was negatively associated with observed emotional support $(r=-.164, p=.040)$. Relational negativity depicted in children's drawings of themselves with their teachers was not significantly associated with teachers' observed emotional support $(r=-.131, p=$ ns).

\section{Associations with independent observations of children's classroom}

interactions. Child-reported relationship quality was significantly associated with observed teacher-child interactions (see Table 4). YCATS Warmth was not associated with observed positive teacher interactions $(r=.078, p=\mathrm{ns})$; however, it was negatively associated with observed classroom conflict interactions $(r=-.173, p=.030)$. As expected, child-reported YCATS Conflict was positively associated with observed conflict interactions $(r=.206, p=.009)$. YCATS Conflict was marginally negatively associated with observed positive teacher interactions $(r=-.134, p<.092)$. Drawing Relational Negativity was marginally positively associated with observed conflict 
interactions $(r=.146, p=.073)$ and was negatively associated with observer-reported positive teacher interactions $(r=-.190, p=.020)$.

\section{Post Hoc Analyses: Partial Correlations}

Children's age and verbal ability were significantly associated with children's relationship perceptions as reported on the YCATS and expressed in their drawings, and therefore these characteristics were a potential threat to construct validity. Thus, we examined the associations between children's relationship perceptions and teachers' relationship perceptions, independent observations of teachers' emotional support, and independent observations of children's classroom interactions after accounting for child age and verbal ability using partial correlations (See Table 5). Children's report of YCATS Warmth continued to be positively associated with teachers' observed emotional support $(r=.183, p=.029)$. YCATS Conflict was negatively associated with observed teacher emotional support $(r=-.170, p=.041)$ and positively associated with children's observed conflict interactions $(r=.176, p=.35)$. Drawing Relational Negativity was negatively associated with children's observed positive interactions with their teacher $(r$ $=-.197, p=.019)$ and with teacher-reported closeness $(\mathrm{r}=.169, \mathrm{p}=.046)$ and positively associated with teacher-reported conflict $(r=-.174, p=.039)$. This pattern of associations is consistent with the bivariate correlations, with the exception of the partial correlations between Drawing Relational Negativity and teacher-reported closeness and conflict, which were statistically significant in the partial correlations accounting for child age and verbal ability, but not in the bivariate correlations.

\section{Discussion}


Warm, supportive early teacher-child relationships are important for children's academic, social, and behavioral development. Yet, few researchers have examined how preschool children perceive these relationships. These early teacher-child relationships have been linked to important developmental outcomes, including the quality of subsequent teacher-child relationships, children's academic achievement, behavior problems, and social development (Hamre \& Pianta, 2001; Peisner-Feinberg et al., 2001; Roorda et al., 2011). We examined children's relationship perceptions in a sample of children with disruptive behavior, who are at-risk for developing poor teacher-child relationships (Baker, 2006; Baker et al., 2008; Hughes et al., 1999), which have been linked to negative child outcomes such as lower grades and standardized test scores and more disciplinary issues (Hamre \& Pianta, 2001). The present study was among the first to examine children's perceptions of the teacher-child relationship during preschool, a formative developmental period for children's relationship perceptions (Pianta, 1999), and the first, to our knowledge, to employ a sample of children with children with elevated behavior problems inclusive of three-year-old children. This study examined the reliability and validity of children's report of the teacher-child relationship through two types of measures, a self-report in which children were directly asked about aspects of their relationship in a structured interview and a representational measure in which children drew a picture of themselves with their teacher. We examined the associations between these two measures of children's relationship perceptions and children's characteristics, teachers' relationship perceptions and independent observations of children's and teachers' interactions in the classroom. 
We found that preschool children with disruptive behavior were reliable reporters of their relationship with their teacher. Children's self-reports of warmth and conflict with their teacher on the Young Children's Appraisals of Teacher Support (YCATS) as well as their representations of relational negativity in a teacher-child drawing fit the hypothesized measure structures well, which was consistent with prior research using these measure with preschool, kindergarten, and first grade children (YCATS; Mantzicopoulos \& Neuharth-Pritchett, 2003; Spilt et al., 2010) and kindergarten age children (Drawing; Harrison et al., 2007). Additionally, the internal consistency, range, means, and standard deviations for both the YCATS and drawing measures were comparable to previous uses of these measures, further supporting the reliability of these measures in our sample of preschool children. As would be expected given our sample of children with disruptive behavior who tend to have less positive teacher-child relationships, relational negativity in children's drawings was somewhat higher in the present study than in the Harrison et al. (2007) study. Child-reported warmth and conflict on the YCATS were not significantly associated, which replicates findings from two previous studies (Mantzicopoulos \& Neuharth-Pritchett, 2003; Spilt et al., 2010). These findings provide good evidence that preschool children as young as three who display high levels of disruptive behavior can reliably report on their perceptions of quality of their relationship with their teacher on both a self-report and a representational measure.

We also found support for the validity of preschool children's report of the teacher-child relationship in a structured interview and a representational drawing. First, children's reports on these two measures were associated with each other in the expected directions. That is, children who expressed greater relational negativity in their drawings 
also reported more conflict and less warmth on a structure interview (YCATS). This consistency between children's self-report of their relationship perceptions through two different approaches to assessing these perceptions indicates that these measures both assess the construct of interest—children's perceptions of the teacher-child relationship.

Further support for the validity of children's report of their relationship perceptions was found in the associations between children's perceptions and children's characteristics, which were consistent with previous research. We found that preschool children who were younger, male, and African-American reported relationships with their teachers that were less positive than their older, female, Caucasian and Hispanic peers. These links between children's characteristics and their perceptions of the teacher-child relationship are largely consistent with prior research with children's and teachers' perceptions of teacher-child relationships with preschool-aged and slightly older children (Baker, 2006; Birch \& Ladd, 1997; Ewing \& Taylor, 2009; Hamre \& Pianta, 2001; Harrison et al., 2007; Hughes et al., 2005; Kesner, 2000; Mantzicopoulos \& NeuharthPritchett, 2003; Murray \& Murray, 2004; Silver et al., 2005). Additionally, children living in households with parents with higher levels of education and a greater income-toneeds ratio, indications of children socioeconomic status, reported less conflict with their teacher, which aligns with prior research finding that children from lower SES families are at-risk for poorer adjustment to school (NICHD ECCRN, 2002b). Children's higher receptive language ability was associated less relational negativity expressed in children's drawings. This result is in line with previous research indicating that teachers report more conflict in their relationships with behaviorally uninhibited children who have lower language complexity (Rudasill et al., 2006). However, previous work with this teacher- 
child drawing measure found no association between level of receptive language skill and relational negativity in children's drawings (Harrison et al., 2007). It is likely that receptive language skills served as an indication of children's developmental level in our study, which was variable in our sample of children. It may also be that children with low language ability are less able to understand conversations and directions from their teacher, which may contribute to lower engagement, less shared positive affect, more noncompliance, and thus more negativity with their teacher. Finally, children's teacherrated behavior problems were not related to children's relationship perceptions. Because our sample consisted of children identified by their teacher as evidencing behavior problems, the typical range of behavior problems may have been restricted, thus limiting our ability to observe associations between child-reported relationship quality and teacher-rated behavior problems. Overall, the consistency between the child characteristics linked with children's relationship perceptions in the present study and in prior research with child and teacher relationship perceptions supports the validity of assessing preschool children's own perceptions of their relationship with their teacher. Children's perceptions of the teacher-child relationship as expressed through a self-report structured interview (YCATS) and representation in a drawing task were not significantly associated with teacher-reported relationship quality, a result that was in contrast to our hypotheses. These findings also contrast previous work that found associations in the expected directions between teachers' perceptions and both measures of child-reported perceptions used in this paper (Harrison et al., 2007; Mantzicopoulos \& Neuharth-Pritchett, 2003; Spilt et al, 2010). However, it is important to note that all of these reported associations were modest (correlations of .30 or less), though significant. 
Further, low agreement between teacher and child reports of relationship quality have been observed among kindergarten and elementary school age children (Hughes, 2011; Murray et al., 2008). Our findings could also be specific to the population of children in the present study, those who have elevated levels of disruptive behavior. The samples employed in prior work were not selected based on children's behavior, but were rather community samples, Head Start samples, or samples selected based on maternal characteristics. It may be that for children who display behavior problems, their perceptions of the relationship are less concordant with their teachers' perceptions of the relationship. That is, these children and these teachers are not as well aligned in how they perceive the teacher-child relationship. In addition, children with disruptive behavior disorders tend to have social skills deficits, inaccurate perceptions of social situations, and positive illusory bias when rating their abilities (DuPaul, McGoey, Eckert, \& van Barkle, 2001; Merrell \& Wolfe, 1998; Owens \& Hoza, 2003). Perhaps these children do not attend to or differently interpret some of the interactions they have with their teachers. Yet, in the present study, both teacher and child reports of the teacher-child relationship were associated with independent observations of interactions between the teacher and child. Thus, it appears that children and teachers are taking into account the actual interactions they are having with each other as they form their perceptions of the relationship. However, this lack of agreement and attunement may be due to teachers and children attending to different aspects of their interactions in the classroom, which could be problematic for how teachers and children interact with each other and may potentially contribute to more discord in their relationship. The discrepant reports of relationship quality also underscore the importance of understanding children's perceptions of the 
teacher-child relationship in addition to teachers' perceptions, as their reports may provide different information.

Further evidence for the validity of children's relationship perceptions was found in the links between children's perceptions and observations of teachers' emotionally supportive interactions with children in the classroom. Children who reported more warmth and less conflict in their relationship with their teacher on the YCATS tended to have teachers who were attuned and responsive to children's needs and emotions and engaged with children in warm, supportive and reciprocal interactions. These associations indicate that children attend to how their teachers respond to children in the classroom and that children may internalize this experience into their perception of their relationship with their teacher. These findings are consistent with attachment theory and prior research, suggesting that adults' responsiveness and sensitivity to children's emotional cues contribute to children forming internal working models of relationships as consistent, affectively positive, and supportive of emotional and behavioral regulation (Bowlby, 1988; Pianta, 1999). These findings are also in line with prior research linking the emotional support a child experiences in the classroom to multiple indicators of their social competence (Curby et al., 2009; Mashburn et al., 2008).

We also found support for the validity of preschool children's report of the teacher-child relationship in their associations with independent observations of children's classroom interactions in the expected directions. Specifically, children's higher positive interactions with teachers-high emotional connection, expressed positive emotions, and adaptive communication with teachers - were related to children perceiving lower levels of relational negativity with the teacher as expressed through 
children's drawings. These findings are consistent with theoretical and empirical work on young children's attachment-related behaviors in the teacher-child relationship (Pianta, 1999; Pianta, Nimetz, \& Bennett, 1997). That is, the child's tracking of and attunement with the teacher, sharing reciprocal positive emotional interactions, using the teacher as a secure base from which to explore the classroom, and experiencing the teacher as safe haven for comfort indicate that the child is using the teacher as an attachment figure in positive, developmentally appropriate ways (Bowlby, 1988; Pianta et al., 1997; Verschueren \& Koomen, 2012). As noted by Verschueren and Koomen (2012) teachers play a particularly important role as an attachment figure with young and vulnerable children, such as those with behavior problems, because these children's "attachment system[s] get activated more easily" and they require more adult assistance for emotional and behavioral regulation (p. 207). In the present study, children's observed behavior was consistent with attachment theory and research based on the representations portrayed in their drawings, which supports the validity drawings as a way to assess young children's internal working models of teacher-child relationship. Further, this finding suggests that the actual observed interactions children experience with their teacher inform their perceptions of the relationship they have with the teacher.

Additionally, child-reported warmth and conflict (YCATS) were associated with observed conflictual interactions in the classroom in the expected directions. Children who reported more warmth and less conflict in their relationship with their teacher were observed to match classroom expectations for their behavior, comply with teachers' directions and engage in minimal aggression, negative affect and attention seeking behavior with teachers and peers. These findings are consistent with research on teacher- 
child relationships indicating that when children enter classrooms with less regulated behavior (e.g., hyperactivity, impulsivity), they often have more difficulty establishing the affectively positive, close, supportive relationships that could help foster the development of these behavioral competencies (Birch \& Ladd, 1998). These findings are also consistent with attachment research and theory demonstrating that warm, responsive, low conflict adult-child interactions, including those with a teacher, support children's ability to regulate their own emotions and behavior (Denham \& Burton, 1996; Pianta, 1997). Children who do not experience and engage in these types of interactions with their teacher miss the opportunity to benefit from the adult interactions that could support the development these self-regulatory competencies. Additionally, these findings suggest that children internalize the information they take in from their interactions with their teacher to form their perceptions, or internal working models, of their relationship with the teacher. This finding aligns with attachment theory and our similar finding that less relational negativity in children's drawings was associated with more positive observed child-teacher interactions.

Although these associations were encouraging, the associations between children's perceptions and their age and verbal ability, discussed previously, were a potential threat to the validity of the child-report measures of the teacher-child relationship. That is, it could be that the child-report measures were really indications of children's developmental level (age, verbal ability) and these variables explained the associations between children's report of their relationships with their teachers and our validity measures. Therefore, we were interested in whether the associations we observed between children's relationship perceptions and teachers' perceptions, independent 
observations of children's classroom interactions, and independent observations of teachers' emotional support held after accounting for children's age and receptive vocabulary skills. We found that even after accounting for children's age and verbal ability, the pattern of associations between child relationship perceptions and observations teachers' practice and of children's interactions found in the bivariate associations was the largely same in the partial correlations. Only child-reported YCATS Warmth was no longer associated with observed conflictual interactions in the classroom. Therefore, child age and verbal ability did not explain the associations between children's relationship perceptions and the observed emotional support and child-teacher interactions observed in classrooms. Interestingly, once accounting for child age and verbal ability, children who expressed more relational negativity in their drawings had teachers who perceived more conflict and less closeness in their relationship. Thus, it appears that child age and verbal ability were related to children and teachers' differing perceptions of the teacher-child relationships because once these child characteristics were accounted for, their relationship perceptions were more aligned. These associations between children's perceptions of their relationship with their teacher and observations of children's classroom interactions and teachers' provision of a supportive, positive emotional classroom climate even after accounting for child age and developmental level, provide further support for the validity of children's report of this relationship.

In summary, the results from this study provide sound evidence that we can accurately assess young children's own perceptions of their relationship with their teacher. In assessing children's perceptions using multiple assessment methods we found that using a structured interview and a representational drawing did not provide identical 
information about children's perception of the relationship as evidenced by their significant though modest associations with each other. And, we found some differential patterns of expected associations between these measures and teachers' perceptions, observed classroom interactions, and teachers' emotionally supportive practice. The different measurement approaches may account for the differential patterns of association with the validation constructs and aspects of the teacher-child relationship that were assessed. For instance, drawings are thought to allow children to describe qualities of their internal working model of their relationship with their teacher that may be difficult for them to understand cognitively and that may not be consciously understood (Harrison et al., 2007; Fury et al., 1997), which in turn would make it unlikely for them to express during an interview. However, the structured interview has the benefit of employing a parallel format (self-report on direct questions) and structure (Warmth and Conflict scales) to how teachers' perceptions are typically assessed through the Student Teacher Relationship Scale (Mantzicopoulos \& Neuharth-Pritchett, 2003; Pianta, 2001). These findings suggest that both of these approaches, a structured interview and a representational drawing, assess some common aspects of children's perceptions of the teacher-child relationship, but they may also each assess unique aspects of children's relationship perceptions. Understanding how using both of these measures together may provide a comprehensive assessment of children's relationship perceptions will be important in future work.

Several limitations of the present study deserve attention. First, we had a relatively small sample size, and the generalizability of our findings is limited to preschool-aged children who evidence high levels of behavior problems in the classroom. 
Second, there was a considerable amount of attrition over the course of the school year from the originally selected participants, as there is substantial turn over in preschool classrooms for children with disruptive behavior problems. Third, we examined teacherchild relationships at one point during the school year, and therefore we did not examine change in these relationships. We do not know what children's relationship perceptions were at the beginning of the year and how they may have changed. Finally, due to the study design, teacher-reported closeness and conflict (STRS), which were obtained postintervention, were assessed at the same time as the independent observations of children's interactions (inCLASS) and child-reported relationship perceptions (YCATS and drawing) for about one-third of the sample; however, they were assessed earlier in the year for the remainder of the sample. It is possible that teacher-child relationships changed between our assessment of teachers perceptions and the end of the year when the other measures were collected, which could be one reason that we did not observe an association between teachers' and children's relationship perceptions before partialling out child age and verbal ability.

The findings from the present study have several implications for understanding teacher-child relationships and for future research. First, our findings indicate that even very young children and children with early disruptive behavior can reliably report on their perceptions of the teacher-child relationship. Children's perspectives appear to provide important information about their internal working models of teacher-child relationships and how high quality teacher-child relationships contribute to positive child outcomes. The present study suggests that understanding the child's point of view is important as it may also provide information not captured by teachers' report or 
independent observations. Additionally, our findings provide some indication that both self-report and representational measures provide information about children's relationship perceptions. Importantly, our findings suggest that the objectively observed interactions in the classroom, both teachers' general practice with all students and the dyadic interactions between a particular child and teacher, to which children are exposed inform children's internalized perceptions of the teacher-child relationship. Finally, our findings indicate that males, younger children, children with lower language abilities, and African-American children are less likely to have a positive perception of their relationship with their teacher. Therefore, it may be important for teachers to make intentional efforts to foster high quality, warm relationships with these students. Intervention efforts may also target ways for teachers to enhance their relationships with these students who tend to perceive more negative relationships.

Future research should address how preschool children's perceptions of the teacher-child relationship longitudinally predict their academic, social, and behavioral outcomes. Teachers' relationship perceptions, as well as elementary school-aged children's perceptions, have been shown to predict these outcomes for children. Thus, the predicative validity of preschool children's perceptions could provide additional support for the validity of these reports. Future work should also explore methods for obtaining the most comprehensive and accurate estimate of children's perceptions of teacher-child relationship quality. For instance, this research could explore the value of employing multiple assessment methods, including a structured interview, representational drawings, observations of actual interactions like those employed in the present study, as well as additional methods such as children's narratives about their relationship. This work could 
examine how to combine these measures to obtain a comprehensive, rich picture of a child's experiences in his/her relationship with his/her teacher. Future research should also examine a comprehensive array of teacher and classroom characteristics that are related to children's perceptions of warm, supportive relationships with their teachers. Given the associations between observed teacher-child interactions in the classroom and children's relationship perceptions found in the present study, future research should examine whether preschool children's relationship perceptions are amenable to change through early intervention that targets changes in teacher-child interactions. This future work should also examine whether children's internal working models of teacher-child relationships contribute to children's social and behavioral functioning in the classroom. Further, this work should investigate children's internal working models as a mechanism by which early teacher-child relationships longitudinally predict children's outcomes by testing whether children's relationship perceptions mediate the relations between early teacher-child relationships and children's outcomes. This research could further our understanding of factors that support children's perceptions of positive teacher-child relationships and how these relationships promote children's healthy development. 


\section{References}

Anastopoulos, A. D. (1998). Oppositional defiant disorder/conduct disorder rating scale. Unpublished manuscript. University of North Carolina at Greensboro.

Baker, J. A. (2006). Contributions of teacher-child relationships to positive school adjustment during elementary school. Journal of School Psychology, 44(3), 211 229.

Baker, J. A., Grant, S., \& Morlock, L. (2008). The teacher-student relationship as a developmental context for children with internalizing or externalizing behavior problems. School Psychology Quarterly, 23(1), 3 - 15.

Birch, S. H. \& Ladd, G. W. (1997). The teacher-child relationship and children's early school adjustment. Journal of School Psychology, 35(1), 61 - 79.

Birch, S. H. \& Ladd, G. W. (1998). Children's interpersonal behaviors and the teacher-child relationship. Developmental Psychology, 34(5), 934 - 946.

Bowlby, J. (1988). A secure base: Parent-child attachment and healthy human development. London: Routledge.

Bradley, R.H. \& Corwyn, R.F. (2002). Socioeconomic status and child development. Annual Review of Psychology, 53, 371 - 399.

Bretherton, I. (1999). Updating the 'internal working model' construct: Some reflections. Attachment \& Human Development, 1(3), 343 - 357.

Buyse, E., Verschueren, K., Doumen, S., Van Damme, J., \& Maes, F. (2008). Classroom problem behavior and teacher-child relationships in kindergarten: The moderating role of classroom climate. Journal of School Psychology, 46(4), 367 - 391.

Curby, T. W., LoCasale-Crouch, J., Konold, T. R., Pianta, R. C., Howes, C., Burchinal, M., ... \& Barbarin, O. (2009). The relations of observed pre-K classroom quality profiles to children's achievement and social competence. Early Education and Development, 20(2), $346-372$.

Dallaire, D. H., Ciccone, A., \& Wilson, L. C. (2012). The family drawings of at-risk children: Concurrent relations with contact with incarcerated parents, caregiver behavior, and stress. Attachment and Human Development, 14(2), 161 - 183.

Denham, S. A. \& Burton, R. (1996). A social-emotional intervention for at-risk 4-yearolds. Journal of School Psychology, 34(3), 225 - 245. 
Downer, J. T., Booren, L. M., Hamre, B., Pianta, R. C., \& Williford, A. (2011). The Individualized Classroom Assessment Scoring (inCLASS). Unpublished technical manual, University of Virginia.

Downer, J. T., Booren, L. M., Lima, O. K., Luckner, A. E., \& Pianta, R. C. (2010). The individualized classroom assessment scoring system (inCLASS): Preliminary reliability and validity of a system for observing preschoolers' competence in classroom interactions. Early Childhood Research Quarterly, 25(1), 1 - 16.

Dubow, E. F., Tisak, J., Causey, D., Hryshko, A., \& Reid, G. (1991). A Two-Year Longitudinal Study of Stressful Life Events, Social Support, and Social ProblemSolving Skills: Contributions to Children's Behavioral and Academic Adjustment. Child Development, 62, 583 - 599.

DuPaul, G. J., McGoey, K. E., Eckert, T. L., \& van Barkle, J. (2001). Preschool children with attention-deficit/hyperactivity disorder: Impairments in behavioral, social, and school functioning. Journal of the American Academy of Child \& Adolescent Psychiatry, 40(5), $508-415$.

DuPaul, G. J., Power, T. J., Anastopoulos, A. D., \& Reid, R. (1998). The ADHD Rating Scale IV. New York: Guilford Press.

Dunn, L. M. \& Dunn, D. M. (2007). Peabody Picture Vocabulary Test $-4^{\text {th }}$ Edition. Bloomington, MN: NCS Pearson.

Ewing, A. R. \& Taylor, A. R. (2009). The role of child gender and ethnicity in teacherchild relationship quality and children's behavioral adjustment in preschool. Early Childhood Research Quarterly, 24(1), 92 - 105.

Eyberg, S. M. \& Pincus, D. (1999). Eyberg child behavior inventory and sutter-eyberg student behavior inventory-revised: Professional manual. Psychological Assessment Resources.

Floyd, F. J. \& Widaman, K. F. (1995). Factor analysis in the development and refinement of clinical assessment instruments. Psychological Assessment, 7(3), 286 - 299.

Fury, G., Carlson, E. A., \& Sroufe, L. A. (1997). Children's representations of attachment relationships in family drawings. Child Development, 68(6), $1154-1164$.

Hamre, B. K. \& Pianta, R. C. (2001). Early teacher-child relationships and the trajectory of children's school outcomes through eighth grade. Child Development, 72(2), $625-638$.

Hamre, B. K. \& Pianta, R. C. (2005). Can instructional and emotional support in the firstgrade classroom make a difference for children at risk of school failure? Child Development, 76(5), $949-967$. 
Hamre, B. K., Pianta, R. C., Downer, J. T., \& Mashburn, A. J. (2008). Teachers' perceptions of conflict with young students: Looking beyond problem behaviors. Social Development, 17(1), 115 - 136.

Harrison, L. J., Clarke, L., \& Ungerer, J. A. (2007). Children's drawings provide a new perspective on teacher--child relationship quality and school adjustment. Early Childhood Research Quarterly, 22(1), 55 - 71.

Henricsson, L. \& Rydell, A. M. (2004). Elementary school children with behavior problems: Teacher-Child relations and self-perception. A prospective study. Merril-Palmer Quarterly, 50(2), 111 - 138.

Howes, C., Galinsky, E., \& Kontos, S. (1998). Child care caregiver sensitivity and attachment. Social Development, 7(1), 25 - 36.

Howes, C., Phillipsen, L. C., \& Peisner-Feinberg, E. (2000). The consistency of perceived teacher-child relationships between preschool and kindergarten. Journal of School Psychology, 38(2), 113 - 132.

Hu, L. \& Bentler, P. M. (1999). Cutoff criteria for fit indexes in covariance structure analysis: Conventional criteria versus new alternatives. Structural Equation Modeling: A Multidisciplinary Journal, 6(1), 1 - 55.

Hughes, J. N. (2011). Longitudinal effects of teacher and student perceptions of teacherstudent relationship qualities on academic adjustment. The Elementary School Journal, 112(1), $38-60$.

Hughes, J. N., Cavell, T. A., \& Jackson, T. (1999). Influence of the teacher-student relationship on childhood conduct problems: A prospective study. Journal of Clinical Child Psychology, 28(2), 173 - 184.

Hughes, J. N., Gleason, K. A., \& Zhang, D. (2005). Relationship influences on teachers' perceptions of academic competence in academically at-risk minority and majority first grade students. Journal of School Psychology, 43(4), $303-320$.

Kesner, J. E. (2000). Teacher characteristics and the quality of child--teacher relationships. Journal of School Psychology, 38(2), 133 - 149.

Madigan, S., Ladd, M., \& Goldberg, S. (2003). A picture is worth a thousand words: Children's representations of family as indicators of early attachment. Attachment \& Human Development, 5(1), $19-37$.

Maldonado-Carreño, C. \& Votruba-Drzal, E. (2011). Teacher-Child relationships and the development of academic and behavioral skills during elementary school: A within- and between-child analysis. Child Development, 82(2), 601616. 
Mantzicopoulos, P. (2005). Conflictual relationships between kindergarten children and their teachers: Associations with child and classroom context variables. Journal of School Psychology, 43(5), 425 - 442.

Mantzicopoulos, P. \& Neuharth-Pritchett, S. (2003). Development and validation of a measure to assess head start children's appraisals of teacher support. Journal of School Psychology, 41(6), 431 - 451.

Mashburn, A. J., Pianta, R. C., Hamre, B. K., Downer, J. T., Barbarin, O. A., Bryant, D., ... \& Howes, C. (2008). Measures of classroom quality in prekindergarten and children's development of academic, language, and social skills. Child development, 79(3), $732-749$.

Merrell, K. W. \& Wolfe, T. M. (1998). The relationship of teacher-rated social skills deficits and ADHD characteristics among kindergarten-age children. Psychology in the Schools, 35(2), $101-110$.

Murray, C. \& Murray, K. M. (2004). Child level correlates of teacher--student relationships: An examination of demographic characteristics, academic orientations, and behavioral orientations. Psychology in the Schools, 41(7), 751 762.

Murray, C., Murray, K. M., \& Waas, G. A. (2008). Child and teacher reports of teacherstudent relationships: Concordance of perspectives and associations with school adjustment in urban kindergarten classrooms. Journal of Applied Developmental Psychology, 29(1), $49-61$.

Muthén, L. K. \& Muthén, B. O. (1998-2012). Mplus user's guide (6th ed.). Los Angeles, CA: Muthén \& Muthén.

NICHD Early Child Care Research Network (2002). The relation of global first-grade classroom environment to structural classroom features and teacher and student behaviors. Elementary School Journal, 102(5), 367 - 386.

NICHD Early Child Care Research Network. (2002b). The interaction of child care and family risk in relation to child development at 24 and 36 months. Applied Developmental Science, 6, 144 - 156.

NICHD Early Child Care Research Network (2003). Social functioning in first grade: Associations with earlier home and child care predictors and with current classroom experiences. Child Development, 74(6), 1639 - 1662.

NICHD Early Child Care Research Network (2005). Early child care and children's development in the primary grades: Follow-Up results from the NICHD study of early child care. American Educational Research Journal, 537 - 570. 
Nunnally, J. C. \& Bernstein, I. H. (1994). Psychometric theory. McGraw, New York.

O’Connor, E. E., Dearing, E., \& Collins, B. A. (2011). Teacher-child relationship and behavior problem trajectories in elementary school. American Educational Research Journal, 48(1), 120 - 162.

O’Connor, E. \& McCartney, K. (2007). Examining teacher--child relationships and achievement as part of an ecological model of development. American Educational Research Journal, 44(2), 340 - 369.

Owens, J. S. \& Hoza, B. (2003). The role of inattention and hyperactivity/impulsivity in the positive illusory bias. Journal of Consulting and Clinical Psychology, 71(4), 680-691.

Palermo, F., Hanish, L. D., Martin, C. L., Fabes, R. A., \& Reiser, M. (2007).

Preschoolers' academic readiness: What role does the teacher-child relationship play? Early Childhood Research Quarterly, 22(4), 407 - 422.

Peisner-Feinberg, E. S., Burchinal, M. R., Clifford, R. M., Culkin, M. L., Howes, C., Kagan, S. L., \& Yozejian, N. (2001). The relation of preschool child-care quality to children's cognitive and social developmental trajectories through second grade. Child Development, 72(5), 1534 - 1553.

Pianta, R. C. (1997). Adult-child relationships processes and early schooling. Early Education and Development, 8(1), 11 - 26.

Pianta, R. C. (1999). Enhancing Relationships Between Children and Teachers. Washington, DC: American Psychological Association.

Pianta, R. C. (2001). Student-Teacher Relationship Scale. Odessa, FL: PAR.

Pianta, R. C., Nimetz, S. L., \& Bennett, E. (1997). Mother-child relationships, teacherchild relationships, and school outcomes in preschool and kindergarten. Early Childhood Research Quarterly, 12(3), 263 - 280.

Pianta, R. C. \& Stuhlman, M. W. (2004). Teacher-Child relationships and children's success in the first years of school. School Psychology Review, 33, $444-458$.

Pianta, R. C., Steinberg, M. S., \& Rollins, K. B. (1995). The first two years of school: Teacher-Child relationships and deflections in children's classroom adjustment. Development and Psychopathology, 7(02), 295 - 312.

Querido, J. G. \& Eyberg, S. M. (2004). Psychometric properties of the sutter-eyberg student behavior inventory-revised with preschool children. Behavior Therapy, $34(1), 1-15$. 
Rey, R. B., Smith, A. L., Yoon, J., Somers, C., \& Barnett, D. (2007). Relationships between teachers and urban african american children. School Psychology International, 28(3), $346-364$.

Roorda, D. L., Koomen, H. M. Y., Spilt, J. L., \& Oort, F. J. (2011). The influence of affective teacher--student relationships on students' school engagement and achievement. Review of Educational Research, 81(4), 493 - 529.

Rudasill, K. M., Gallagher, K. C., \& White, J. M. (2010). Temperamental attention and activity, classroom emotional support, and academic achievement in third grade. Journal of School Psychology, 48(2), 113 - 134.

Rudasill, K. M., Rimm-Kaufman, S. E., Justice, L. M., \& Pence, K. (2006). Temperament and language skills as predictors of teacher-child relationship quality in preschool. Early Education and Development, 17(2), 271 - 291.

Sabol, T. J. \& Pianta, R. C. (2012). Recent trends in research on teacher-child relationships. Attachment \& Human Development, 14(3), 213 - 231.

Silver, R. B., Measelle, J. R., Armstrong, J. M., \& Essex, M. J. (2005). Trajectories of classroom externalizing behavior: Contributions of child characteristics, family characteristics, and the teacher-child relationship during the school transition. Journal of School Psychology, 43(1), 39 - 60.

Spilt, J. L., Koomen, H. M. Y., \& Mantzicopoulos, P. Y. (2010). Young children's perceptions of teacher--child relationships: An evaluation of two instruments and the role of child gender in kindergarten. Journal of Applied Developmental Psychology, 31(6), $428-438$.

Thijs, J. \& Koomen, H. M. Y. (2009). Toward a further understanding of teachers' reports of early teacher-child relationships: Examining the roles of behavior appraisals and attributions. Early Childhood Research Quarterly, 24(2), 186 - 197.

Vitiello, V. E., Booren, L. M., Downer, J. T., \& Williford, A. (2012). Variation in children's classroom engagement throughout a day in preschool: Relations to classroom and child factors. Early Childhood Research Quarterly, 27, 210 - 220.

Verschueren, K. \& Koomen, H. M. (2012). Teacher-Child relationships from an attachment perspective. Attachment \& Human Development, 14(3), 205 - 211. 
Table 1

Descriptive Statistics: Child Demographics

\begin{tabular}{l|ccccc}
\hline & $N$ & Minimum & Maximum & Mean & $S D$ \\
\hline Child Demographics & & & & & \\
Child Age at Interview (years) & 156 & 3.45 & 6.12 & 4.88 & 0.54 \\
Male & 158 & 0 & 1 & 0.67 & 0.47 \\
Income to Needs Ratio & 151 & 0.22 & 5.16 & 1.78 & 1.51 \\
Maternal Education & 155 & 11 & 20 & 14.34 & 2.29 \\
African American & 156 & 0 & 1 & 0.44 & 0.50 \\
Hispanic & 156 & 0 & 1 & 0.09 & 0.29 \\
Caucasian & 156 & 0 & 1 & 0.32 & 0.47 \\
Asian & 156 & 0 & 1 & 0.01 & 0.08 \\
Multiracial & 156 & 0 & 1 & 0.13 & 0.34 \\
Other & 156 & 0 & 1 & 0.01 & 0.08 \\
Receptive Language (PPVT) & 148 & 62 & 133 & 99.34 & 15.56 \\
Child Behavior Problems & 136 & 48 & 256 & 144.71 & 40.91 \\
\hline
\end{tabular}


Table 2

Descriptive Statistics: Teacher-Child Relationship Quality

\begin{tabular}{|c|c|c|c|c|c|}
\hline & $N$ & Minimum & Maximum & Mean & $S D$ \\
\hline \multicolumn{6}{|c|}{ Child-Reported Relationship Quality } \\
\hline Drawing Negativity & 151 & 1.43 & 7.00 & 4.75 & 1.15 \\
\hline YCATS Conflict & 158 & 0.00 & 1.00 & 0.35 & 0.28 \\
\hline YCATS Warmth & 158 & 0.18 & 1.00 & 0.85 & 0.20 \\
\hline \multicolumn{6}{|c|}{ Teacher-Reported Relationship Quality } \\
\hline STRS Closeness & 153 & 2.00 & 5.00 & 4.30 & 0.63 \\
\hline STRS Conflict & 153 & 1.00 & 4.71 & 2.27 & 1.03 \\
\hline \multicolumn{6}{|c|}{ Observed Teacher-Child Interactions } \\
\hline inCLASS Teacher Interactions & 158 & 1.06 & 3.88 & 2.24 & 0.48 \\
\hline inCLASS Conflict & 158 & 1.00 & 2.75 & 1.45 & 0.32 \\
\hline \multicolumn{6}{|c|}{ Observed Teacher Emotional Support } \\
\hline CLASS Emotional Support & 158 & 2.50 & 6.75 & 4.85 & 0.80 \\
\hline
\end{tabular}



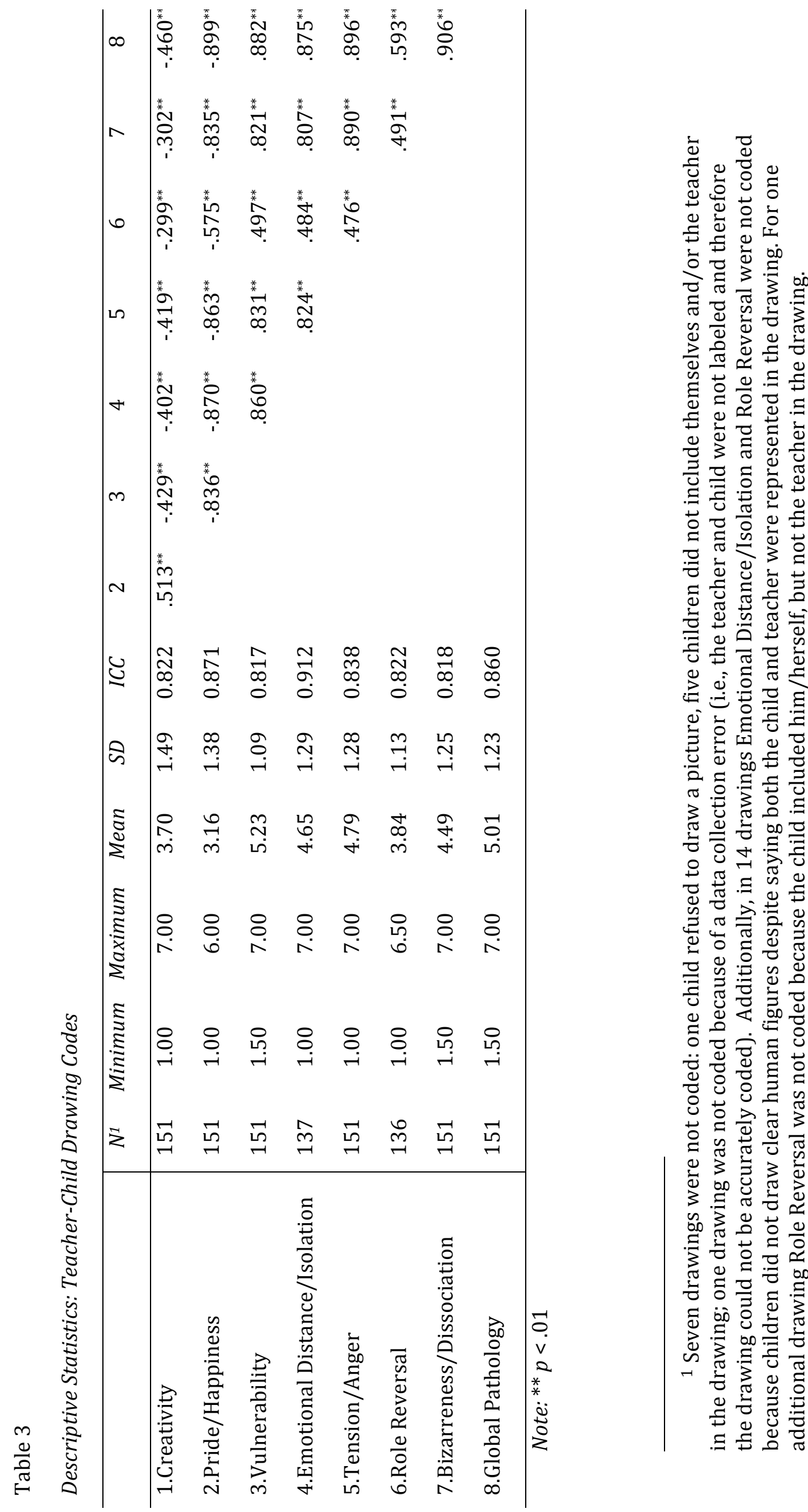


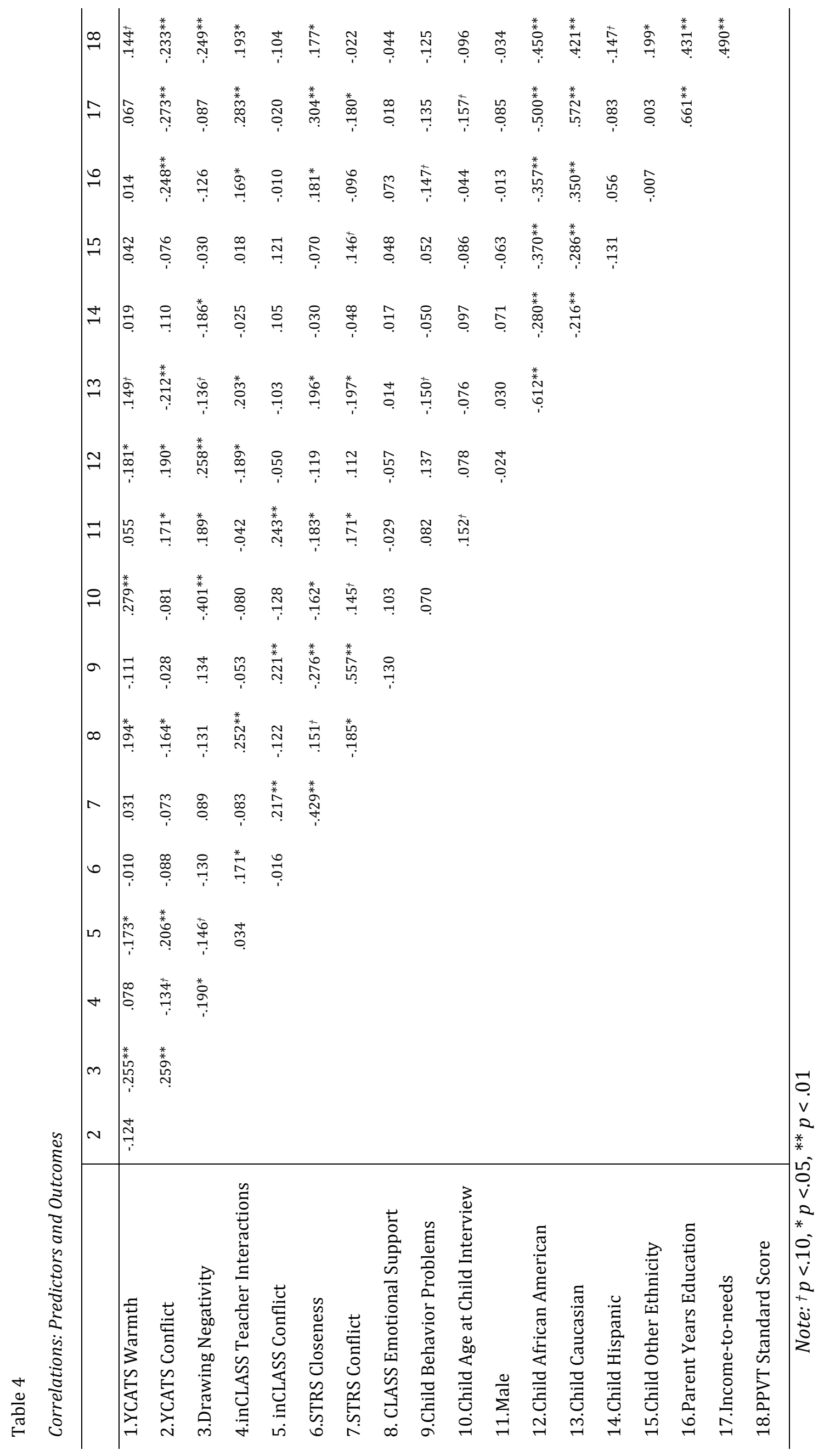




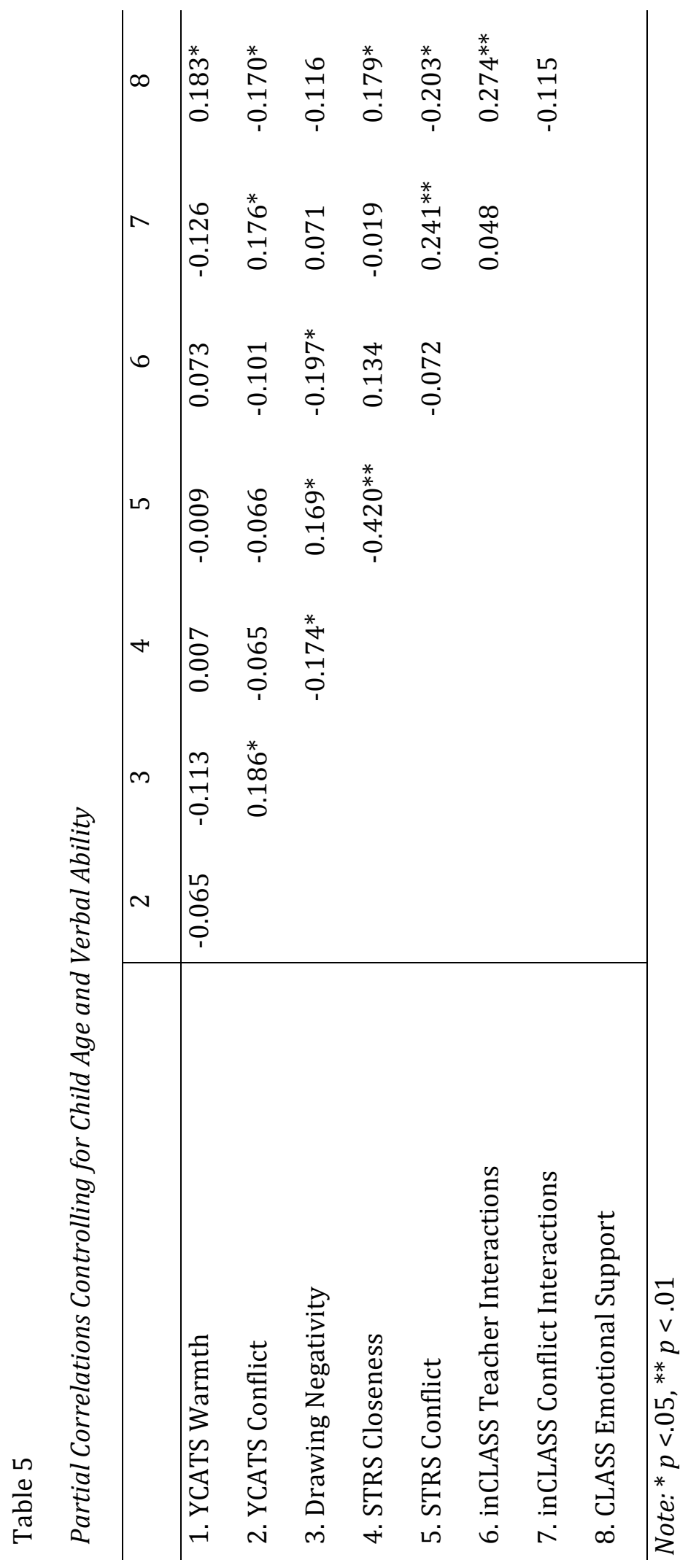




\section{Supplemental References}

(Referenced in Conceptual Link and full reference not provided elsewhere)

Arnold, D. H. (1997). Co-Occurrence of externalizing behavior problems and emergent academic difficulties in young high-risk boys: A preliminary evaluation of patterns and mechanisms. Journal of Applied Developmental Psychology, 18(3), 317-330.

Bronfenbrenner, U. (2005). Making human beings human: Bioecological perspective on human development. Thousand Oaks, CA: Sage Publications Inc.

Sabol \& Pianta, 2012). Recent trends in research on teacher-child relationships. Attachment and Human Development, 14(3), 213 - 231.

Spilt, J. L., Koomen, H. M. Y., Thijs, J. T., van der Leij, A. (2012). Supporting teachers with disruptive children: the potential of relationship-focused refection. Attachment and Human Development, 14(3), $305-318$.

Tremblay, R. E., Nagin, D. S., Séguin, J. R., Zoccolillo, M., Zelazo, P. D., Boivin, M., et al. (2004). Physical aggression during early childhood: Trajectories and predictors. Pediatrics, 114(1), e43-e50.

Verschueren, K. \& Koomen, H.M.Y. (2012). Teacher-child relationships from an attachment perspective. Attachment and Human Development, 14(3), 205 - 211. 
Warmth/Support

\section{Appendix A}

27. My teacher smiles at me.

1. My teacher likes my family.

10. My teacher is my friend.

13. My teacher says nice things about my work.

7. My teacher likes me.

16. My teacher helps me when I do not understand.

21. My teacher remembers special days for me.

25. My teacher answers my questions.

19. My teacher tells good stories.

3. My teacher tells me I am smart.

23. My teacher chooses me to help him/her.

4. My teacher makes the class fun.

\section{Conflict}

24. My teacher tells me I do not listen.

14. My teacher gets mad at me.

20. My teacher tells me that I do not try hard enough.

8. My teacher tells me I am doing something wrong a lot.

5. My teacher gives me work that is too hard for me.

17. My teacher is sometimes mean.

22. My teacher has too many rules for me.

26. My teacher tells me to do things I don't want to do.

11. My teacher tells me to stop doing things that I like doing.

2. My teacher tells me I am going to get in trouble a lot.

\section{Emotional Resource}

6. My teacher helps me when I need it.

9. My teacher makes me feel better when I get mad.

18. My teacher makes me feel better when I get sad.

15. My teacher helps me solve problems.

12. My teacher is happy when I am happy.

28. My teacher likes playing with me.

29. My teacher likes to see the things that I make.

30. My teacher knows the things I like to play with.

\section{Practice}

1. My teacher is older than me.

2. My teacher has blue hair.

4. My teacher has 10 legs.

6. My teacher is a cat.

3. My teacher tells me I do not have teeth.

5. My teacher tells me I do not have a belly button. 